\title{
Belt and Suspenders and More: The Incremental Impact of Energy Efficiency Subsidies in the Presence of Existing Policy Instruments
}

\section{Citation}

Houde, Sebastien and Joseph E. Aldy. 2014. Belt and Suspenders and More: The Incremental Impact of Energy Efficiency Subsidies in the Presence of Existing Policy Instruments. Working Paper, Harvard Kennedy School.

\section{Published Version}

10.3386/w20541

\section{Permanent link}

http://nrs.harvard.edu/urn-3:HUL.InstRepos:24890955

\section{Terms of Use}

This article was downloaded from Harvard University's DASH repository, and is made available under the terms and conditions applicable to Other Posted Material, as set forth at http:// nrs.harvard.edu/urn-3:HUL.InstRepos:dash.current.terms-of-use\#LAA

\section{Share Your Story}

The Harvard community has made this article openly available.

Please share how this access benefits you. Submit a story.

\section{Accessibility}


NBER WORKING PAPER SERIES

\title{
BELT AND SUSPENDERS AND MORE: \\ THE INCREMENTAL IMPACT OF ENERGY EFFICIENCY SUBSIDIES IN THE PRESENCE OF EXISTING POLICY INSTRUMENTS
}

\author{
Sébastien Houde \\ Joseph E. Aldy \\ Working Paper 20541 \\ http://www.nber.org/papers/w20541 \\ NATIONAL BUREAU OF ECONOMIC RESEARCH \\ 1050 Massachusetts Avenue \\ Cambridge, MA 02138 \\ October 2014
}

We first would like to thank Hasan Nazar, who worked on this project during his master's of public policy studies and as a research assistant at Harvard. We thank Chris Cloutier, Brandon Hurlbut, Lani MacRae, Susanne Rivera, and Toby Swope for assistance with the DOE SEEARP data. We would also like to thank Lucas Davis, in addition to numerous seminar participants at Harvard, the Stanford Institute of Theoretical Economics, and the AERE summer conference in Banff. The views expressed herein are those of the authors and do not necessarily reflect the views of the National Bureau of Economic Research.

NBER working papers are circulated for discussion and comment purposes. They have not been peerreviewed or been subject to the review by the NBER Board of Directors that accompanies official NBER publications.

(C) 2014 by Sébastien Houde and Joseph E. Aldy. All rights reserved. Short sections of text, not to exceed two paragraphs, may be quoted without explicit permission provided that full credit, including (C) notice, is given to the source. 
Belt and Suspenders and More: The Incremental Impact of Energy Efficiency Subsidies in the Presence of Existing Policy Instruments

Sébastien Houde and Joseph E. Aldy

NBER Working Paper No. 20541

October 2014

JEL No. H31,Q4,Q48,Q58

\begin{abstract}
$\underline{\text { ABSTRACT }}$
The effectiveness of investment subsidies depends on the existing array of regulatory and information mandates, especially in the energy efficiency space. Some consumers respond to information disclosure by purchasing energy-efficient durables (and thus may increase the inframarginal take-up of a subsequent subsidy), while other consumers may locate at the lower bound of a minimum efficiency standard (and a given subsidy may be insufficient to change their investment toward a more energy-efficient option). We investigate the incremental impact of energy efficiency rebates in the context of regulatory and information mandates by evaluating the State Energy Efficient Appliance Rebate Program (SEEARP) implemented through the 2009 American Recovery and Reinvestment Act. The design of the program - Federal funds allocated to states on a per capita basis with significant discretion in state program design and implementation - facilitates our empirical analysis. Using transaction-level data on appliance sales, we show that most program participants were inframarginal due to important shortterm intertemporal substitutions where consumers delayed their purchases by a few weeks. We find evidence that some consumers accelerated the replacement of their old appliances by a few years, but overall the impact of the program on long-term energy demand is likely to be very small. Our estimated measures of cost-effectiveness are an order of magnitude higher than estimated for other energy efficiency programs in the literature. We also show that designing subsidies that reflect, in part, underlying attribute-based regulatory mandates can result in perverse effects, such as upgrading to larger, less energy-efficient models.
\end{abstract}

Sébastien Houde

2222 Symons Hall

University of Maryland

Department of Agricultural and Resource Economics

College Park, MD 20742

shoude@umd.edu

Joseph E. Aldy

Harvard Kennedy School

Taubman 382, Mailbox 57

79 JFK Street

Cambridge, MA 02138

and NBER

joseph_aldy@hks.harvard.edu 


\section{Introduction}

Over the past 40 years, policymakers have implemented an array of instruments - regulatory mandates, information campaigns, and technology subsidies - to promote energy efficiency. For energy-consuming durables, it is quite common that an individual consumer purchases a product designed under an energy efficiency standard, marketed subject to government-required information disclosure, and eligible for a subsidy. For example, an individual buying a Toyota Prius in 2006 contributed to Toyota's compliance with Department of Transportation Corporate Average Fuel Economy standards, likely learned of the fuel savings of the hybrid from the vehicle's Environmental Protection Agency fuel economy label, and benefited from a Federal tax credit administered by the Internal Revenue Service. Likewise, appliances such as refrigerators, dishwashers, and clothes washers are subject to Federal minimum energy efficiency standards, information disclosure on typical annual energy usage, and occasionally various kinds of local, state, and Federal rebates and tax credits. Given scarce resources and the existing overlay of policy instruments, what is the incremental impact of energy efficiency subsidies on energy outcomes?

We focus on the incremental impact on subsidies, in lieu of the incremental impact of standards or the incremental impact of information, for three reasons. First, efficiency standards for automobiles and appliances have been a part of Federal law for decades. Likewise, information disclosure programs for automobiles and appliances also date to the mid-1970s. Subsidy instruments, such as tax credits and rebates, have frequently been "turned on" for short periods of time and then "turned off" (e.g., through the one-time 2009 economic stimulus bill, occasional tax extender bills, and occasional utility rebate programs). Thus, subsidies, in practice, appear to be the marginal

policy lever in the energy efficiency space. Second, subsidies are the marginal policy lever on the extensive margin, which facilitates our analysis. Third, state governments and utilities (subject to state regulation) may implement such subsidies to an even greater extent in the future. In 2010, utility consumer-funded energy efficiency programs amounted to about $\$ 5$ billion and such expenditures could double by 2025 (Barbose, Goldda, Hoffa, and Billingsley 2013). Appliance rebates have traditionally been a significant component of such programs. The Environmental Protection Agency has recently proposed regulating greenhouse gas emissions in the power sector, through a framework implemented by the states (EPA 2014a). In its proposed regulation and regulatory impact analysis, the EPA notes that rebates for high-efficiency appliances could represent one approach for reducing power sector emissions (EPA 2014a,b). Our findings could inform how 
federal, state, and local program managers could tailor their energy efficiency programs to promote cost-effectiveness and maximize their net social benefit.

To address the question of the impact of subsidies on energy outcome, we evaluate the State Energy Efficient Appliance Rebate Program (SEEARP) implemented through the 2009 American Recovery and Reinvestment Act. The program, informally known as the "Cash for Appliances" program ("C4A"), delivered $\$ 300$ million to state governments so that they could provide rebates to consumers purchasing residential appliances that met or exceeded the ENERGY STAR (ES) certification requirement. Using transaction-level data, we estimate the energy savings for the three major appliance categories that attracted the most funds: refrigerators, clothes washers, and dishwashers. We find that the program did not have a meaningful impact on aggregate electricity consumption. For example, the average energy savings for refrigerator rebate programs was a statistically significant, but economically minuscule $0.08 \%$. This reflects the very high rate of freeriding behavior by individuals claiming the rebates. We estimate that the ratio of "switchers" (marginal rebate claimants) to "freeriders" (inframarginal rebate claimants) is 1:10, 1:12, and 3:8, for refrigerators, clothes washers, and dishwashers, respectively. As a result, the cost per kilowatthour saved is on the order of about $\$ 0.25$ to $\$ 1.50$, depending on assumptions and appliance category. The low end of this range is four times the average cost-effectiveness of utility-sponsored energy efficiency programs (Arimura, Li, Newell, and Palmer 2012).

Several reasons explain these results. First, some consumers responded to the program by simply delaying their purchases until their state's rebate program opened. Second, the design of the rebate program - in particular the eligibility premised on the ES program, which is in turn a function of minimum energy efficiency standards - influenced the behavioral response to rebates. The minimum efficiency standards vary by size and style for a given category of appliance, which results in ES certification and hence SEEARP eligibility varying as a function of product attributes. For example, a consumer may buy an ES-certified refrigerator with a bottom-mounted freezer and through-thedoor ice service that requires more electricity annually than a non-certified top-mounted freezer with an icemaker but without through-the-door ice service. For some appliances, this appears to be particularly problematic - we observe significant changes in ES market shares - but the overall impact on electricity consumption is quite modest. Finally, we also find some evidence that the generous rebates may have induced a small income effect that led consumers to purchase larger appliances. 
The design and implementation of this program facilitate our empirical analysis. First, the Federal government allocated funds to the states on a per capita basis; thus the "size" of this stimulus program, at the state level, is exogenous of the state's economic condition in 2009 and 2010. Second, the states had significant discretion in the design of their programs, in terms of start dates, eligible appliance categories, rebate amounts, and other characteristics. We combine this rich source of variation with unique micro-data on individual appliance sales from a major, national retailer matched with demographic information. Our main estimators rely on a differencein-differences strategy, and include an extensive set of controls to account for pre-existing time trends, intertemporal substitution, and sorting into the program.

Our results can inform the emerging empirical literature on the use of multiple policy instruments to address a single societal objective. Several recent papers have highlighted the potential interactive impacts of overlapping greenhouse gas mitigation policies, such as a cap-and-trade program and renewable portfolio standards (Goulder and Stavins 2011; Levinson 2012). In the context of biofuels policy, scholars have also illustrated the potential welfare losses and unintentional incentives associated with the historically complicated overlay of policies to support ethanol, including the ethanol blenders tax credit, the Clean Air Act oxygenate mandate, an import tariff, and some state-specific ethanol mandates (de Gorter and Just 2010). While this previous work focuses on multiple instruments faced by firms, and in many cases the unique impacts of policies overlaying cap-and-trade, our research highlights the impact of a fiscal instrument (appliance rebates) in the presence of information and minimum standards all focused on individual consumer behavior.

Our findings add to the growing body of evidence suggesting that energy efficiency subsidies tend to have a high cost to society due to various unintended consequences. Davis (2008) shows that subsidizing energy-efficient clothes washers induce people to use them more. Davis, Fuchs, and Gertler (2013) find that a large-scale rebate program in Mexico for energy-efficient air conditioners (ACs) and refrigerators may have actually increased (ACs) or led to modest reduction (refrigerators) in electricity consumption. The fact that consumers may have replaced an old non-functioning appliance, have been prone to a rebound effect, or have upgraded to an appliance with more features could explain these results. Boomhower and Davis (2014) also find that for the same program, a large proportion of the program participants $(>65 \%)$ would have purchased an appliance in the absence of rebates. This estimate of "freeriders" is on par with other recent studies in the United 
States. For instance, Alberini, Gans, and Towe (2014) find evidence that rebate programs in Maryland for energy-efficient heat pumps had a similarly high proportion of inframarginal participants (50\%-89\%). Our paper represents one of the first ex post nationwide analyses of the impacts of clean energy spending on energy efficiency outcomes. Like the above studies (Boomhower and Davis 2014; Alberini, Gans, and Towe 2014), we show that the econometric estimates of the program are much less favorable than engineering estimates. This reinforces the role of using credible research designs to estimate the returns to energy efficiency programs (Allcott and Greenstone 2012).

In addition, this analysis contributes to the literature on the effectiveness of Recovery Act programs. Several papers have also looked at a similar program: Cash for Clunkers. ${ }^{1}$ Our results are consistent with the findings of Mian and Sufi (2012); Li, Linn, and Spiller (2013); Hoekstra, Puller, and West (2014). These three studies all found significant intertemporal shifting as a large share of the participants took advantage of the rebates by pulling forward their car purchase decision by a few months. We also show that $\mathrm{C} 4 \mathrm{~A}$ had a high proportion of inframarginal participants (73\%-92\%), and this is partly attributable to short-term intertemporal substitution. We find some evidence, for two out of three of the appliance categories that we study, that consumers pulled forward their appliance purchase decision by a few years. However, a large number of consumers also delayed their purchases by a few weeks until the start of their state's C4A program.

One important difference between $\mathrm{C} 4 \mathrm{~A}$ and Cash for Clunkers is that the latter program was implemented uniformly across the United States, which makes finding a valid counterfactual quite challenging. Mian and Sufi (2012)'s empirical strategy exploits variation in the share of clunkers in different cities' pre-program implementation; Li, Linn, and Spiller (2013)'s strategy relies on car sales from Canada; and Hoekstra, Puller, and West (2014) exploit a sharp discontinuity in the eligibly criteria for clunkers. Under C4A, states designed their own rebate programs. We therefore exploit variation in the timing of the programs, rebate amount, and appliance coverage across states to estimate the various impacts of the rebates.

The remainder of the paper proceeds as follows. Section 2 describes the appliance efficiency policy landscape. Section 3 presents a framework for evaluating multiple, overlapping energy efficiency policy instruments. Section 4 presents the data. Section 5 presents our empirical strategy and main

\footnotetext{
${ }^{1}$ Technically, Cash for Clunkers was not part of the American Recovery and Reinvestment Act. Nonetheless, Cash for Clunkers was intended to stimulate investment in new, energy-efficient vehicles and thus was similar to various Recovery Act clean energy programs (Aldy 2013).
} 
results. Section 6 investigates whether the program induces an income effect and upgrading. Section 7 presents a policy analysis with counterfactual scenarios. Conclusions follow.

\section{Appliance Efficiency Policy Landscape}

Since the oil shocks of the 1970s, local, state, and federal governments have employed an array of policy instruments to promote the energy efficiency of appliances (and energy efficiency more generally). The 1975 Energy Policy and Conservation Act established a national energy conservation program, including EnergyGuide labels for residential appliances. These labels provide a common set of information on all appliances within a product category, including typical annual energy use and operating cost and a comparison to the range of operating costs of similar models. The Federal Trade Commission (FTC) implements the EnergyGuide label program and undertakes occasional revisions of the program, including expansion to new products, updates of energy use and cost information, and modifications of the label format.

The 1987 National Appliance Energy Conservation Act created minimum efficiency standards for appliances. The act established the initial Federal standards and delegated authority to the Department of Energy (DOE) to administer and periodically update the standards. These national standards preempt state efficiency standards. For example, refrigerators have been subject to California standards promulgated in 1978, 1980, and 1987 and national standards promulgated in 1990, 1993, and 2001.

The Environmental Protection Agency (EPA) launched in 1992 the ENERGY STAR (ES) program, a voluntary initiative for appliance manufacturers (and others) to demonstrate the energy efficiency of their products. ${ }^{2}$ An appliance model can earn the ES label, a simple brand-like logo, if its efficiency exceeds by a certain percentage the minimum standard for that appliance category. For most appliances, the certification is binary, i.e., a product either meets the requirement, or does not. ${ }^{3}$ A number of appliance rebate programs (including the SEEARP discussed below) employ the ES certification requirement as the basis for appliance eligibility.

\footnotetext{
${ }^{2}$ The ES program is now operated jointly by EPA and DOE.

${ }^{3}$ The EPA has recently experimented with a multi-tiered system.
} 
State and local governments as well as utilities also implement a wide array of efficiency policies. These include tax credits, tax deductions, and rebates ${ }^{4}$ mandates to utilities to improve the efficiency and conservation by its customer base through so-called Energy Efficiency Resource Standards $;^{5}$ rebates to customers for reductions in electricity consumption (Ito 2012); and normmotivated information provision (Allcott 2011).

The Energy Policy Act of 2005 created the State Energy Efficient Appliance Rebate Program (SEEARP) to provide guidance in the design of and federal support for state rebate programs. In 2009, the American Recovery and Reinvestment Act made the initial appropriation to SEEARP, in what became informally known as "Cash for Appliances."

The 2005 act stipulates that SEEARP allocate federal funds to state programs proportional to each state's share of the national population. In addition, SEEARP requires states to use ES certification or more stringent but similar criteria for rebate eligibility. ${ }^{6}$ Table 1 summarizes the eligibility criteria used for the three appliance categories that we study. Most states allocated rebates for products that just met the ES certification, although for clothes washers and dishwashers several states adopted more stringent efficiency criteria.

Under SEEARP, states have sovereignty over the design of several elements of their rebate programs. As a result, the $\mathrm{C} 4 \mathrm{~A}$ program gave rise to a collection of 56 different programs ${ }^{7}$ that differed in the rebate amounts offered, appliances covered, eligibility criteria, timing and duration, and mechanisms to claim the rebates.

\footnotetext{
${ }^{4}$ Examples of state and local governments (and quasi-governmental entities) providing ES-based appliance rebates and tax benefits include the following. The New Jersey Office of Clean Energy offers rebates for EScertified refrigerators and clothes washers. Oregon Trust, a non-profit created by the Oregon state legislature and funded through utility-assessed consumer charges, implements rebates for ES-certified clothes washers, refrigerators, and freezers. The city of Fort Collins (Colorado) offers clothes washer and dishwasher rebates based on ES ratings. The state of Missouri implements a "Show-Me Green Sales Tax Holiday" that exempts ES-rated appliances from the state sales tax for one week each year.

${ }^{5}$ American Council for an Energy-Efficient Economy (2012) notes that 24 states representing approximately two-thirds of U.S. electricity sales have implemented long-term energy efficiency resource standards.

${ }^{6}$ The Energy Policy Act of 2005 was amended in 2007 to allow eligibility criteria more stringent than the ES requirements. These more stringent requirements must, however, be based on a formula similar to the one used to determine ES eligibility.

${ }^{7}$ The District of Columbia and territories also received funds, but we focus on the 50 states in our empirical analysis.
} 
Consumers could claim a rebate, typically through online and mail options, by providing proof of purchase and residency. Some states established a reservation system where consumers could reserve rebates prior to going to the store. Most states did not offer rebates for online purchases. Rebates were limited to one for each appliance category, but several states allowed households to claim multiple rebates. New York offered rebates for bundled purchases (i.e., multiple appliances purchased at once). Alaska offered additional incentives to rural residents. Kansas, Ohio, Oregon, and Montana employed means-tested eligibility criteria for their rebate programs. In most states, however, all households were eligible to claim rebates for qualifying appliances. Several states provided additional incentives if the old appliance was hauled away and recycled.

The states offered economically significant rebates, on average $12 \%-15 \%$ of sales prices for refrigerators, dishwashers, and clothes washers, and these varied greatly among states. Most states offered a fixed rebate amount for a qualifying purchase, but four states, Florida, Illinois, North Carolina, and Oregon, offered ad valorem rebates (e.g., $20 \%$ of the price paid (FL), or $70 \%(\mathrm{OR}))^{8}$

States also varied in the timing of the implementation of their rebate programs. On July 14, 2009, DOE issued a press release announcing the program and allocation of funds to the states. State governments began to draft design and implementation plans for C4A, which they submitted to DOE for review and approval. According to Google Trends, consumers first started to search for the program in June 2009. In August 2009, search queries rapidly increased and appear to be correlated with ABC News's national story comparing the program with Cash for Clunkers (August 20, 2009). States began advertising their programs in November and December 2009. The first program started the second week of December 2009 in Kansas. By April 2010, more than 80\% of the states had launched their C4A programs (Figure 2). The programs lasted 26 weeks on average, although program duration was quite heterogeneous. Programs in Iowa, Illinois, Massachusetts, and Texas exhausted all rebate funds in only one day, ${ }^{9}$ while Alaska's program lasted 91 weeks.

\footnotetext{
${ }^{8}$ In some cases, the rebates claimed were extremely generous; the maximum rebates often exceed several thousand dollars (Table 2). These numbers are outliers and should be put in the context of the Great Recession. Program administrators were directed to distribute the stimulus funds quickly, which may have led them to distribute unclaimed funds to bundled purchases.

${ }^{9}$ Programs in Illinois, Massachusetts, and Texas, however, reopened for a second phase that lasted longer.
} 
Several states offered the rebates in different phases, where the program closed temporarily between phases. ${ }^{10}$

\section{The Simple Economics of Energy Efficiency Rebates}

The previous section describes the extensive, overlapping, and complicated set of policy instruments focused on residential energy efficiency. We now present a simple economic framework for evaluating this policy space, with a focus on minimum efficiency standards, certification, and rebates for energy-efficient appliances. This will motivate our empirical analysis of the incremental impact of the SEEARP.

Consider that energy efficiency is simply measured as the absolute amount of energy saved. The Federal minimum energy efficiency standards and ES certification are examples of attributebased regulation (Ito and Sallee 2014) where the maximum amount of energy a given appliance model can consume is a function of size and other attributes. In the size/energy efficiency space, a minimum efficiency standard (MEF) and ES requirement can be represented by two downward sloping parallel lines (Figure 1), where only bundles above the minimum standard are allowed to be present on the market, and certified products are all bundles above the ES requirement. If each consumer values both size and efficiency, a consumer's optimal bundle corresponds to the point where the indifference curve (U) is tangent to the budget constraint (W). Regulations requiring information disclosure about energy efficiency, such as EnergyGuide, aim to induce movements along the efficiency dimension. Minimum standards, the ES certification, and subsidies, however, may induce movements in both the size and efficiency dimensions. Their impact on energy savings is thus ambiguous.

To illustrate, consider Panel A of Figure 1, which depicts the case where the appliance model purchased in equilibrium just meets the ES requirement, as is often the case in several markets (Houde 2014). Offering a rebate $\mathrm{R}$ for purchasing an ES product may first induce the so-called freerider problem, a well-known source of economic inefficiency in this context (Joskow and Marron 1992). Because program administrators cannot restrict the access to a rebate program, consumers that would have purchased an ES product absent rebates can simply claim the rebate and make

\footnotetext{
${ }^{10}$ States that interrupted their programs are Arizona, California, Florida, Georgia, Illinois, Massachusetts, Michigan, Minnesota, Montana, North Carolina, New Jersey, Ohio, Oregon, Texas, Vermont, and Washington.
} 
the exact same purchase. It is also possible that the rebate induces a small income effect, which can be represented by an outward movement of the budget constraint. As a result, a consumer may purchase a more efficient, but also larger appliance (Panel B). Depending on consumers' preferences over size and efficiency, it is possible that the income effect induces the purchase of a larger (smaller), but less (more) efficient appliance. Only in the case where firms offer products that bunch exclusively at the ES requirement will the income effect unambiguously lead to more efficient purchases (Panel C).

Even for consumers that could not afford ES products in the first place, offering a rebate $\mathrm{R}$ does not ensure that a more efficient appliance will be purchased. Panel D illustrates the case where the rebate leads to the adoption of a more efficient and larger appliance. It is, however, easy to construct an example (Panel E) where the rebate has a perverse effect and leads to the adoption of a less efficient product. In this example, this perverse effect can be ruled out only if the minimum standard and ES requirement are set independently of size and solely lie in the energy efficiency space (Panel F). More generally, rebates are at risk to be perverse when energy efficiency and the attributes used to set the regulation are inversely correlated. In such case, rebates become implicit subsidies for specific attributes other than energy efficiency.

\section{Data and Preliminary Evidence}

The DOE required state program administrators to collect detailed data on their programs. The DOE compiled these data and provided us a dataset that includes all rebate claims, approximately 1.8 million made in the 50 U.S. states. For each rebate claim, we observe the characteristics of the products purchased, such as the manufacturer model number, brand, and price paid. In addition, we observe the amount of the rebate, the dates of the purchase and rebate application, and zip code of the household. Some states also collected information about the appliance that was replaced, whether the old appliance was hauled away, and the retailer where the purchase was made.

One limitation of the DOE data is that they only contain information about C4A participants and do not provide information to construct a valid counterfactual of participants' behavior in the absence of rebates. Thus, for our primary analyses, we rely on transaction-level data that were provided by a large retailer with non-marginal market shares $(>5 \%)$ in the appliance market. The retailer has brick-and-mortar stores in every state and an online store. The data cover the period starting from January 2008 to November 2012. For each transaction, we observe the manufacturer 
model number of the product purchased, the location of the store, the price paid, taxes, and a unique household identifier. For a large number of households, consumer-specific demographic data, including income, education level, housing type, age of head of the household, political orientation, home ownership, and family size, are matched to appliance purchase data by household identifier. Demographic information is collected by a third party (Acxiom) and the match is performed by the retailer. About half the transactions (ranging over 44\%-49\% across the three appliance categories we focus on) have a complete match with all the demographic information that we use. We do not observe the exact location of each household, but we know the location of the store where the household purchased its appliance(s); we assume that households lived in the same state where they made their purchase(s). In addition to the prices paid, we also observe the manufacturers' suggested retail prices. The retailer has a national price policy. Retail prices are thus set at the national level and vary idiosyncratically across stores. For each appliance, we observe attribute information such as expected electricity consumption, size, the ES certification, and numerous other features.

A possible limitation of our analysis is that the retailer might not be fully representative of the appliance market. We can address this concern using the DOE data, which recorded the retailer where each participant made a purchase. ${ }^{11}$ Table A.1 compares prices, rebates claimed, and the energy consumption and the size of the products purchased under $\mathrm{C} 4 \mathrm{~A}$ at our retailer versus all other retailers observed in the DOE data. We found that on average prices tend to be slightly higher, especially for refrigerators, at our retailer relatively to other retailers. Except for refrigerators, there are no statistically significant differences in size. For energy consumption, there is no clear pattern. Overall, we found that the differences are modest, and find good support for external validity.

We collected information about state programs - including appliances covered, rebate amount, eligibility criteria, and start and end dates - from each state's program website. We also conducted interviews with program administrators in several states to learn more about the implementation of their programs.

Table 2 provides summary statistics of the program. Refrigerators, clothes washers, and dishwashers were the most common products covered by the programs. These three appliances attracted

\footnotetext{
${ }^{11}$ Not all states recorded this information.
} 
$85 \%$ of the claims, and $65 \%$ of the funds distributed nationwide. For our analysis, we focus on instore purchases of these three appliances. ${ }^{12}$ Kansas, Oregon, Alaska, and Iowa offered the most generous rebates. Rebate amounts in other states were, nevertheless, economically significant. ${ }^{13}$

The ES program covers all three appliance categories evaluated in our study. Over January-June 2009, national ES market shares were $46 \%$ for refrigerators, $53 \%$ for clothes washers, and $75 \%$ for dishwashers (Table 3). These national averages mask state-level variation - in some states the number of ES models offered is higher, and in others it is lower. Figure 2 plots the first evidence of the impact of rebates on market shares. Each panel plots the nationwide ES market share for an appliance category and the number of state rebate programs active at different points in time. All ES-certified appliance models as of January 2010 are included in the market shares. ${ }^{14}$ For refrigerators and clothes washers, market shares appear to peak at the time when most rebate programs were enacted. The patterns suggest potentially short-lived impacts.

\section{Energy Savings}

\subsection{Empirical Strategy}

We model the decision to replace an energy-intensive durable as a two-step decision where consumers first decide when to replace and then what new model to purchase. The market for a durable consists of a population of consumers that can make a purchase at different points in time $t$ over a time horizon starting at $t=0$ and ending at $t=T$. The market share of a particular product $j$ over the entire time horizon $T$ is then the (weighted) sum of the market shares at different times $t$. In particular, if we define the market share of product $j$ over $T$ by $\mathcal{M}_{j}$, by the law of iterated expectations we have:

$$
\mathcal{M}_{j}=\sum_{t} \sigma_{j \mid t}\left(\Omega_{t}\right) \cdot \delta_{t}\left(\mathcal{I}_{t}\right)
$$

\footnotetext{
${ }^{12} \mathrm{We}$ also looked at electric water heaters to investigate whether the behavioral response to rebates for a less popular product was similar to the most popular ones. We found similar results (Appendix). Additional results can be requested from the authors.

${ }^{13}$ Figure A.1 in the Appendix plots the average price paid along with the average rebate amount claimed across states for these different appliances.

${ }^{14}$ Note that for dishwashers, the certification requirement changed in August 2009, July 2011, and January 2012. For clothes washers, the certification requirement changed in July 2009 and January 2011. For refrigerators, the requirement did not change during the 2009-2012 time period.
} 
where $\sigma_{j \mid t}\left(\Omega_{t}\right)$ represents the market share of product $j$ conditional on the fact that consumers make a purchase at time $t$, and $\delta_{t}\left(\mathcal{I}_{t}\right)$ is the fraction of consumers that decide to replace their durable at time $t$. $\Omega_{t}$ represents the characteristics of the products and consumers present on the market at time $t$. Similarly, $\mathcal{I}_{t}$ represents the information set and the characteristics that consumers have at $t$, which both determine whether consumers make a purchase at this particular time. This may include expectations about current and future prices, product availability, expected remaining lifetime of their durable, the cost of going to the store, and, crucially, rebates.

Because rebates enter both $\Omega_{t}$ and $\mathcal{I}_{t}$, they impact decisions on two margins. First, consumers who want to take advantage of a rebate program can do so by waiting for the start of the program or pulling forward their decision to replace their durable during the program window. Second, when the rebate program is active, consumers can substitute and purchase rebate-eligible products. Rebates then lead to energy savings via two mechanisms. First, consumers who pull forward their purchases accelerate the replacement of older and less efficient appliances. Note that consumers waiting for the start of a program have the opposite effect and contribute to an overall increase in energy demand by holding on to their old appliances longer. ${ }^{15}$ Second, consumers may substitute toward more energy-efficient products.

In this framework, the average energy consumption of the products purchased over a time horizon $T$ is given by:

$$
E[e \mid R]=\sum_{j} \mathcal{M}_{j} e_{j}=\sum_{j} \sum_{t=0}^{T} \sigma_{j \mid t}\left(\Omega_{j}\right) \cdot \delta_{t}\left(\mathcal{I}_{t}\right) \cdot e_{j}=\sum_{t=0}^{T} \delta_{t}\left(\mathcal{I}_{t}\right) \cdot \bar{e}_{t}
$$

where $e_{j}$ is the energy consumption of product $j$, and $\sum_{j} \sigma_{j \mid t}\left(\Omega_{t}\right) \cdot e_{j}=\bar{e}_{t}$ is the average energy consumption purchased at time $t$, and the rebate amount $R$ enters $\Omega_{t}$ and $\mathcal{I}_{t}$, for each $t .{ }^{16}$

The energy savings associated with a program offering a rebate amount $r$ is the quantity $E[e \mid R=$ $r]-E[e \mid R=0]$, where $E[e \mid R=r]$ is the average energy consumption purchased over the entire time horizon for which rebates impacted consumers' decisions, and $E[e \mid R=0]$ is the counterfactual quantity where rebates do not impact decisions. The main challenge in estimating the quantity

\footnotetext{
${ }^{15}$ In the present context, the $\mathrm{C} 4 \mathrm{~A}$ program was first mentioned in the new media in the summer of 2009 and most programs started less than a year after. Thus, the effect of delayed replacement is likely limited.

${ }^{16}$ Throughout the paper, we refer to the energy consumption of an appliance based on the expected energy consumption estimated for that model's EnergyGuide label. Thus, our analysis abstracts from potential rebound effects, which are likely to be modest for refrigerators, but possibly larger for dishwashers and clothes washers.
} 
$E[e \mid R=r]$ is to define the appropriate time horizon over which a rebate program had an impact. To obtain an internally valid estimate of $E[e \mid R=r]-E[e \mid R=0]$, we need to estimate $E[e \mid R=r]$ over a time horizon where the distribution of consumer characteristics is exactly the same as for $E[e \mid R=0]$.

We distinguish among four distinct time periods of a rebate program: the pre-announcement period, the period between the announcement and the start of a rebate program (the pre-rebate period), the rebate period, and the post-rebate period. Rebates enter consumers' information set, $\mathcal{I}_{t}$, following the announcement of the program, which leads consumers to substitute intertemporally. The quantity $E[e \mid R=r]$ needs to be estimated from the beginning of the pre-rebate period to the end of the post-rebate period. The pre-rebate period should begin at the exact time the consumer who first learned about rebates decided to wait for the start of the program. Presumably, this may have happened following the announcement of the program. Similarly, the end of the post-rebate period should be defined as the purchase date that the last consumer who decided to pull forward his purchase would have chosen if rebates had not been offered. These two consumers are not observed. Our strategy to define the beginning of the pre-rebate period and the end of the post-rebate period will then consist of conducting sensitivity analysis. If we were to define the pre-period and post-period accurately, the overall size of the market over which $E[e \mid R=r]$ is estimated should remain constant because an increase in sales in the rebate period should be canceled by the decreases in the pre-rebate and post-rebate periods. ${ }^{17}$ Therefore, the impact of a rebate program on sales over the entire time horizon for which rebates impacted consumers should be zero. In essence, our empirical strategy then consists of looking at two outcome variables: total sales and the energy consumption purchased by each household, and estimate the quantities $\frac{\partial \delta_{t}\left(\mathcal{I}_{t}\right)}{\partial R}$ and $\frac{\partial \bar{e}_{t}}{\partial R}$ at different points in time. The effect of rebates on total sales will inform us about the extent of the intertemporal substitution and help us determine how long the effects of the program lasted.

To determine the causal effect of rebates on each of these two outcome variables, we rely on difference-in-differences (DD) estimators that exploit variation in program coverage and rebate amount across appliance categories, time, and states. The effect of rebates on weekly sales for a given appliance type is estimated with the following model:

$$
\log \left(\text { sales }_{s, t}\right)=\alpha_{s y}+\gamma_{t}+\sum_{l=t}^{T} \rho_{l} \cdot \text { DPeriod }_{s, l t} \cdot R_{s}+\epsilon_{s, t}
$$

\footnotetext{
${ }^{17}$ This is only true if we assume that the rebate program induces consumers to replace an existing appliance. Note that a dozen states required the recycling of an existing appliance in order to receive a rebate for a new appliance.
} 
where $_{\text {DPeriod }}, l t$ is a dummy variable that takes the value one if week $t$ falls in the period $l$ of a rebate program. The rebate amount offered in state $s$ is given by $R_{s}$, and corresponds to the rebate amount reported on the program websites. ${ }^{18}$ For programs that provided ad valorem rebates, we compute an average rebate amount by multiplying the percentage incentive by the average price specific to each appliance category. By interacting $\operatorname{DPeriod}_{s, l t}$ and $R_{s}, \rho_{l}$ measures the effect of a rebate in a particular period of the program. For instance, we can estimate the impact of rebates in the first week where rebates are offered, the week just before the start, and the week just after the end. The DD estimator is implemented by adding two sets of fixed effects: $\alpha_{s y}$ and $\gamma_{t}$, which are respectively state-year and week-year fixed effects. The week-year fixed effects take out the effects of promotions and advertising campaigns implemented by the retailer, seasonality, and other shocks that impact the market of each appliance type. The fact that the retailer has a national price policy implies that the week-year fixed effects capture the effect of the retailer's national pricing strategy. The state-year fixed effects control for pre-existing time trends in different states and state-specific unobservables that may be correlated with the design and implementation of rebate programs. They also control for rebate programs offered by state governments and/or energy utilities, which may vary from year to year and have been found to impact the ES market shares for some appliances (Datta and Gulati 2009). The dummy variables DPeriod $_{s, l t}$ are not perfectly correlated with week-year fixed effects because only a subset of states implemented rebate programs for a particular appliance category and the timing of the programs varied across states. For the estimation of Equation 3, we use weighted least squares to account for the fact that larger states should count more in the identification of the coefficients $\rho_{l}$. Annual appliance category sales in each state are used as weights.

We use a similar specification to estimate the effect of rebates on effective energy consumption purchased by individual households. We use the log of the estimated annual electricity consumption $(\mathrm{kWh} / \mathrm{y})$ of the product purchased ${ }^{19}$ by each household $i$ as the dependent variable:

$$
\log \left(k W h_{s, t, i}\right)=\alpha_{s y}+\gamma_{t}+\sum_{l=t}^{T} \lambda_{l} \cdot T w_{s, l t} \cdot R_{s}+\beta X_{i}+\epsilon_{s, t, i}
$$

We also add $X_{i}$ a vector of household-specific demographics that includes income, education, age of the head of the household, family size, political orientation, type of housing, and a home ownership dummy.

\footnotetext{
${ }^{18}$ In the base specifications, we assume that the marginal impact of rebates is the same across all states. We do not account for differences in eligibility criteria, mechanisms to claim rebates, or other factors that may have impacted the behavioral response to the rebates. We address heterogeneity later in this section.

${ }^{19}$ We use the estimate reported by the manufacturers. Therefore, we do not account for household-specific consumption patterns.
} 
The main threat to internal validity in our empirical strategy is that the features of state rebate programs could be correlated with the impacts of the Great Recession in each state. Although the use of state-year fixed effects alleviates this concern, we cannot completely rule out this source of endogeneity. We, however, consider that this is not a major issue. As discussed earlier, the allocation of funds to each state was predetermined by the Energy Policy Act of 2005, and was therefore exogenous to the economic conditions. States had the sovereignty to determine several other features of their programs, which could have been influenced by the local economic conditions at that time. Through our interviews with the various program administrators, however, we concluded that it is unlikely that the program features adopted in each state were systematically correlated with the Great Recession. For all state program administrators, C4A represented their first experience with a large-scale rebate program. Moreover, there was no precedent at the federal level. We argue that the inexperience of the state program administrators, the absence of past examples, and the difficulty to forecast the effects of the recession as it was unfolding make the features of each state program idiosyncratic. The relative timing of a state's initial plan submission, DOE feedback, negotiation over modifications, and final plan approval also appeared to be idiosyncratic. Furthermore, Equation 4 includes demographics, which allows us to control for changes in consumer demographics that could have been caused by the recession and that program administrators may have tried to address. For instance, program administrators in states where low-income households were hit hard by the recession may have decided to offer more generous rebates to attract these consumers to appliance stores. By controlling for income, however, we are estimating the effect of a rebate on the energy efficiency purchased for individuals with similar income. In sum, our estimates $\lambda_{l}$ exclude the changes in demographics induced by rebates.

Under the log-specification, the coefficients $\rho_{l}$ and $\lambda_{l}$ correspond respectively to the percentage change in sales and energy consumption at different periods of a rebate program relative to their pre-announcement levels. ${ }^{20}$ The overall percentage change in energy consumption associated with a rebate program can be estimated by weighting and averaging the estimates $\lambda_{l}$ over the different periods, where we employ period-specific sales in each period. This can be done directly in the estimation framework by defining a dummy variable that covers the entire rebate period, in addition to the pre-rebate and post-rebate periods. In particular, suppose that DallPeriod $_{s, l t}$ is a dummy variable that identifies the pre-rebate period, the rebate period, and the post-rebate period, by estimating the model:

$$
\log \left(k W h_{s, t, i}\right)=\nu_{s}+\gamma_{t}+\lambda \cdot \text { DallPeriod }_{s, l t} \cdot R_{s}+\beta X_{j}+\epsilon_{s, t, i}
$$

\footnotetext{
${ }^{20}$ In all specifications, we omit the dummy variable that identifies the pre-announcement period.
} 
where the coefficient $\lambda$ is a weighted average of the dynamic effects of rebates, and an estimate of the overall energy savings relative to the pre-announcement level. In this specification, we rely on state fixed effects instead of state-year fixed effects because some programs ran for more than one year. ${ }^{21}$ The coefficient $\lambda$ should be interpreted as a reduced-form estimate of the average impact of a program that does not distinguish between, but accounts for, consumers that substituted over time and between products. Note that by working with data disaggregated at the household level, periods with the highest sales will have more observations and thus have more weight to identify $\lambda$, which allows the effect of intertemporal substitution to be accounted for.

We will present the estimate of $\lambda$ for various definitions of the dummy DallPeriod, which vary in terms of start dates of the pre-rebate and end dates of the post-rebate periods, along with similar estimates of the effect of rebates on total sales. In specifications where we define the length of the pre-rebate and post-rebate periods so that we can still detect a significant impact of rebates on total sales, we will know that the total market size over which $E[e \mid R=r]$ is computed will not be constant relative to the counterfactual scenario. For these specifications, the coefficient $\lambda$ will then overestimate the impact of rebates, because marginal consumers will be over-represented in the population of consumers.

\subsection{Results}

Tables 4-6 present the results. We estimated the regression models separately for the three appliance categories. To estimate the impact of rebates on electricity consumption purchased, we use the log of the annual electricity consumption purchased by each consumer as the dependent variable. Our primary sample includes only transactions that were successfully matched with demographic information. Specifications that estimate the impact of rebates on sales use the log of the weekly sales in each state, and use all observed sales. For all specifications, standard errors are clustered at the state level. The dummy variable that identifies the pre-announcement period is always omitted.

Focusing on sales, we observe that rebate programs had a large impact mostly in the first three weeks of the programs, and especially in the first week (Specification IV). In the week preceding the start of the programs, however, sales tend to decrease. For refrigerators, we observe a statistically significant reduction of $3.9 \%$. The $15 \%$ increase in sales observed in the first week of the rebate programs is then partly offset by a decrease in sales in the week just prior. For clothes washers, sales decrease by $5.7 \%$ in the week prior to the start of the programs, which offset as much as $40 \%$

\footnotetext{
${ }^{21}$ In the Appendix, we show that for our main specifications, using state fixed effects instead of state-year fixed effects has little impact on the results.
} 
of the increase in sales of the first week of the rebate programs. For dishwashers, the reduction in the week prior is not statistically significant.

In the week just after the end of the rebate programs, the impact on sales is not statistically significant for all three appliance categories. However, for refrigerators and dishwashers, we detect a decrease in sales several weeks (more than 10) after the program ended, which suggests that the program may have had a small impact on long-term sales. ${ }^{22}$ Our results are partly consistent with the findings of Mian and Sufi (2012) who found that the Cash for Clunkers program led to a significant decrease in sales in the post-rebate period. In the present case, we, however, also found evidence of an important short-term intertemporal substitution where consumers waited one or two weeks to replace their current appliance. The next results show that the share of consumers who pulled forward their purchase decisions appears to be modest, representing about $1 \%-2 \%$ of total sales.

Specifications I, II, and III in Tables 4-6 present different estimates of the effects of the rebate programs averaging over the pre-rebate, rebate, and post-rebate periods. For the first estimate (Specification I), the duration of a pre-rebate program is defined as the two months preceding the start of a program, and the post-rebate period consists of two weeks following the effective end of a program. The second specification (Specification II) defines the pre-rebate period as the four months preceding the start of a program, and the post-rebate as the two months following the end of a program. The third estimate (Specification III) defines the pre-rebate period from the date that "Cash for Appliances" was first mentioned in the news media (July 2009) to the start of a program, and the post-rebate period consists of three months after the effective end date of a program. For states that temporally interrupted their program, the period between two rebate periods is attributed to the post-rebate period, and the second rebate period is counted as the continuation of the first rebate period. The durations of the pre-rebate period and post-rebate period were chosen to capture the short-term and long-term substitution effects. Longer or shorter periods could have been used. Accounting for the intertemporal substitution, the rebate programs had a statistically significant impact on refrigerator sales in all three specifications. For dishwashers, the impact on sales can be detected in the first two specifications. For clothes washers, the effect is significant in the second specification only. For each of the three appliance categories, the statistically significant sales increases ranged from 1\%-2\% above the counterfactual. Altogether, the estimates of rebates

\footnotetext{
${ }^{22}$ These results are robust to the way we define the last period of the post-rebate period. For instance, if we define a dummy variable that identifies weeks 10 to 15 of the post-rebate period, and a dummy variable that identifies all the weeks after the $15^{\text {th }}$ week, we still detect statistically significant decreases in sales between weeks 10 and 15 and after week 15 for both refrigerators and dishwashers, but not for clothes washers.
} 
on sales suggest that the effects of the rebates were short-lived, and some consumers who took advantage of the rebates would have still replaced their appliances in the year that the rebates were offered. The overall stimulus effect of the program was then modest: it leveraged little incremental private investment, although it did provide a means for transferring resources to households who participated in the program. It is beyond the scope of this paper to assess the marginal impact of these transfers on non-appliance consumption and subsequent measures of economic activity.

Turning to the average electricity consumption purchased, for all three appliance categories the impact of rebates on electricity consumption tends to be quite small when we account for intertemporal substitution (Specifications I, II, and III). For refrigerators, the reduction is statistically significant but economically small (about $0.085 \%$, or less than $1 \mathrm{kWh} /$ year) for two of the model specifications. For dishwashers and clothes washers, however, there are no statistically significant reductions when evaluating the rebate programs over all time periods. For clothes washers, electricity consumption purchased fell a statistically significant $5 \%$ in week one and a statistically significant $2 \%$ in weeks two and three. Statistically significant increases in electricity consumption purchased in several of the weeks in each of the pre- and post-rebate periods illustrate the cumulative zero impact of rebates on clothes washers' electricity consumption. Interestingly, rebates spurred a $25 \%$ increase in sales in the first week of the dishwasher programs, but a statistically insignificant $0.4 \%$ decline in electricity consumption. This likely reflects the small difference in electricity consumption between ES-certified and non-ES models (less than 10\%) and, as we show next, that consumers substituted to slightly larger models during the rebate period. For clothes washers, the ES requirement translates into a larger difference in electricity consumption between ES-certified and non-ES models.

Figure 3 presents non-parametric estimates of the dynamic effects of rebates on electricity consumption and ES market shares. Panels on the left plot the normalized average electricity consumption purchased as a function of time before and after the start of each rebate program. The figure shows a smoothed time-varying average that was estimated by regressing normalized electricity consumption on flexible regression splines. The normalized electricity consumption is the residual of a regression of electricity consumption purchased by each household on state and week-year fixed effects. The figure is consistent with the previous regression estimates. For dishwashers and refrigerators, the rebates had very small effects on electricity consumption, no greater than $2 \mathrm{kWh} / \mathrm{yr}$ savings even in the first week of the program. For clothes washers, there is a more substantial short-term effect, on the order of $10 \mathrm{kWh} / \mathrm{yr}$, that rapidly fades off.

Panels on the right of Figure 3 show similar plots where we have employed the normalized ES market share as the dependent variable. The figure shows that rebate programs increased ES 
market shares for all three appliance categories by 3\%-6\%. Again, there is evidence that the effects were short-lived, and that consumers delayed their purchases to take advantage of the rebates, but it is not clear whether consumers pulled forward their purchases. The fact that the increase in ES market shares did not deliver energy savings for some appliances is a cautionary tale for the design of rebate programs.

\subsection{Robustness Tests}

Our empirical strategy exploits variations across time and regions to isolate the effects of rebates. The time fixed effects are then crucial for controlling the effects of the retailer's pricing and advertising strategies. One concern is that the retailer implemented different strategies in each state, and that idiosyncratic promotions and marketing efforts are correlated with the rebate programs. ${ }^{23}$ Our empirical strategy cannot rule out these unobservables. We, however, find that the week-year fixed effects do well in controlling for the retailer's strategies. In the Appendix (Figure A.2), we compare the ES market shares with normalized market shares, which are the residuals of a regression of market shares on week-year and state fixed effects. If these fixed effects were to capture most of the variations that are not attributable to rebates, we should expect that the normalized market shares in states that did not offer rebates for a given appliance category would be tightly concentrated around zero. This is exactly what we observe.

In the Appendix, we also present alternative specifications. First, we estimate the effect of rebates on electricity consumption purchased using the whole universe of transactions and not controlling for demographics. Doing so has little impact on the estimates, suggesting that transactions that were successfully matched (44\%-49\%) with demographic information are representative of the whole dataset. We then perform the estimation using only transactions matched with demographic information, but we do not control for demographics in the estimation. Again, this has little impact on the estimates. Changes in demographics are therefore not an important source of endogeneity. For the third specification test, we excluded five states from the analysis: Florida, Iowa, Illinois, North Carolina, and Oregon. Iowa was excluded because the DOE data revealed that several claims differed drastically from the program guidelines. We found 375 instances of rebate claims covering $90 \%$ of the appliance cost and exceeding $\$ 1,000$. Other states were excluded because they offered ad valorem rebates. For these states, using the average rebate amount then leads to measurement error. Performing the estimation without these five states leads to qualitatively similar results

\footnotetext{
${ }^{23}$ Please keep in mind that this national retailer employed a national pricing strategy for appliances during the study period.
} 
for all three appliance categories. Finally, the last robustness test takes the level of electricity consumption purchased as the dependent variable. Results are also replicated closely.

\subsection{Heterogeneity by State}

One important feature of the legislation establishing SEEARP is that it provides sovereignty to states over the design of their rebate programs. Our empirical strategy has so far exploited variation in coverage, timing, and rebate amount across states to estimate the average treatment effect of a rebate on sales and electricity consumption, where the average was taken over all state programs. State programs under C4A, however, differed with respect to other dimensions, such as the mechanisms to claim rebates, eligibility criteria, reservation system, additional incentives for hauling away the old appliances, and expected program length. In this section, we seek to investigate heterogeneity in the effects of rebate programs across states.

Our empirical strategy is similar as before. We rely on a DD estimator to estimate a treatment effect in each state. In this specification, we use variation over time to control for state-specific effects, and variations in rebate coverage across states to control for time-specific effects. Variation in rebate amounts is not a source of identification anymore given that it is confounded with other program features. Our identification then relies on the difference in the timing of the program and the fact that only a subset of states offers rebates for particular appliance categories. The model that we estimate is:

$$
\log \left(k W h_{s, t, i}\right)=\nu_{s}+\mu_{t}+\sum_{l=t}^{T} \lambda_{l, s} \cdot T w_{s, l t} \cdot \text { Dstate }_{s}+\beta X_{i}+\epsilon_{s, t, i}
$$

Figure 4 presents the estimation results graphically by illustrating the effects of rebate programs on energy consumption. Each estimate represents a percentage change in electricity consumption purchased relative to the pre-announcement period. We present two estimates for each state. The first estimate reflects the effect of rebate programs during the rebate period only. The second estimate accounts for the effect of intertemporal substitution. For this second estimate, the time horizon considered includes two months of the pre-rebate period and two weeks of the post-rebate period.

Overall, these findings mirror the previous results: the largest energy consumption reductions are observed for clothes washers, and accounting for intertemporal substitution reduces the magnitude of the estimated energy savings. For each appliance category, a few states have large reductions, but most states have small, statistically insignificant reductions. Energy consumption appears 
to increase under some state rebate programs, but these estimates tend to have large confidence intervals.

We also investigate how program design could explain the variation among states by regressing the mean estimate for each state on a vector of program characteristics, such as the average rebate amount, program duration, whether the rebates were ad valorem or not, whether rebates could be claimed online, the existence of a reservation system, incentive or requirement for hauling away the old appliance, and the eligibility criteria. The results are presented in the Appendix (Table A.8). More generous rebates tend to lead to larger energy savings for all appliances, except refrigerators, where the effect is not statistically significant. Offering an ad valorem rebate has the opposite effect. Having an eligibility criterion stricter than ES contributed to larger savings for dishwashers, but not for clothes washers. Recycling incentives also had an impact for dishwashers, but not for clothes washers. We do not find statistically significant effects for other program features.

\subsection{Switchers, Freeriders, and Non-takers}

A unique feature of our data is that we observe the number of rebate participants shopping at our retailer in a number of states. This allows us to quantify the take-up rate, and distinguish among different types of participants. We define as takers the consumers who claimed a rebate. They fall into two categories: (1) switchers - the consumers who substituted away from a non-ES product, and purchased an ES product because of the existence of rebates; and (2) freeriders the consumers who purchased an ES product and claimed a rebate, but would have bought an ES product in the absence of the rebate program. We define the non-takers as the consumers who made a purchase during the rebate period, but did not claim a rebate. Non-takers either purchased a non-ES product, or purchased a certified product, but did not claim a rebate. These last consumers may have been unaware of the rebates, found that the transaction costs to claim rebates were too high, or were simply ineligible under the state program (e.g., for those states that employed means testing for rebate eligibility).

We integrate our national retailer data with the DOE data for the 13 states that identify the retailer in their SEEARP reporting. For these states, the proportion of takers is simply the total number of rebate claims divided by total sales at our retailer. To estimate the switchers' share of rebate claims, we employ a state-specific estimator where our dependent variable is the log of total sales of ES products:

$$
\log \left(\operatorname{SalesE}_{s, t}\right)=\nu_{s}+\mu_{t}+\sum_{l=t}^{T} \lambda_{l} \cdot T w_{s, l t} \cdot \text { Dstate }_{s}+\epsilon_{s, t}
$$


As before, the index $s$ denotes state and $t$ denotes week. We use this model to estimate product sales with rebates and separately to estimate product sales without rebates by setting the dummies $T w_{s, l t}$ to zero. The difference between the predicted sales with and without rebates yields the estimated number of switchers. This approach allows us to estimate the number of switchers for each week that rebates were offered accounting for the intertemporal substitution in the pre-rebate and the post-rebate periods. We simply estimate the number of freeriders as the difference between the total number of rebate claims and the estimated number of switchers. ${ }^{24}$

Table 7 reports the estimates for all states for which the retailer's and DOE's data were successfully matched. The second and eighth columns are the DD estimates of the effect of rebates on the sales of ES products. The estimates of the second column correspond to the percentage change in sales during the rebate period only. In the eighth column, the effect of rebates is measured over the rebate period, two months of the pre-rebate period, and two weeks of the post-rebate period. The other columns report the proportions of switchers, freeriders, non-takers who bought an ES product, and non-takers who bought a non-ES product among the whole population of consumers.

The first important result to note is that the proportion of switchers tends to be small relative to the proportion of freeriders. Focusing on the estimates for the rebate period only and the U.S. average, the ratio of switchers to freeriders is 1:4, 2:5, and 13:3 for refrigerators, clothes washers, and dishwashers, respectively. If we account for the effect of intertemporal substitution, these ratios fall substantially to $1: 10,1: 12$, and 3:8. These estimates imply that among the program participants, $91 \%$ (refrigerators), $92 \%$ (clothes washers), and $73 \%$ (dishwashers) of the participants were freeriders.

The second important result is that there are large variations across states. During the rebate period only, rebates had a large impact on ES market share. This is especially true in Florida, which had a generous but short-lived program. In Massachusetts, Ohio, Oklahoma, and South Carolina, the effects tend also to be large for all three appliance categories. Some estimates, however, are small and imprecisely estimated, and others are even negative (Virginia). Once we include the prerebate period and post-rebate period, the effects are much smaller, consistent with our previous results.

A third important result is that the fraction of non-takers is large. This suggests that the transaction costs of claiming a rebate deterred some consumers. The share of consumers that bought non-ES appliances varies between $10 \%$ and $30 \%$ of the market. The fact that these consumers did

\footnotetext{
${ }^{24}$ Note that under this approach, it is possible to obtain a negative proportion of freeriders if we overestimate the number of switchers.
} 
not purchase an ES product even in the presence of the generous subsidies implies that financial incentives may not be the best way to change their behavior.

\section{Income Effect and Upgrading}

We now investigate the impact rebates had on the type of product that consumers purchased. In particular, we test if rebates induced an income effect and led consumers to purchase higher quality appliances. Our empirical strategy relies again on a DD estimator, except that our outcome variables are various product attributes, such as appliance size, style, and other add-ons.

Table 8 presents the results for models with size as the outcome variable. ${ }^{25}$ We present two specifications for each appliance category. In the first specification, we consider all transactions and find that during the rebate program, especially in the first week, the average appliance size increases modestly. We can attribute this increase to two factors: ES products are larger on average due to the certification requirement and an income effect. To isolate the income effect, the second specification conditions on a purchase of an ES product. That is, we test if the rebates influence the type of ES appliance models purchased. If the income effect is important, it should be reflected in the average characteristics of ES models purchased. Conditioning on an ES purchase, we still find small increases in the size of ES products purchased, which provides evidence of a small income effect induced by the rebates. These increases are less than $1 \%$. Note that these estimates correspond to an intent-to-treat, as not all consumers that purchased an ES product claimed a rebate. By matching the DOE and retailer's data for a subset of states, we find that in the first week of the rebate programs, $23 \%$ and $33 \%$ of the consumers who purchased an ES refrigerator or clothes washer, respectively, claimed a $\mathrm{C} 4 \mathrm{~A}$ rebate. This suggests that the magnitude of the income effect on size is on the order of $2 \%$ to $3 \%$.

Table 8 presents similar regressions where the outcome variable is a binary categorical variable that describes the style of the appliance. For refrigerators, we distinguish between top-freezer (1) and other styles ( 0 if bottom-freezer or side-by-side). For clothes washers, we distinguish between top-load (1) and front-load (0). According to industry experts, top-freezer and top-load models tend to be perceived as lower quality by consumers. More importantly, the ES requirements vary across these different appliance styles. For refrigerators, manufacturers tend to certify more bottom-freezer

\footnotetext{
${ }^{25}$ We present only results for refrigerators and clothes washers for which we observe the overall volume measured in cubic feet. For dishwashers, size is a categorical variable that takes four different values. Using an ordered probit, we found qualitatively similar results for dishwashers. Figure A.3 in the Appendix provides similar graphical evidence. Using a non-paramatric estimator, we show that the size of the appliances purchased increased slightly in the initial weeks of the rebate programs, but dropped just before the start.
} 
and side-by-side refrigerators, and for clothes washers, ES models tend to be front-load (Table 3). These manufacturers' decisions may reflect both a lower opportunity cost to meet the certification requirement for these appliance styles and a desire to bundle the ES certification with higher quality products. We find that the market share of top-freezer and top-load models decreases significantly during the rebate programs. However, we don't find evidence that this decrease is attributable to an income effect - when we condition on ES purchases (second specification), the effects are close to zero and not significant. In sum, it appears that the rebates do not induce consumers to seek higher quality along this dimension. On the other hand, the ES requirements distort choice by favoring particular appliance styles.

As a proxy for overall quality, we employ manufacturer suggested retail price (MSRP) - set when the product entered the market - as an outcome variable (Table 9). The MSRP we use, therefore, does not vary over time. We find that during the first week of the rebate programs, the average price increases for all three appliance categories. Once we condition on a purchase of an ES product, the effects are mixed. For dishwashers, we still detect a significant price increase. Note that the proportion of takers in the first week for dishwashers is $34 \%$. The upgrade due to a possible income effect is thus economically significant. For clothes washers, the estimates are close to zero throughout the rebate period. For refrigerators, we find a price decrease during the rebate period, suggesting that ES models purchased were of lower overall quality during the rebate period.

Overall, we found mixed evidence that rebates led to an important income effect. It appears that some consumers who took advantage of the generous rebate programs upgraded to larger appliances. Moreover, we only find robust evidence that rebates led consumers to purchase higher quality models for dishwashers. For refrigerators, we observe the opposite effect, and no effect for clothes washers. On the other hand, our results clearly show the nature of the ES certification requirement also induced consumers to choose different appliance styles.

\section{Policy Analysis}

\subsection{Cost-Effectiveness Analysis}

How does the cost-effectiveness of C4A compare to other energy-efficiency programs? To investigate this question, we propose a simple approach to measure cost-effectiveness. First, we assume that freeriders do not contribute to energy savings. We then consider that for marginal consumers the savings correspond to the difference in the average (non-sales weighted) electricity consumption between the eligible models and non-eligible models offered on the market. To illustrate, if the eligibility criterion is the ES certification, the average savings for the whole population of participants 
$\left(\overline{k W h}_{\text {Saved }}\right)$ is given by:

$$
\overline{k W h}_{\text {Saved }}=\left(1-P_{\text {free }}\right) \cdot\left(\overline{k W h} / y^{E S}-\overline{k W h} / y^{\text {NonES }}\right) \cdot \text { Lifetime }
$$

where $P_{\text {free }}$ is the proportion of freeriders among the population of consumers that claimed a rebate, and $\overline{k W h} / y^{E S}-\overline{k W h} / y^{N o n E S}$ is the difference in average annual electricity consumption between ES-certified and non-ES-certified models offered. This difference is then multiplied by the average lifetime of the appliance. For all of our calculations, we assume a 15-year lifetime. For all three appliances, we compute the electricity consumption of the model offered using data from NPD Group, a market research company. The NPD data are point of sales from a large sample of appliance retailers, including the one for which we collected data. The NPD data have been used in several recent studies of the appliance market (Houde 2014; Spurlock 2013; Ashenfelter, Hosken, and Weinberg 2013). They provide monthly sales at the model level from the year 2001 to 2011. For our policy analysis, we impute the choice set for the years 2010-2011 using sales recorded by NPD.

We also present cost-effectiveness estimates adjusted for the effect of accelerated replacement. In constructing our adjustments, we have made assumptions biased toward showing how accelerated replacement could most improve cost-effectiveness. We first assume that all switchers replaced their old appliances five years earlier than they would have in the absence of the program. We selected five years after inspecting the manufacturing year for a subset of refrigerators that were scrapped under $\mathrm{C} 4 \mathrm{~A} .{ }^{26}$ For these replaced refrigerators, we found that the average manufacturing year was 2001 and the average electricity consumption was $639 \mathrm{kWh} / \mathrm{y}$. Again, assuming that the average life expectancy of a refrigerator is 15 years $^{27}$ implies that marginal consumers (switchers) may have pulled forward their replacement decision by five years under $\mathrm{C} 4 \mathrm{~A}$, on average.

\footnotetext{
${ }^{26}$ To identify the manufacturing year of the refrigerators replaced, we matched the DOE data with data from the California Energy Commission, which provides historical attribute data for refrigerators dating back to 1978. Our matching procedure can only recover detailed attribute information for a subset of refrigerators that were replaced under C4A (approximately 10,000) because not all states recorded the manufacturer appliance numbers of the replaced appliances. There were also some inconsistencies in the way the manufacturer numbers for replaced appliances were recorded in the C4A database. For clothes washers and dishwashers, we could not recover attribute information on the replaced appliances, because we do not have historical attribute data.

${ }^{27}$ The DOE assumes a lifetime of 18 years in its regulatory impact analysis of minimum efficiency standards for refrigerators. According to a study of the National Association of Home Builders (NAHB 2007), the average life expectancy of refrigerators is 13 years.
} 
We then compute the total amount of energy saved by taking the difference in electricity consumption of an ES-rated appliance purchased in 2010 and an appliance purchased 10 years before (in 2001). We then sum this difference over 5 years. For the remaining, 10 years of the appliance lifetime, the average savings are simply the difference between an ES and non ES-rated appliance purchased in 2010 .

For clothes washers and dishwashers, we adjust for accelerated replacement under the same assumptions: C4A marginal consumers replaced clothes washers and dishwashers that were about 10 years old and the average lifetime of an appliance is 15 years. ${ }^{28}$ The average electricity consumption of a clothes washer or a dishwasher purchased in 2001 is $793 \mathrm{kWh} / \mathrm{y}$ and $457 \mathrm{kWh} / \mathrm{y}$, respectively.

Table 10 compares our cost-effectiveness measure for different proportions of freeriders, including our preferred estimates. ${ }^{29}$ At the average rebate amount offered for all three appliance categories, the $\mathrm{C} 4 \mathrm{~A}$ did not perform well. The dollar amount spent for each $\mathrm{kWh}$ saved is $\$ 1.46$ for refrigerators, $\$ 0.44$ for clothes washers, and $\$ 0.61$ for dishwashers. This well exceeds the cost found for other utility-funded programs, which is $\$ 0.06$, on average (Arimura, Li, Newell, and Palmer 2012). Table 10 also shows that $\mathrm{C} 4 \mathrm{~A}$ would have cost more than $\$ 0.13$ per $\mathrm{kWh}$ saved for refrigerators and dishwashers even if there is zero freeriding. Due to the much larger difference between ES and non-ES clothes washers' energy consumption, lower-freeriding proportions of $50 \%$ or less would have delivered cost-effectiveness on par with other utility-funded programs.

Even after adjusting for accelerated replacement, the cost-effectiveness estimates remain high (Table A.10). The adjustment reduces the cost of each kWh saved by about a factor of two at best, with cost-effectiveness under accelerated replacement ranging from $\$ 0.25$ to $\$ 0.98$ per $\mathrm{kWh}$.

Would it have been possible to achieve better cost-effectiveness using alternative eligibility criteria? One limitation of ES-based rebates is that they provide an implicit subsidy for other attributes. To avoid these perverse incentives, we consider criteria solely based on electricity consumption. In other words, we construct a rebate that is not a function of the existing information (ENERGY STAR) and regulatory (minimum efficiency standards) programs. For instance, we consider offering rebates only for products in the lower 5 th, 10th, or 20th percentiles of electricity consumption. Of course, products that consume less electricity in absolute terms tend be smaller, and may have

\footnotetext{
${ }^{28}$ According to NAHB (2007), the average life expectancy of clothes washers and dishwashers is 10 years and 9 years, respectively. Thus, our assumptions are biased toward estimating greater energy savings and lower cost per kWh saved from C4A.

${ }^{29}$ Our preferred estimates of the proportion of freeriders are from Table 7 (columns 9 and 10). The ratio of the proportions of switchers and freeriders in the overall population implies that the proportion of freeriders among program participants is $91 \%, 92 \%$, and $73 \%$ for refrigerators, clothes washers, and dishwashers.
} 
fewer features. Eligible products are thus most likely inferior in the non-energy dimension, which is at the source of welfare losses. The cost-effectiveness metric does not account for these losses. The estimates reported in Table 10 should then be interpreted as an upper bound for the potential benefits of using a particular criterion. We find that using non-attribute based rebates improves the cost-effectiveness for refrigerators and dishwashers, only. However, the cost per unit energy saved is still high for these two appliance categories. For instance, the cost is above $\$ 0.20$ for each $\mathrm{kWh}$ saved if the proportion of freeriders is $75 \%$.

\subsection{Comparison with Other Estimates}

The DOE contracted the consulting group D\&R International to evaluate the impact of the C4A program. According to D\&R, C4A had a large impact and led to important energy savings (D\&R, 2013). Their estimate of the overall savings is 2 trillion BTU per year, and the major appliances contributed to savings of 815 billion of BTU per year.

To put these aggregate energy savings in perspective, $D \& R$ estimated average annual savings per rebate claim of $116 \mathrm{kWh} / \mathrm{y}, 257 \mathrm{kWh} / \mathrm{y}$, and $57 \mathrm{kWh} / \mathrm{y}$ for refrigerators, clothes washers, and dishwashers, respectively. ${ }^{30}$ We cannot reconcile these large energy savings with our estimated free-riding behavior. If we were to use Equation 8 to impute the proportion of freeriders using the same assumptions as above, we would find that the D\&R estimates imply that the proportions of freeriders would fall below $0 \%$ for all three appliance categories. (I.e., the proportions of switchers would exceed 100\%.) Even after accounting for the effect of accelerated replacement, these estimates appear to be overly optimistic. For example, assuming that all refrigerator rebate claimants were switchers and they each scrapped a 10-year-old refrigerator and purchased an ES refrigerator five years earlier than they would have in the absence of the program, then the proportion of switchers would still exceed $100 \%$. Under these same assumptions, the proportion of freeriders would have to be no more than 25\%-30\% for clothes washers and dishwashers, respectively, well below the $92 \%$ and $73 \%$ estimated free-riding rates in our analysis. These differences illustrate the importance of explicitly accounting for free-riding behavior, including through intertemporal substitution beyond the time horizon of program operation, in assessing the impact of energy efficiency subsidies on investment decisions and energy outcomes.

\footnotetext{
${ }^{30}$ Table A.9 reports their estimates for the three appliances that we study.
} 


\section{Conclusion}

In this paper, we investigate the incremental impact of an energy-efficient appliance rebate program, Cash for Appliances, in light of existing standards and information disclosure programs. We present a collection of estimators that suggest that the energy savings associated with the program are most likely very small. Our national estimators suggest energy savings of less than $1 \mathrm{kWh} /$ year for refrigerators, and fairly precise statistical zero effects for clothes washers and dishwashers. The state-specific estimators illustrate statistically significant but relatively small (e.g., a few percentage points) declines in electricity consumption for the states with the greatest energy savings

The modest energy savings reflect several factors. First, consumers substituted over time to take advantage of the rebates: some consumers who took advantage of the rebates by purchasing energyefficient appliances would have made a similar purchase a few weeks earlier if the rebates had not been offered. We find evidence that some other consumers may have accelerated the replacement of their old appliances by a few years. Even after making a generous adjustment for the effect of accelerated replacement, however, the overall impact of the program on long-term energy demand is likely to remain modest.

Second, the reliance on ES certification, which itself relies on attribute-based minimum standards, appeared to undermine the energy-saving objective of the rebate programs. The ES requirement and minimum efficiency standards define energy efficiency as a function of size, style, and other features. As a result, we find that rebates for ES products act as an implicit subsidy for some attributes. Moreover, we also find that the generous rebates induced a small income effect, and led consumers, at least some, to purchase larger appliances.

Third, program administrators could not identify switchers from freeriders. By making all ES purchases eligible for a rebate within a given program, many consumers who already planned to buy an ES-rated appliance could claim the rebate without a change in behavior. Indeed, it may reflect the relative success of energy labels and ES labeling that ES-rated appliances constituted about one-half to three-quarters of market share in the months leading up to the implementation of $\mathrm{C} 4 \mathrm{~A}$ for our three appliance categories. These larger market shares, however, also risk creating a substantial number of inframarginal rebate claimants, which undermines the cost-effectiveness and efficacy of C4A.

We estimate freeriding rates of $73 \%$ to $92 \%$ across our three appliance categories. As a result, our measures of cost-effectiveness, ranging from $\$ 0.44$ to $\$ 1.46$ per kWh saved, are an order of magnitude greater than the $\$ 0.06$ per $\mathrm{kWh}$ average cost-effectiveness estimated for utility-sponsored energy 
efficiency programs. Even after generous assumptions about accelerated replacement, the cost per $\mathrm{kWh}$ saved of $\mathrm{C} 4 \mathrm{~A}$ remains 4 to 16 times greater than this average in the literature.

While our empirical analysis focused on the implementation of a 2009 Recovery Act program, it has implications for energy efficiency policies in an array of contexts. First, energy-efficient appliance rebate programs are a common element of state, local, and utility energy programs and an emerging element of U.S. climate change policy. The Northeast and Mid-Atlantic states that operate the Regional Greenhouse Gas Initiative, a utility-sector carbon dioxide cap-and-trade program, direct some of the revenues generated through the quarterly auctions of emission allowances to energy-efficient appliance rebate programs. As noted above, the Environmental Protection Agency has also identified energy-efficient appliance rebate programs as one policy option in implementing power sector greenhouse gas emission performance standards. Second, the energy policy space is characterized by a mix of overlapping policy instruments. This analysis illustrates the potential for the presence of multiple pre-existing instruments to undermine the cost-effectiveness of a new (marginal) policy instrument. Instrument design that fails to account for this complicated policy space may risk higher costs and/or lower efficacy.

\section{References}

Alberini, A., W. Gans, And C. Towe (2014): "Free Riding, Upsizing, and Energy Efficiency Incentives in Maryland Homes," The Energy Journal, Forthcoming.

Aldy, J. E. (2013): "Policy Monitor. A Preliminary Assessment of the American Recovery and Reinvestment Act's Clean Energy Package," Review of Environmental Economics and Policy, pp. $136-155$.

Allcott, H. (2011): "Social Norms and Energy Conservation," Journal of Public Economics, 95(9), 1082-1095.

Allcott, H., And M. Greenstone (2012): "Is There an Energy Efficiency Gap?," Journal of Economic Perspectives, 26(1), 3-28.

American Council for an Energy-Efficient Economy (2012): "State Energy Efficiency Resource Standards," Discussion paper, Washington, DC.

Arimura, T. H., S. Li, R. G. Newell, And K. Palmer (2012): "Cost-Effectiveness of Electricity Energy Efficiency Programs," The Energy Journal, 33(2), 63-99.

Ashenfelter, O. C., D. S. Hosken, And M. C. Weinberg (2013): "The Price Effects of a Large Merger of Manufacturers: A Case Study of Maytag-Whirlpool," American Economic Journal: Economic Policy, 5(1), 239-261. 
Barbose, G. L., C. A. Goldda, M. Hoffa, And M. Billingsley (2013): "The Future of Utility Customer-Funded Energy Efficiency Programs in the United States: Projected Spending and Savings to 2025," Working paper LBNL-5803E, Berkeley, CA.

Boomhower, J., And L. W. Davis (2014): "A Credible Approach for Measuring Inframarginal Participation in Energy Efficiency Programs," Journal of Public Economics, 113(0), 67-79.

Datta, S., And S. Gulati (2009): "Utility Rebates for Energy Star Appliances: Are They Effective?," Working paper, University of British Columbia.

Davis, L., A. Fuchs, And P. Gertler (2013): "Cash for Coolers: Evaluating a Large-Scale Appliance Replacement Program in Mexico," WP-230R, Energy Institute at Haas.

Davis, L. W. (2008): "Durable Goods and Residential Demand for Energy and Water: Evidence from a Field Trial," The RAND Journal of Economics, 39(2), 530-546.

De Gorter, H., And D. R. Just (2010): "The Social Costs and Benefits of Biofuels: The Intersection of Environmental, Energy and Agricultural Policy," Applied Economic Perspectives and Policy, 32(1), 4-32.

EPA (2014a): "Carbon Pollution Emission Guidelines for Existing Stationary Sources: Electric Utility Generating Units," Discussion paper, Washington, DC.

— (2014b): "Regulatory Impact Analysis for the Proposed Carbon Pollution Guidelines for Existing Power Plants and Emission Standards for Modified and Reconstructed Power Plants," Discussion paper, Washington, DC.

Goulder, L. H., And R. N. Stavins (2011): "Challenges from State-Federal Interactions in US Climate Change Policy," American Economic Review, 101(3), 252-257.

Hoekstra, M., S. L. Puller, And J. West (2014): "Cash for Corollas: When Stimulus Reduces Spending," Working paper 20349, National Bureau of Economic Research.

Houde, S. (2014): "Bunching with the Stars: How Firms Respond to Environmental Certification," Working paper, University of Maryland.

Iто, K. (2012): "Does Conservation Targeting Work? Evidence from a Statewide Electricity Rebate Program in California," Working paper, Energy Institute at Haas.

Ito, K., AND J. M. SAlleE (2014): "The Economics of Attribute-Based Regulation: Theory and Evidence from Fuel-Economy Standards," Working paper.

Joskow, P. L., And D. B. Marron (1992): "What Does a Negawatt Really Cost? Evidence from Utility Conservation Programs," The Energy Journal, pp. 41-74. 
Levinson, A. (2012): Belts and Suspenders: Interactions among Climate Policy Regulationspp. 127-140. University of Chicago Press, Chicago, IL.

Li, S., J. Linn, And E. SpIller (2013): "Evaluating Cash-for-Clunkers: Program Effects on Auto Sales and the Environment," Journal of Environmental Economics and Management, 65(2), 175193.

Mian, A., And A. Sufi (2012): "The Effects of Fiscal Stimulus: Evidence from the 2009 Cash for Clunkers Program," The Quarterly Journal of Economics, 127(3), 1107-1142.

NAHB (2007): "Study of Life Expectancy of Home Components," Report, National Association of Home Builders and Bank of America Home Equity.

Spurlock, C. A. (2013): “Appliance Efficiency Standards and Price Discrimination," Working paper, Lawrence Berkeley National Laboratory. 


\section{Figures and Tables}

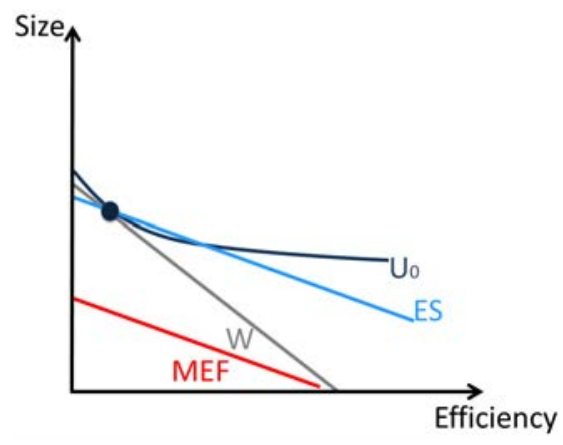

(a) ES Adopter

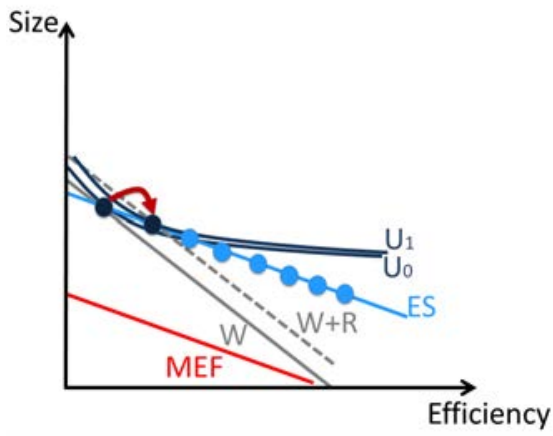

(c) Products Bunching at ES

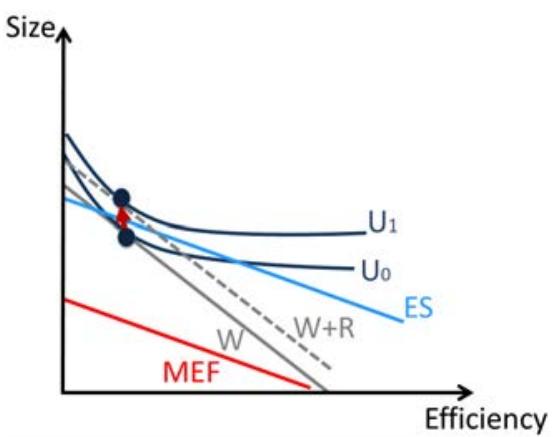

(e) Perverse Rebate

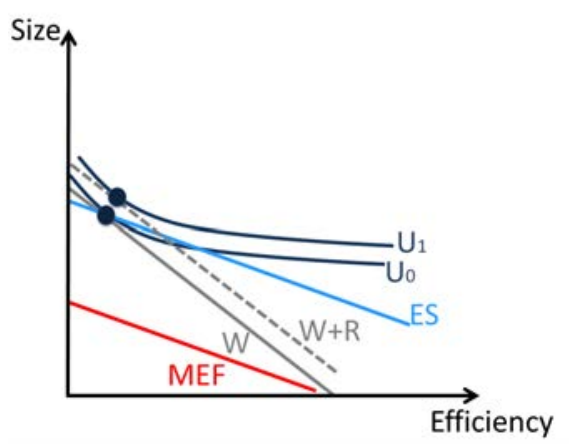

(b) Income Effect

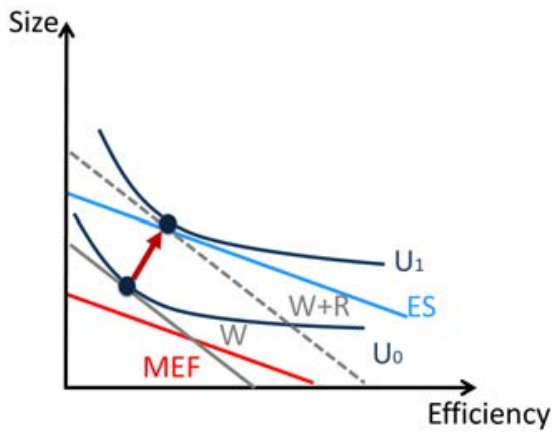

(d) Complier

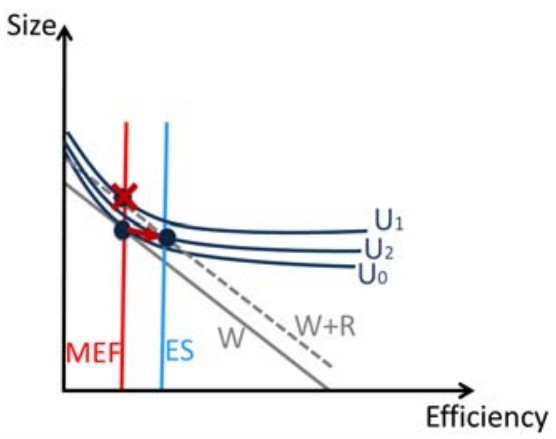

(f) Comparative Statics: Non-AttributeBased Standard

Figure 1. The Simple Economics of Energy Efficiency Rebates 


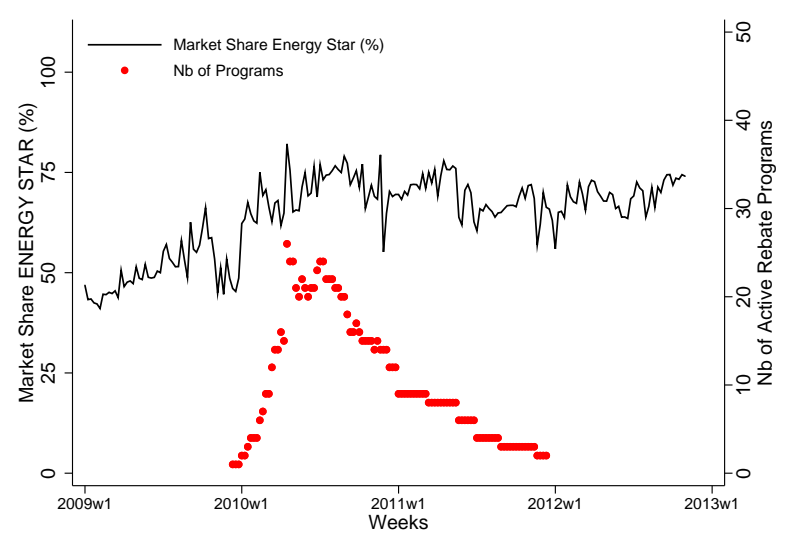

(a) Refrigerators

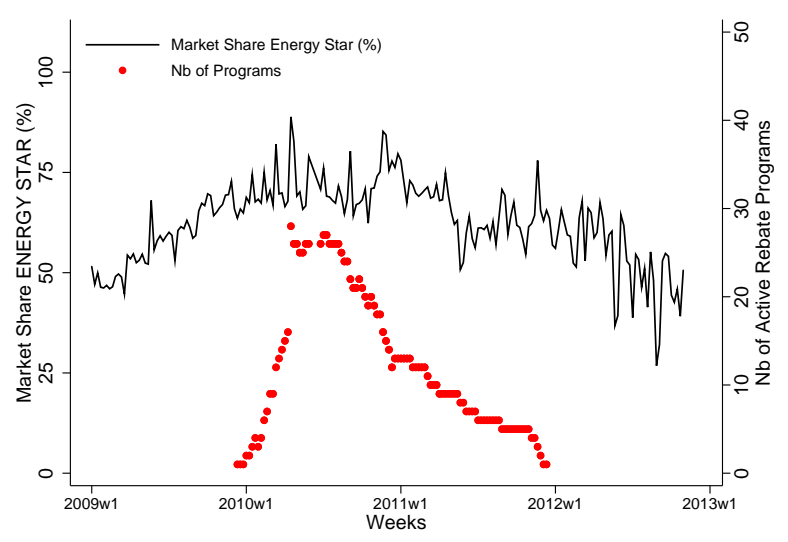

(b) Clothes Washers

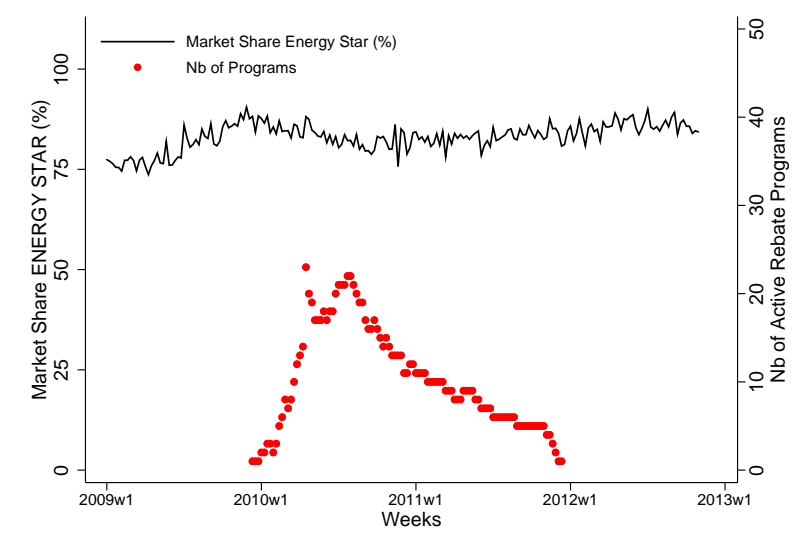

(c) Dishwashers

Figure 2. ENERGY STAR National Market Shares vs. Number of Active Rebate Programs

Each panel shows the weekly ES market share at the national level and the number of active state rebate programs. Appliance models that were ES certified as of January 1, 2010 are included in the ES market share for the whole time horizon. 


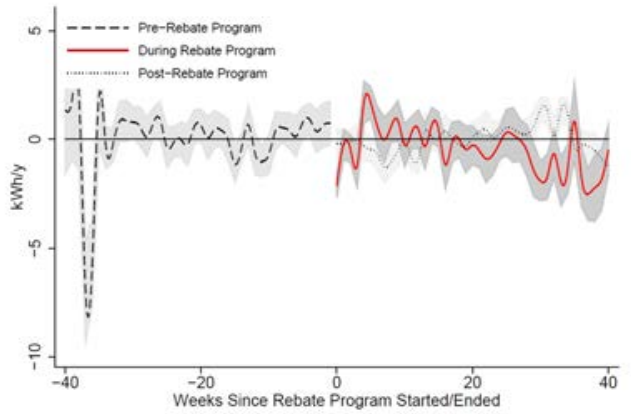

(a) Refrigerators: $\mathrm{kWh} / \mathrm{y}$

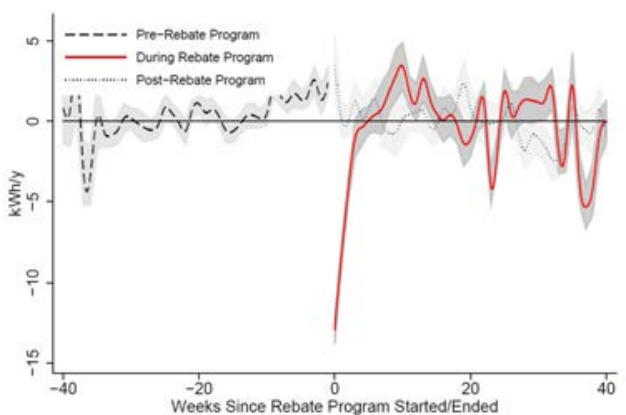

(c) Clothes Washers: kWh/y

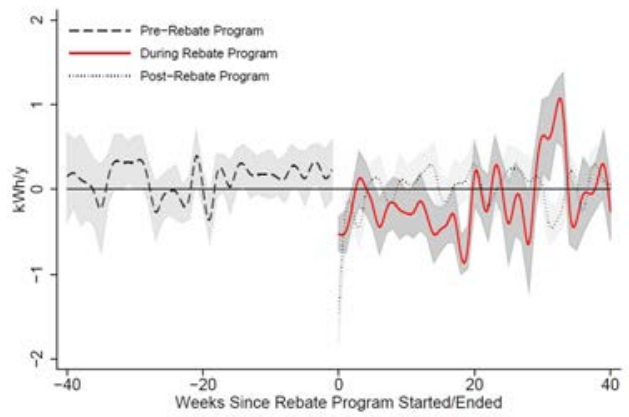

(e) Dishwashers: $\mathrm{kWh} / \mathrm{y}$

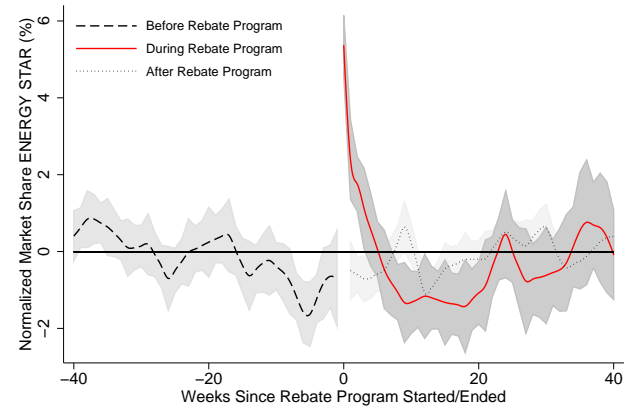

(b) Refrigerators: ES market share

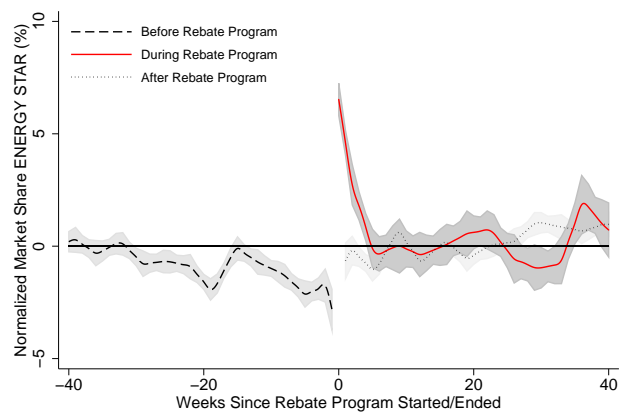

(d) Clothes Washers: ES market share

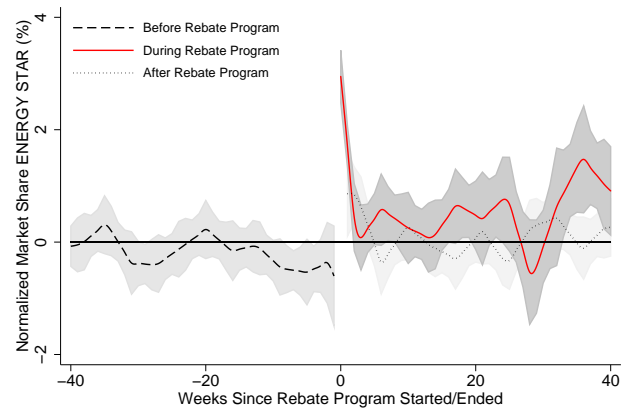

(f) Dishwashers: ES market share

Figure 3. Electricity Consumption Purchased and ENERGY STAR Market Share Since Program Start/End Date

The figure shows the normalized electricity consumption purchased $(\mathrm{kWh} / \mathrm{y})$ and normalized ES market share fitted with a flexible regression spline on a variable that counts the number of weeks since a rebate program started/ended in each state. The figure presents the fitted spline and the $95 \%$ confidence interval. The positive part of the X-axis measures both the time since a rebate program started and the time since a program ended. The figure shows that the rebate programs had marginal impact for refrigerators and dishwashers; even in the first week of the programs electricity consumption dropped by less than $2 \mathrm{kWh} / \mathrm{y}$. For clothes washers, electricity consumption decreased by about $12 \mathrm{kWh} / \mathrm{y}$ in the first week. 


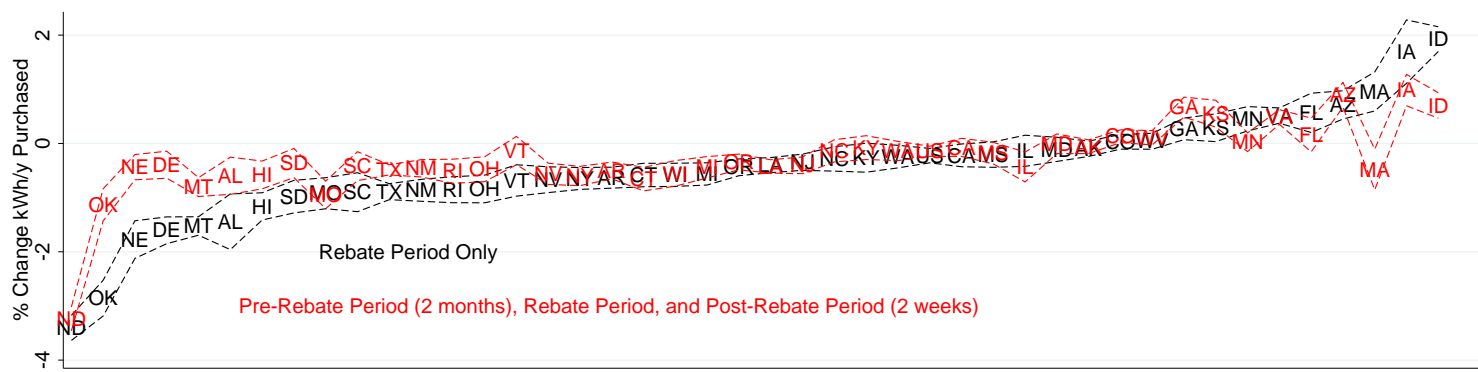

(a) Refrigerators

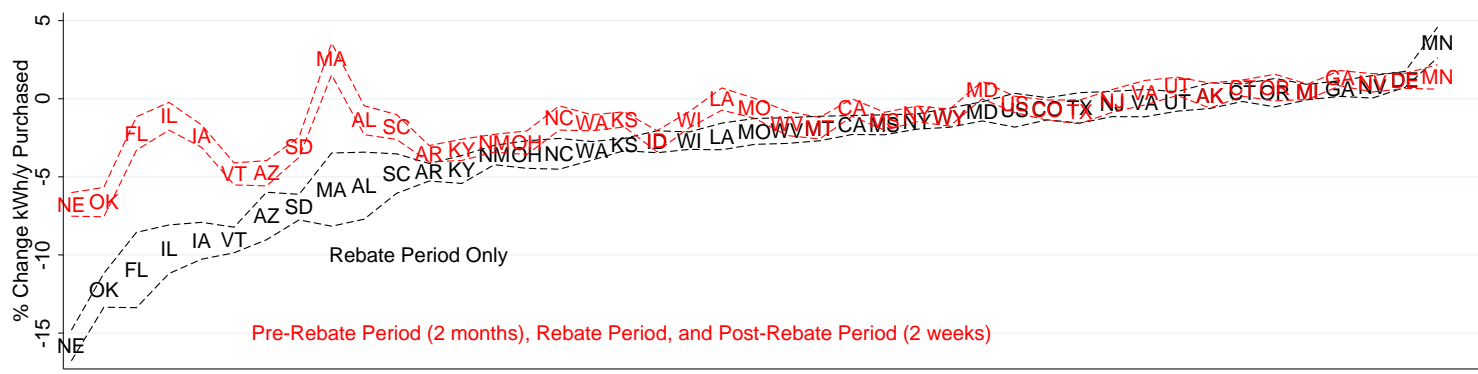

(b) Clothes Washers

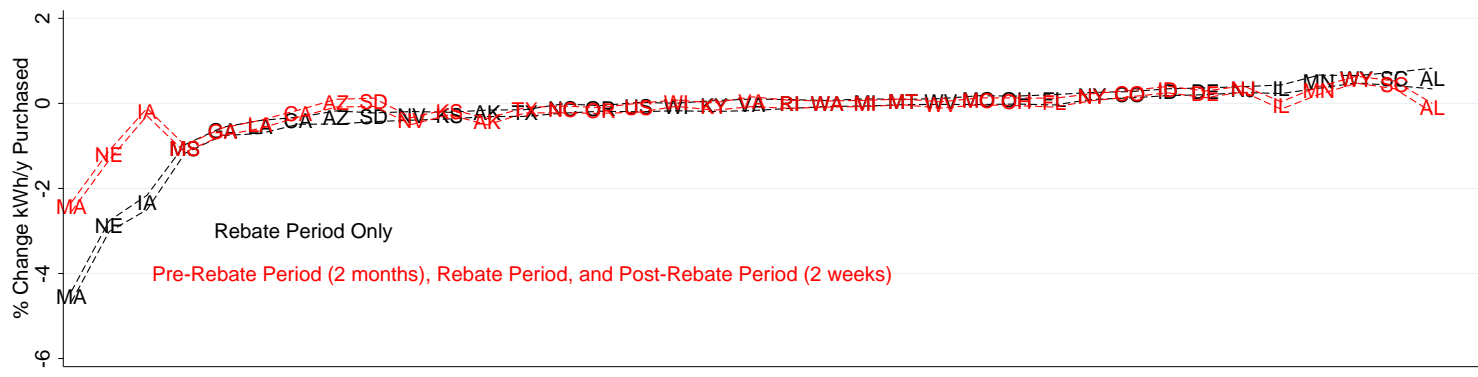

(c) Dishwashers

Figure 4. Impact of Rebates on kWh/y Purchased by State

Each panel shows the average percentage change in electricity consumption purchased $(\mathrm{kWh} / \mathrm{y})$. For each state, two estimates are shown: the change during the rebate period only, and the change during the period that includes two months before the rebate period, the rebate period, and two weeks after the rebate period. 
TABle 1. Rebates and Eligibility Criteria for Each State

\begin{tabular}{|c|c|c|c|c|c|c|}
\hline & \multicolumn{2}{|c|}{ Refrigerators } & \multicolumn{2}{|c|}{ Clothes Washers } & \multicolumn{2}{|c|}{ Dishwashers } \\
\hline & Rebate & Criteria & Rebate & Criteria & Rebate & Criteria \\
\hline $\mathrm{AK}$ & $300-600$ & ES rural/non-rural & $300-600$ & ES & $300-600$ & ES rural/non-rural \\
\hline $\mathrm{AL}$ & 150 & $\mathrm{ES}$ & 100 & ES & 75 & $\mathrm{ES}$ \\
\hline $\mathrm{AR}$ & 275 & ES & 225 & ES & - & \\
\hline $\mathrm{AZ}$ & $200-300$ & ES & $125-200$ & ES \& Above ES & $75-125$ & ES \& Above ES \\
\hline $\mathrm{CA}$ & 200 & ES & 100 & Above ES & 100 & Above ES \\
\hline $\mathrm{CO}$ & $50-100$ & ES & 75 & ES & 50 & Above ES \\
\hline $\mathrm{CT}$ & 50 & ES & 100 & Above ES & - & \\
\hline $\mathrm{DE}$ & 100 & $\mathrm{ES}$ & 75 & $\mathrm{ES}$ & 75 & $\mathrm{ES}$ \\
\hline FL & $20 \%$ & ES & $20 \%$ & ES & $20 \%$ & ES \\
\hline GA & 50 & ES & $50-99$ & ES \& Above ES & $50-99$ & ES \& Above ES \\
\hline HI & 250 & ES & - & & - & \\
\hline IA & $200-500$ & ES & 200 & $\mathrm{ES}$ & $200-250$ & ES \& Above ES \\
\hline ID & 75 & ES & 75 & $\mathrm{ES}$ & 50 & ES \\
\hline IL & $15 \%$ & ES & $15 \%$ & ES & $15 \%$ & ES \\
\hline IN & - & & - & & - & \\
\hline $\mathrm{KS}$ & 700 & ES & 800 & Above ES & 400 & Above ES \\
\hline $\mathrm{KY}$ & 50 & ES & 100 & $\mathrm{ES}$ & 50 & $\mathrm{ES}$ \\
\hline LA & 250 & ES & 100 & $\mathrm{ES}$ & 150 & $\mathrm{ES}$ \\
\hline MA & 200 & ES \& Above ES & 175 & ES & 250 & ES \& Above ES \\
\hline $\mathrm{MD}$ & 50 & ES \& Above ES & 100 & ES & - & \\
\hline $\mathrm{ME}$ & - & & - & & - & \\
\hline MI & $50-100$ & ES \& Above ES & 50 & $\mathrm{ES}$ & $25-50$ & ES \& Above ES \\
\hline $\mathrm{MN}$ & 100 & ES & 200 & ES & 150 & $\mathrm{ES}$ \\
\hline $\mathrm{MO}$ & 250 & ES & 125 & ES & 125 & $\mathrm{ES}$ \\
\hline MS & 75 & ES & $100-150$ & ES \& Above ES & $75-100$ & ES \& Above ES \\
\hline MT & 100 & ES & 100 & ES & 50 & ES \\
\hline $\mathrm{NC}$ & $15 \%$ & ES & 100 & $\mathrm{ES}$ & 75 or $15 \%$ & $\mathrm{ES}$ \\
\hline ND & 150 & ES & - & & - & \\
\hline $\mathrm{NE}$ & 200 & ES & $100-200$ & ES \& Above ES & 150 & Above ES \\
\hline NJ & $75-100$ & & 35 & ES & $25-50$ & ES \& Above ES \\
\hline NM & 200 & ES & 200 & $\mathrm{ES}$ & - & \\
\hline NV & 200 & ES & 150 & ES & 100 & ES \\
\hline NY & 75-105 & & $75-100$ & ES \& Above ES & 165 & $\mathrm{ES}$ \\
\hline $\mathrm{OH}$ & 100 & $\mathrm{ES}$ & 150 & $\mathrm{ES}$ & 100 & $\mathrm{ES}$ \\
\hline OK & 200 & ES & 200 & ES & - & \\
\hline OR & $70 \%$ & $\mathrm{ES}$ & $70 \%$ & ES & $70 \%$ & $\mathrm{ES}$ \\
\hline RI & 150 & ES & - & & 150 & ES \\
\hline $\mathrm{SC}$ & 50 & ES & 100 & ES & 50 & $\mathrm{ES}$ \\
\hline $\mathrm{SD}$ & 150 & $\mathrm{ES}$ & 100 & $\mathrm{ES}$ & 75 & $\mathrm{ES}$ \\
\hline $\mathrm{TX}$ & $175-315$ & ES & $100-225$ & ES \& Above ES & $85-185$ & ES \\
\hline $\mathrm{UT}$ & - & & 75 & ES & & \\
\hline VA & 60 & ES & $75-350$ & ES \& Above ES & $50-275$ & ES \& Above ES \\
\hline $\mathrm{VT}$ & 75 & ES & 150 & ES & - & \\
\hline WA & 75 & $\mathrm{ES}$ & 150 & $\mathrm{ES}$ & 75 & $\mathrm{ES}$ \\
\hline WI & 75 & ES & 100 & $\mathrm{ES}$ & 25 & $\mathrm{ES}$ \\
\hline WV & 100 & $\mathrm{ES}$ & $50-75$ & Above ES & $50-75$ & ES \& Above ES \\
\hline WY & - & & 100 & ES & 50 & $\mathrm{ES}$ \\
\hline
\end{tabular}


TABle 2. Summary Statistics: Cash for Appliances

\begin{tabular}{|c|c|c|c|c|c|c|}
\hline Product & $\begin{array}{l}\text { \# of States } \\
\text { Offering Re- } \\
\text { bates }\end{array}$ & $\begin{array}{l}\# \quad \text { of } \\
\text { Claims }\end{array}$ & $\begin{array}{l}\text { Amount } \\
\text { Distributed } \\
(\$ \mathrm{M})\end{array}$ & $\begin{array}{l}\text { Average } \\
\text { Price } \\
\text { Paid }(\$)\end{array}$ & $\begin{array}{l}\text { Average } \\
\text { Rebate } \\
\text { Claimed } \\
(\$)\end{array}$ & $\begin{array}{l}\text { Max } \\
\text { Rebate } \\
\text { Claimed } \\
(\$)\end{array}$ \\
\hline Air Conditioners & 30 & 70,781 & 25.6 & 4,511 & 361 & 3,812 \\
\hline Boilers & 18 & 7,678 & 4.0 & 5,516 & 518 & 4,036 \\
\hline Clothes Washers & 43 & 580,863 & 62.1 & 698 & 107 & 1,034 \\
\hline Dishwashers & 37 & 316,117 & 26.6 & 543 & 84 & 47,751 \\
\hline Electric Water Heaters & 25 & 3,267 & 1.0 & 1,636 & 307 & 1,816 \\
\hline Freezers & 26 & 24,312 & 2.5 & 579 & 103 & 1,500 \\
\hline Furnaces & 34 & 76,469 & 30.9 & 5,772 & 404 & 3,227 \\
\hline Gas/Propane Water Heaters & 30 & 15,766 & 2.1 & 703 & 130 & 1,742 \\
\hline Gas/Propane Water Heaters (Tankless) & 31 & 11,140 & 3.0 & 2,266 & 267 & 1,223 \\
\hline Heat Pumps & 26 & 47,470 & 23.6 & 6,403 & 497 & 4,400 \\
\hline Refrigerators & 44 & 613,561 & 78.8 & 1,112 & 128 & 7,085 \\
\hline Solar Water Heaters & 15 & 634 & 0.8 & 7,961 & 1,308 & 2,500 \\
\hline Total & & $1,768,058$ & 260.9 & & & \\
\hline
\end{tabular}

Notes: Data collected by program administrators and provided to the Department of Energy. Excludes U.S. territories. 
TABle 3. Summary Statistics: Retailer's Choice Set

\begin{tabular}{|c|c|c|c|}
\hline & \multicolumn{3}{|c|}{ Appliances } \\
\hline & Refrigerators & Clothes Washers & Dishwashers \\
\hline \multicolumn{4}{|c|}{ ES Market Share Pre-Announcement Period (January-July 2009) } \\
\hline Mean & $46 \%$ & $53 \%$ & $75 \%$ \\
\hline SD (across states) & $8 \%$ & $10 \%$ & $12 \%$ \\
\hline \multicolumn{4}{|c|}{ Number of Models Offered in 2010-2011 } \\
\hline ES & 1,405 & 440 & 741 \\
\hline Non-ES & 1,360 & 189 & 86 \\
\hline \multicolumn{4}{|c|}{ Average Electricity Consumption (kWh/year), 2010-2011 Models } \\
\hline ES & 499 & 196 & 312 \\
\hline Non-ES & 547 & 442 & 339 \\
\hline \multicolumn{4}{|c|}{ Average Size, 2010-2011 Models } \\
\hline $\mathrm{ES}$ & 27.9 & 3.6 & 2.0 \\
\hline Non-ES & 26.5 & 3.3 & 1.4 \\
\hline \multicolumn{4}{|c|}{ Average Price (\$), 2010-2011 Models } \\
\hline ES & 1,645 & 952 & 707 \\
\hline Non-ES & 1,894 & 648 & 570 \\
\hline \multicolumn{4}{|c|}{ Style, 2010-2011 Models } \\
\hline & $\%$ Top-freezer & $\%$ Top-load & \\
\hline ES & 18 & 30 & - \\
\hline Non-ES & 27 & 63 & - \\
\hline \multicolumn{4}{|c|}{$\begin{array}{l}\text { Notes: Summary statistics for number of models, electricity consumption, size, } \\
\text { price, and style are non-sales weighted. The metric "size" is measured in cubic } \\
\text { feet for clothes washers and refrigerators. For dishwashers, size is defined with } \\
\text { a categorical variable, where } 1=\text { standard, } 2=\text { tall, } 3=\text { giant, and } 4=\text { super } \\
\text { capacity. The price corresponds to the retail price. }\end{array}$} \\
\hline
\end{tabular}


TABLE 4. The Effect of Rebates on Sales and kWh: Refrigerators

\begin{tabular}{|c|c|c|c|c|c|c|c|c|}
\hline \multirow[t]{2}{*}{ Dep. Variable } & \multicolumn{4}{|c|}{$\log ($ sales $)$} & \multicolumn{4}{|c|}{$\log (\mathrm{kWh})$} \\
\hline & $\mathbf{I}$ & II & III & IV & $\mathbf{I}$ & II & III & IV \\
\hline \multicolumn{9}{|l|}{ All Periods } \\
\hline Rebate $\times$ Dall: 2 Months Before, & $0.0092^{*}$ & & & & $-0.00082^{* *}$ & & & \\
\hline During, and 2 Weeks After & $(0.0036)$ & & & & $(0.00027)$ & & & \\
\hline Rebate $\times$ Dall: 4 Months Before, & & $0.021^{* * *}$ & & & & $-0.00084^{* *}$ & & \\
\hline During, and 2 Months After & & $(0.0041)$ & & & & $(0.00025)$ & & \\
\hline Rebate $\times$ Dall: Since Announce- & & & $0.0093^{*}$ & & & & -0.00037 & \\
\hline ment to 3 Months After & & & $(0.0045)$ & & & & $(0.00029)$ & \\
\hline \multicolumn{9}{|l|}{ Rebate Period } \\
\hline \multirow[t]{2}{*}{ Rebate $\times$ Week 1} & & & & $0.14^{*}$ & & & & -0.0024 \\
\hline & & & & $(0.061)$ & & & & $(0.0013)$ \\
\hline \multirow{2}{*}{ Rebate $\times$ Weeks 2-3 } & & & & $0.07^{*}$ & & & & -0.00011 \\
\hline & & & & $(0.027)$ & & & & $(0.0021)$ \\
\hline \multirow[t]{2}{*}{ Rebate $\times$ Weeks $4-6$} & & & & -0.019 & & & & -0.00051 \\
\hline & & & & $(0.018)$ & & & & $(0.0006)$ \\
\hline \multirow[t]{2}{*}{ Rebate $\times$ Weeks 7-9 } & & & & -0.026 & & & & -0.0013 \\
\hline & & & & $(0.020)$ & & & & $(0.0011)$ \\
\hline \multirow[t]{2}{*}{ Rebate $\times$ Weeks $10+$} & & & & -0.0091 & & & & -0.0017 \\
\hline & & & & $(0.017)$ & & & & $(0.0011)$ \\
\hline \multicolumn{9}{|l|}{ Pre-Rebate Period } \\
\hline \multirow[t]{2}{*}{ Rebate $\times 1$ Week Before } & & & & $-0.053^{*}$ & & & & 0.0015 \\
\hline & & & & $(0.022)$ & & & & $(0.0009)$ \\
\hline \multirow[t]{2}{*}{ Rebate $\times 2-3$ Weeks Before } & & & & $-0.037^{* *}$ & & & & 0.0012 \\
\hline & & & & $(0.013)$ & & & & $(0.0011)$ \\
\hline \multirow[t]{2}{*}{ Rebate $\times 4-6$ Weeks Before } & & & & $-0.043^{*}$ & & & & 0.00091 \\
\hline & & & & $(0.017)$ & & & & $(0.0009)$ \\
\hline \multirow{2}{*}{ Rebate $\times$ 7-9 Weeks Before } & & & & $-0.042^{* *}$ & & & & 0.0019 \\
\hline & & & & $(0.013)$ & & & & $(0.0011)$ \\
\hline \multirow[t]{2}{*}{ Rebate $\times 10+$ Weeks Before } & & & & -0.0012 & & & & -0.00012 \\
\hline & & & & $(0.010)$ & & & & $(0.0007)$ \\
\hline \multicolumn{9}{|l|}{ Post-Rebate Period } \\
\hline \multirow[t]{2}{*}{ Rebate $\times 1$ Week After } & & & & -0.0086 & & & & 0.0002 \\
\hline & & & & $(0.024)$ & & & & $(0.0011)$ \\
\hline \multirow[t]{2}{*}{ Rebate $\times 2-3$ Weeks After } & & & & 0.00092 & & & & -0.0015 \\
\hline & & & & $(0.018)$ & & & & $(0.0010)$ \\
\hline \multirow[t]{2}{*}{ Rebate $\times 4-6$ Weeks After } & & & & -0.034 & & & & 0.00012 \\
\hline & & & & $(0.020)$ & & & & $(0.0010)$ \\
\hline Rebate $\times 7-9$ Weeks After & & & & -0.024 & & & & 0.00067 \\
\hline & & & & $(0.023)$ & & & & $(0.0008)$ \\
\hline Rebate $\times 10+$ Weeks After & & & & $-0.049 * *$ & & & & 0.000084 \\
\hline & & & & $(0.017)$ & & & & $(0.0007)$ \\
\hline Constant & - & - & - & - & $6.26^{* * *}$ & $6.26^{* * *}$ & $6.26^{* * *}$ & $6.27^{* * *}$ \\
\hline & & & & & $(0.0042)$ & $(0.0041)$ & $(0.0041)$ & $(0.0042)$ \\
\hline State FE & Yes & Yes & Yes & No & Yes & Yes & Yes & No \\
\hline State-Year FE & No & No & No & Yes & No & No & No & Yes \\
\hline Demographics & No & No & No & No & Yes & Yes & Yes & Yes \\
\hline \# Obs. & 12,450 & 12,450 & 12,450 & 12,450 & $>4 \mathrm{M}$ & $>4 \mathrm{M}$ & $>4 \mathrm{M}$ & $>4 \mathrm{M}$ \\
\hline$R^{2}$ & 0.984 & 0.984 & 0.984 & 0.987 & 0.068 & 0.068 & 0.068 & 0.069 \\
\hline
\end{tabular}

Notes: The dummy variable for the pre-announcement period is omitted. Standard errors (in parentheses) clustered at the state level. ${ }^{*}(p<0.05),{ }^{* *}(p<0.01),{ }^{* * *}(p<0.001)$. All specifications have week-year fixed effects. 
TABLE 5. The Effect of Rebates on Sales and kWh: Clothes Washers

\begin{tabular}{|c|c|c|c|c|c|c|c|c|}
\hline \multirow[t]{2}{*}{ Dep. Variable } & \multicolumn{4}{|c|}{$\log$ (sales) } & \multicolumn{4}{|c|}{$\log (\mathrm{kWh})$} \\
\hline & $\mathbf{I}$ & II & III & IV & $\mathbf{I}$ & II & III & IV \\
\hline \multicolumn{9}{|l|}{ All Periods } \\
\hline Rebate $\times$ Dall: 2 Months Before, & 0.0048 & & & & -0.0022 & & & \\
\hline During, and 2 Weeks After & $(0.0045)$ & & & & $(0.0016)$ & & & \\
\hline Rebate $\times$ Dall: 4 Months Before, & & $0.011^{*}$ & & & & -0.0029 & & \\
\hline During, and 2 Months After & & $(0.0046)$ & & & & $(0.0021)$ & & \\
\hline Rebate $\times$ Dall: Since Announce- & & & 0.0024 & & & & -0.0013 & \\
\hline ment to 3 Months After & & & $(0.0051)$ & & & & $(0.0017)$ & \\
\hline \multicolumn{9}{|l|}{ Rebate Period } \\
\hline \multirow{2}{*}{ Rebate $\times$ Week 1} & & & & $0.14^{*}$ & & & & $-0.054^{* * *}$ \\
\hline & & & & $(0.061)$ & & & & $(0.0077)$ \\
\hline \multirow[t]{2}{*}{ Rebate $\times$ Weeks 2-3 } & & & & $0.07^{*}$ & & & & $-0.018^{*}$ \\
\hline & & & & $(0.033)$ & & & & $(0.0074)$ \\
\hline \multirow[t]{2}{*}{ Rebate $\times$ Weeks 4-6 } & & & & 0.0048 & & & & -0.0012 \\
\hline & & & & $(0.015)$ & & & & $(0.0032)$ \\
\hline \multirow[t]{2}{*}{ Rebate $\times$ Weeks 7-9 } & & & & 0.0024 & & & & 0.0013 \\
\hline & & & & $(0.016)$ & & & & $(0.0034)$ \\
\hline \multirow{2}{*}{ Rebate $\times$ Weeks $10+$} & & & & 0.0061 & & & & 0.0011 \\
\hline & & & & $(0.012)$ & & & & $(0.0032)$ \\
\hline \multicolumn{9}{|l|}{ Pre-Rebate Period } \\
\hline \multirow[t]{2}{*}{ Rebate $\times 1$ Week Before } & & & & $-0.063^{* *}$ & & & & $0.0062^{*}$ \\
\hline & & & & $(0.018)$ & & & & $(0.0028)$ \\
\hline \multirow[t]{2}{*}{ Rebate $\times 2-3$ Weeks Before } & & & & -0.03 & & & & 0.0047 \\
\hline & & & & $(0.015)$ & & & & $(0.0040)$ \\
\hline \multirow[t]{2}{*}{ Rebate $\times$ 4- 6 Weeks Before } & & & & -0.015 & & & & $0.0042^{* *}$ \\
\hline & & & & $(0.014)$ & & & & $(0.0015)$ \\
\hline \multirow[t]{2}{*}{ Rebate $\times$ 7-9 Weeks Before } & & & & -0.016 & & & & 0.0038 \\
\hline & & & & $(0.011)$ & & & & $(0.0026)$ \\
\hline \multirow[t]{2}{*}{ Rebate $\times 10+$ Weeks Before } & & & & 0.0055 & & & & -0.00031 \\
\hline & & & & $(0.009)$ & & & & $(0.0013)$ \\
\hline \multicolumn{9}{|l|}{ Post-Rebate Period } \\
\hline \multirow[t]{2}{*}{ Rebate $\times 1$ Week After } & & & & -0.02 & & & & 0.0038 \\
\hline & & & & $(0.019)$ & & & & $(0.0040)$ \\
\hline \multirow[t]{2}{*}{ Rebate $\times 2-3$ Weeks After } & & & & -0.0017 & & & & 0.0019 \\
\hline & & & & $(0.013)$ & & & & $(0.0038)$ \\
\hline \multirow[t]{2}{*}{ Rebate $\times 4-6$ Weeks After } & & & & -0.014 & & & & $0.0043^{*}$ \\
\hline & & & & $(0.017)$ & & & & $(0.0018)$ \\
\hline Rebate $\times 7-9$ Weeks After & & & & 0.0013 & & & & 0.0043 \\
\hline & & & & $(0.016)$ & & & & $(0.0025)$ \\
\hline Rebate $\times 10+$ Weeks After & & & & -0.013 & & & & $0.0073^{*}$ \\
\hline & & & & $(0.016)$ & & & & $(0.0028)$ \\
\hline Constant & - & - & - & - & $5.36^{* * *}$ & $5.36^{* * *}$ & $5.36^{* * *}$ & $5.36^{* * *}$ \\
\hline & & & & & $(0.011)$ & $(0.012)$ & $(0.011)$ & $(0.012)$ \\
\hline State FE & Yes & Yes & Yes & No & Yes & Yes & Yes & No \\
\hline State-Year FE & No & No & No & Yes & No & No & No & Yes \\
\hline Demographics & No & No & No & No & Yes & Yes & Yes & Yes \\
\hline \# Obs. & 12,100 & 12,100 & 12,100 & 12,100 & $>3 \mathrm{M}$ & $>3 \mathrm{M}$ & $>3 \mathrm{M}$ & $>3 \mathrm{M}$ \\
\hline$R^{2}$ & 0.988 & 0.988 & 0.988 & 0.990 & 0.131 & 0.131 & 0.131 & 0.132 \\
\hline
\end{tabular}

Notes: The dummy variable for the pre-announcement period is omitted. Standard errors (in parentheses) clustered at the state level. ${ }^{*}(p<0.05),{ }^{* *}(p<0.01),{ }^{* * *}(p<0.001)$. All specifications have week-year fixed effects. 
TABLE 6. The Effect of Rebates on Sales and kWh: Dishwashers

\begin{tabular}{|c|c|c|c|c|c|c|c|c|}
\hline \multirow[t]{2}{*}{ Dep. Variable } & \multicolumn{4}{|c|}{$\log ($ sales $)$} & \multicolumn{4}{|c|}{$\log (\mathrm{kWh})$} \\
\hline & $\mathbf{I}$ & II & III & IV & $\mathbf{I}$ & II & III & IV \\
\hline \multicolumn{9}{|l|}{ All Periods } \\
\hline Rebate $\times$ Dall: 2 Months Before, & $0.010^{*}$ & & & & -0.00077 & & & \\
\hline During, and 2 Weeks After & $(0.0041)$ & & & & $(0.00042)$ & & & \\
\hline Rebate $\times$ Dall: 4 Months Before, & & $0.015^{* *}$ & & & & -0.00052 & & \\
\hline During, and 2 Months After & & $(0.0057)$ & & & & $(0.00039)$ & & \\
\hline Rebate $\times$ Dall: Since Announce- & & \multirow{2}{*}{\multicolumn{3}{|c|}{$\begin{array}{l}0.0044 \\
(0.0057)\end{array}$}} & & \multirow{2}{*}{\multicolumn{3}{|c|}{$\begin{array}{l}-0.00044 \\
(0.00036)\end{array}$}} \\
\hline ment to 3 Months After & & & & & & & & \\
\hline \multicolumn{9}{|l|}{ Rebate Period } \\
\hline \multirow[t]{2}{*}{ Rebate $\times$ Week 1} & & & & $0.25^{*}$ & & & & -0.0041 \\
\hline & & & & $(0.099)$ & & & & $(0.0029)$ \\
\hline \multirow{2}{*}{ Rebate $\times$ Weeks 2-3 } & & & & 0.07 & & & & -0.0018 \\
\hline & & & & $(0.037)$ & & & & $(0.0007)$ \\
\hline \multirow[t]{2}{*}{ Rebate $\times$ Weeks $4-6$} & & & & -0.01 & & & & -0.00067 \\
\hline & & & & $(0.016)$ & & & & $(0.0007)$ \\
\hline \multirow[t]{2}{*}{ Rebate $\times$ Weeks 7-9 } & & & & -0.0081 & & & & -0.0011 \\
\hline & & & & $(0.016)$ & & & & $(0.0007)$ \\
\hline \multirow[t]{2}{*}{ Rebate $\times$ Weeks $10+$} & & & & -0.01 & & & & -0.0009 \\
\hline & & & & $(0.011)$ & & & & $(0.0006)$ \\
\hline \multicolumn{9}{|l|}{ Pre-Rebate Period } \\
\hline \multirow[t]{2}{*}{ Rebate $\times 1$ Week Before } & & & & -0.063 & & & & -0.0001 \\
\hline & & & & $(0.036)$ & & & & $(0.0011)$ \\
\hline \multirow[t]{2}{*}{ Rebate $\times 2$-3 Weeks Before } & & & & $-0.052^{*}$ & & & & 0.00032 \\
\hline & & & & $(0.022)$ & & & & $(0.0007)$ \\
\hline \multirow[t]{2}{*}{ Rebate $\times$ 4-6 Weeks Before } & & & & -0.036 & & & & -0.00024 \\
\hline & & & & $(0.022)$ & & & & $(0.0006)$ \\
\hline \multirow[t]{2}{*}{ Rebate $\times$ 7-9 Weeks Before } & & & & $-0.035^{*}$ & & & & $-3.9 \mathrm{E}-06$ \\
\hline & & & & $(0.014)$ & & & & $(0.0005)$ \\
\hline \multirow[t]{2}{*}{ Rebate $\times 10+$ Weeks Before } & & & & -0.0083 & & & & 0.00016 \\
\hline & & & & $(0.009)$ & & & & $(0.0006)$ \\
\hline \multicolumn{9}{|l|}{ Post-Rebate Period } \\
\hline \multirow[t]{2}{*}{ Rebate $\times 1$ Week After } & & & & 0.0052 & & & & -0.0062 \\
\hline & & & & $(0.037)$ & & & & $(0.0034)$ \\
\hline Rebate $\times 2-3$ Weeks After & & & & 0.0014 & & & & -0.0016 \\
\hline & & & & $(0.026)$ & & & & $(0.0009)$ \\
\hline Rebate $\times 4-6$ Weeks After & & & & $-0.039^{*}$ & & & & -0.00057 \\
\hline & & & & $(0.019)$ & & & & $(0.0007)$ \\
\hline Rebate $\times 7-9$ Weeks After & & & & -0.029 & & & & $-9.3 \mathrm{E}-05$ \\
\hline & & & & $(0.023)$ & & & & $(0.0007)$ \\
\hline Rebate $\times 10+$ Weeks After & & & & $-0.051^{* *}$ & & & & 0.00036 \\
\hline & & & & $(0.016)$ & & & & $(0.0005)$ \\
\hline Constant & - & - & - & - & $5.84^{* * *}$ & $5.84^{* * *}$ & $5.84^{* * *}$ & $5.84^{* * *}$ \\
\hline & & & & & $(0.0015)$ & $(0.0016)$ & $(0.0015)$ & $(0.0016)$ \\
\hline State FE & Yes & Yes & Yes & No & Yes & Yes & Yes & No \\
\hline State-Year FE & No & No & No & Yes & No & No & No & Yes \\
\hline Demographics & No & No & No & No & Yes & Yes & Yes & Yes \\
\hline \# Obs. & 12,600 & 12,600 & 12,600 & 12,600 & $>2 \mathrm{M}$ & $>2 \mathrm{M}$ & $>2 \mathrm{M}$ & $>2 \mathrm{M}$ \\
\hline$R^{2}$ & 0.982 & 0.982 & 0.982 & 0.984 & 0.402 & 0.402 & 0.402 & 0.403 \\
\hline
\end{tabular}

Notes: The dummy variable for the pre-announcement period is omitted. Standard errors (in parentheses) clustered at the state level. ${ }^{*}(p<0.05),{ }^{* *}(p<0.01),{ }^{* * *}(p<0.001)$. All specifications have week-year fixed effects. 
TABLE 7. Switchers, Freeriders, and Non-Takers

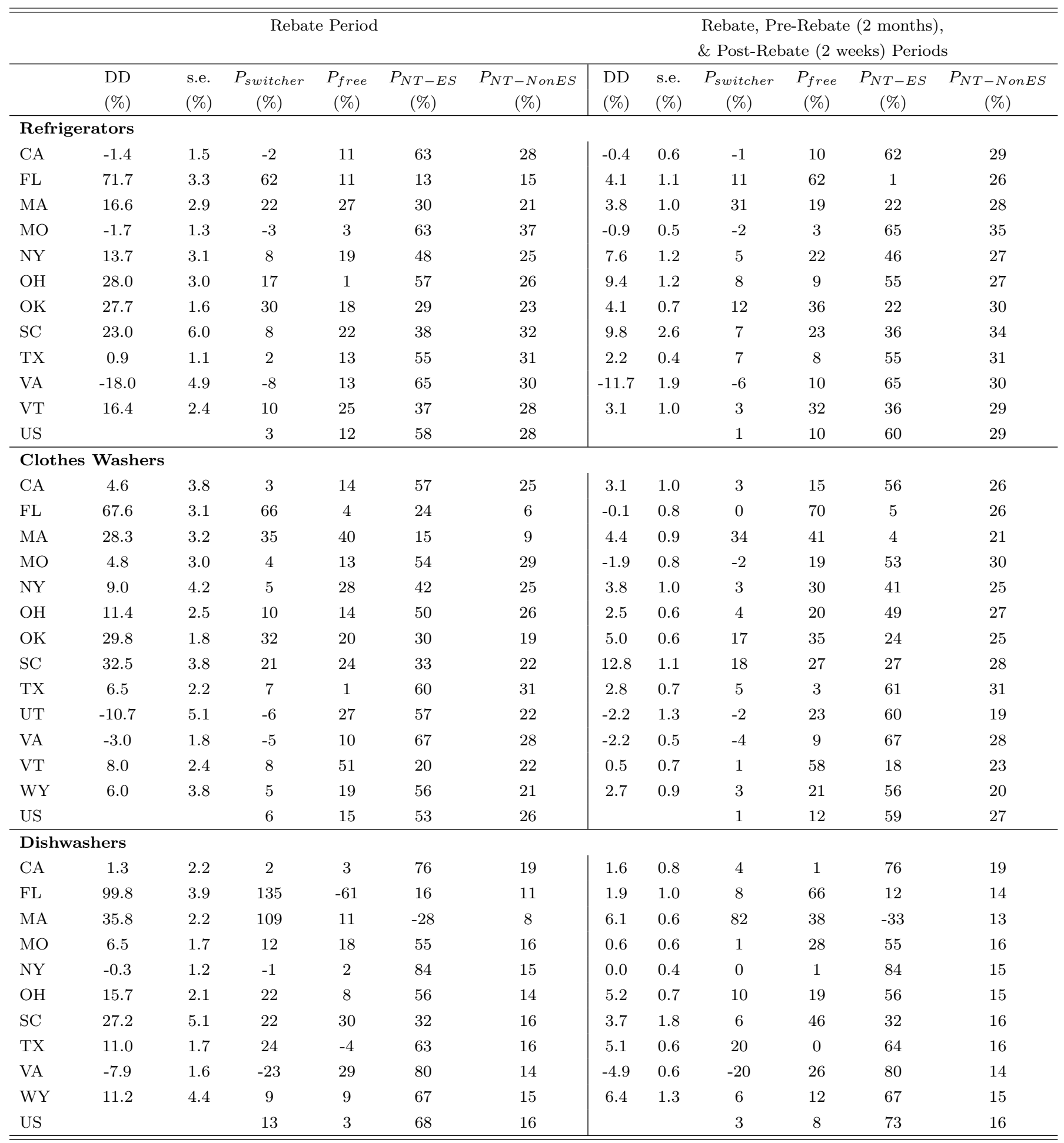

Notes: The second and eighth columns (DD) correspond to the estimated percentage changes in ES market share. The estimates are state-specific and are obtained using a difference-in-differences estimator similar to the one presented in Section 5 . $P_{\text {switcher }}$ is the fraction of switchers for the whole population of consumers that made a purchase during the rebate period (fourth column), or during the rebate period, pre- and post-rebate period (Column 10). Similarly, $P_{\text {free }}$ is the proportion of freeriders, $P_{N T-E S}$ is the proportion of non-takers that purchased an ES product, $P_{N T-N o n E S}$ is the proportion of non-takers that purchased a non-ES product. Note that $P_{\text {switcher }}+P_{\text {free }}+P_{N T-E S}+P_{N T-N o n E S} \approx 100$. 
TABLE 8. The Effect of Rebates on Size and Style

\begin{tabular}{|c|c|c|c|c|c|c|c|c|}
\hline & \multicolumn{2}{|c|}{$\begin{array}{c}\text { Refrigerators } \\
\text { Dependent Variable: }\end{array}$} & \multicolumn{2}{|c|}{$\begin{array}{c}\text { Clothes Washers } \\
\log (\text { Volume Cu. Ft.) }\end{array}$} & \multicolumn{2}{|c|}{$\begin{array}{c}\text { Refrigerators } \\
\text { Dep. Var.: } \\
1=\text { Top Freezer, } 0=\text { other }\end{array}$} & \multicolumn{2}{|c|}{$\begin{array}{c}\text { Clothe Washers } \\
\text { Dep. Var.: } \\
\text { 1=Top Load, } 0=\text { other }\end{array}$} \\
\hline & All & ES Only & All & ES Only & All & ES Only & All & ES Only \\
\hline \multicolumn{9}{|l|}{ Rebate Period } \\
\hline Rebate $\times$ Week 1 & $\begin{array}{l}0.0076^{*} \\
(0.003)\end{array}$ & $\begin{array}{l}0.0061^{*} \\
(0.002)\end{array}$ & $\begin{array}{c}0.0084^{* * *} \\
(0.001)\end{array}$ & $\begin{array}{l}0.0066^{*} \\
(0.003)\end{array}$ & $\begin{array}{c}-0.051^{* * *} \\
(0.013)\end{array}$ & $\begin{array}{l}-0.0065 \\
(0.006)\end{array}$ & $\begin{array}{c}-0.11^{* * *} \\
(0.015)\end{array}$ & $\begin{array}{l}-0.017 \\
(0.010)\end{array}$ \\
\hline Rebate $\times$ Weeks 2-3 & $\begin{array}{l}0.0068 \\
(0.004)\end{array}$ & $\begin{array}{c}0.004 \\
(0.003)\end{array}$ & $\begin{array}{l}0.0019^{*} \\
(0.001)\end{array}$ & $\begin{array}{c}0.002 \\
(0.001)\end{array}$ & $\begin{array}{l}-0.029 * \\
(0.013)\end{array}$ & $\begin{array}{l}-0.0054 \\
(0.008)\end{array}$ & $\begin{array}{l}-0.046^{*} \\
(0.018)\end{array}$ & $\begin{array}{l}-0.021 \\
(0.011)\end{array}$ \\
\hline Rebate $\times$ Weeks 4-6 & $\begin{array}{c}0.00081 \\
(0.002)\end{array}$ & $\begin{array}{l}0.0026^{*} \\
(0.001)\end{array}$ & $\begin{array}{c}0.00068 \\
(0.001)\end{array}$ & $\begin{array}{l}0.0064 \\
(0.004)\end{array}$ & $\begin{array}{c}-0.013^{* * *} \\
(0.003)\end{array}$ & $\begin{array}{c}-0.00032 \\
(0.003)\end{array}$ & $\begin{array}{l}-0.015 \\
(0.011)\end{array}$ & $\begin{array}{l}-0.0013 \\
(0.014)\end{array}$ \\
\hline Rebate $\times$ Weeks 7-9 & $\begin{array}{l}0.0014 \\
(0.002)\end{array}$ & $\begin{array}{l}-0.0006 \\
(0.001)\end{array}$ & $\begin{array}{c}0.00052 \\
(0.000)\end{array}$ & $\begin{array}{c}0.0042^{*} \\
(0.002)\end{array}$ & $\begin{array}{l}-0.014^{*} \\
(0.006)\end{array}$ & $\begin{array}{l}0.0059 \\
(0.003)\end{array}$ & $\begin{array}{l}-0.024^{*} \\
(0.011)\end{array}$ & $\begin{array}{l}-0.013 \\
(0.011)\end{array}$ \\
\hline Rebate $\times$ Weeks $10+$ & $\begin{array}{l}0.0014 \\
(0.002)\end{array}$ & $\begin{array}{c}0.000092 \\
(0.001)\end{array}$ & $\begin{array}{l}0.00063 \\
(0.001)\end{array}$ & $\begin{array}{l}0.012^{* *} \\
(0.004)\end{array}$ & $\begin{array}{c}-0.030^{* * *} \\
(0.007)\end{array}$ & $\begin{array}{c}0.002 \\
(0.002)\end{array}$ & $\begin{array}{l}-0.012 \\
(0.007)\end{array}$ & $\begin{array}{c}0.017 \\
(0.009)\end{array}$ \\
\hline \multicolumn{9}{|l|}{ Pre-Rebate Period } \\
\hline Rebate $\times 1$ Week Before & $\begin{array}{l}0.0012 \\
(0.001)\end{array}$ & $\begin{array}{c}0.0042^{*} \\
(0.002)\end{array}$ & $\begin{array}{c}-0.0015^{* * *} \\
(0.000)\end{array}$ & $\begin{array}{l}-0.0008 \\
(0.001)\end{array}$ & $\begin{array}{r}-0.0098 \\
(0.006)\end{array}$ & $\begin{array}{r}-0.0058 \\
(0.006)\end{array}$ & $\begin{array}{r}-0.0075 \\
(0.005)\end{array}$ & $\begin{array}{c}-0.020^{*} \\
(0.008)\end{array}$ \\
\hline Rebate $\times 2$-3 Weeks Before & $\begin{array}{r}-0.0017 \\
(0.001)\end{array}$ & $\begin{array}{l}0.0035 \\
(0.002)\end{array}$ & $\begin{array}{c}-0.00032 \\
(0.000)\end{array}$ & $\begin{array}{c}0.00087 \\
(0.001)\end{array}$ & $\begin{array}{c}-0.00067 \\
(0.003)\end{array}$ & $\begin{array}{c}-0.0052 \\
(0.004)\end{array}$ & $\begin{array}{c}-0.018^{* * *} \\
(0.004)\end{array}$ & $\begin{array}{c}-0.019^{* * *} \\
(0.004)\end{array}$ \\
\hline Rebate $\times$ 4-6 Weeks Before & $\begin{array}{c}-0.00068 \\
(0.001)\end{array}$ & $\begin{array}{c}0.0056^{* * *} \\
(0.001)\end{array}$ & $\begin{array}{c}-0.00024 \\
(0.000)\end{array}$ & $\begin{array}{c}-0.00047 \\
(0.001)\end{array}$ & $\begin{array}{c}-0.0063^{*} \\
(0.003)\end{array}$ & $\begin{array}{c}-0.0075^{*} \\
(0.003)\end{array}$ & $\begin{array}{c}-0.021^{* *} \\
(0.007)\end{array}$ & $\begin{array}{c}-0.018^{* *} \\
(0.006)\end{array}$ \\
\hline Rebate $\times$ 7-9 Weeks Before & $\begin{array}{c}0.001 \\
(0.001)\end{array}$ & $\begin{array}{c}0.0052^{* * *} \\
(0.001)\end{array}$ & $\begin{array}{c}0.0000097 \\
(0.000)\end{array}$ & $\begin{array}{l}0.0016 \\
(0.001)\end{array}$ & $\begin{array}{c}-0.017^{* * *} \\
(0.004)\end{array}$ & $\begin{array}{c}-0.0082^{* *} \\
(0.003)\end{array}$ & $\begin{array}{c}-0.016^{* *} \\
(0.005)\end{array}$ & $\begin{array}{c}-0.014^{* * *} \\
(0.004)\end{array}$ \\
\hline Rebate $\times 10+$ Weeks Before & $\begin{array}{c}-0.00052 \\
(0.001)\end{array}$ & $\begin{array}{c}0.0038^{* * *} \\
(0.001)\end{array}$ & $\begin{array}{c}0.00014 \\
(0.000)\end{array}$ & $\begin{array}{c}0.000085 \\
(0.000)\end{array}$ & $\begin{array}{c}-0.010^{* * *} \\
(0.002)\end{array}$ & $\begin{array}{r}-0.0031 \\
(0.002)\end{array}$ & $\begin{array}{c}-0.029^{* * *} \\
(0.006)\end{array}$ & $\begin{array}{c}-0.021^{* * *} \\
(0.005)\end{array}$ \\
\hline \multicolumn{9}{|l|}{ Post-Rebate Period } \\
\hline Rebate $\times 1$ Week After & $\begin{array}{l}0.0014 \\
(0.002)\end{array}$ & $\begin{array}{l}0.0017 \\
(0.002)\end{array}$ & $\begin{array}{c}-0.00067 \\
(0.001)\end{array}$ & $\begin{array}{c}0.014^{* * *} \\
(0.002)\end{array}$ & $\begin{array}{c}-0.029^{* *} \\
(0.009)\end{array}$ & $\begin{array}{c}-0.0084 \\
(0.005)\end{array}$ & $\begin{array}{l}-0.016 \\
(0.013)\end{array}$ & $\begin{array}{c}0.020^{* *} \\
(0.007)\end{array}$ \\
\hline Rebate $\times 2$-3 Weeks After & $\begin{array}{c}0.00063 \\
(0.002)\end{array}$ & $\begin{array}{l}0.0031 \\
(0.003)\end{array}$ & $\begin{array}{c}0.00044 \\
(0.000)\end{array}$ & $\begin{array}{c}0.014^{* * *} \\
(0.002)\end{array}$ & $\begin{array}{c}-0.026^{* * *} \\
(0.006)\end{array}$ & $\begin{array}{c}-0.0084^{* *} \\
(0.003)\end{array}$ & $\begin{array}{l}-0.015 \\
(0.012)\end{array}$ & $\begin{array}{c}0.016 \\
(0.010)\end{array}$ \\
\hline Rebate $\times 4-6$ Weeks After & $\begin{array}{c}0.00069 \\
(0.002)\end{array}$ & $\begin{array}{c}0.001 \\
(0.001)\end{array}$ & $\begin{array}{c}-0.000046 \\
(0.001)\end{array}$ & $\begin{array}{c}0.014^{* * *} \\
(0.003)\end{array}$ & $\begin{array}{c}-0.021^{*} \\
(0.009)\end{array}$ & $\begin{array}{c}-0.004 \\
(0.004)\end{array}$ & $\begin{array}{c}-0.0064 \\
(0.007)\end{array}$ & $\begin{array}{c}0.021^{* *} \\
(0.008)\end{array}$ \\
\hline Rebate $\times 7-9$ Weeks After & $\begin{array}{l}0.0018 \\
(0.001)\end{array}$ & $\begin{array}{c}-0.0004 \\
(0.002)\end{array}$ & $\begin{array}{l}0.0004 \\
(0.000)\end{array}$ & $\begin{array}{c}0.013^{* * *} \\
(0.003)\end{array}$ & $\begin{array}{c}-0.024^{* * *} \\
(0.005)\end{array}$ & $\begin{array}{c}-0.0014 \\
(0.006)\end{array}$ & $\begin{array}{l}-0.017 \\
(0.009)\end{array}$ & $\begin{array}{c}0.013 \\
(0.008)\end{array}$ \\
\hline Rebate $\times 10+$ Weeks After & $\begin{array}{l}0.0016 \\
(0.001)\end{array}$ & $\begin{array}{c}0.00071 \\
(0.001)\end{array}$ & $\begin{array}{c}-0.00033 \\
(0.000)\end{array}$ & $\begin{array}{c}0.020^{* * *} \\
(0.003)\end{array}$ & $\begin{array}{c}-0.033^{* * *} \\
(0.006)\end{array}$ & $\begin{array}{c}-0.0092^{* *} \\
(0.003)\end{array}$ & $\begin{array}{l}0.0074 \\
(0.006)\end{array}$ & $\begin{array}{c}0.040^{* * *} \\
(0.004)\end{array}$ \\
\hline State-Year FE & Yes & Yes & Yes & Yes & Yes & Yes & Yes & Yes \\
\hline Week-Year FE & Yes & Yes & Yes & Yes & Yes & Yes & Yes & Yes \\
\hline Demographics & Yes & Yes & Yes & Yes & Yes & Yes & Yes & Yes \\
\hline
\end{tabular}

Notes: The dummy variable for the pre-announcement period is omitted. Standard errors (in parentheses $)$ clustered at the state level. ${ }^{*}(p<0.05),{ }^{* *}(p<0.01),{ }^{* * *}(p<0.001)$ 
TABle 9. The Effect of Rebates on MSRP

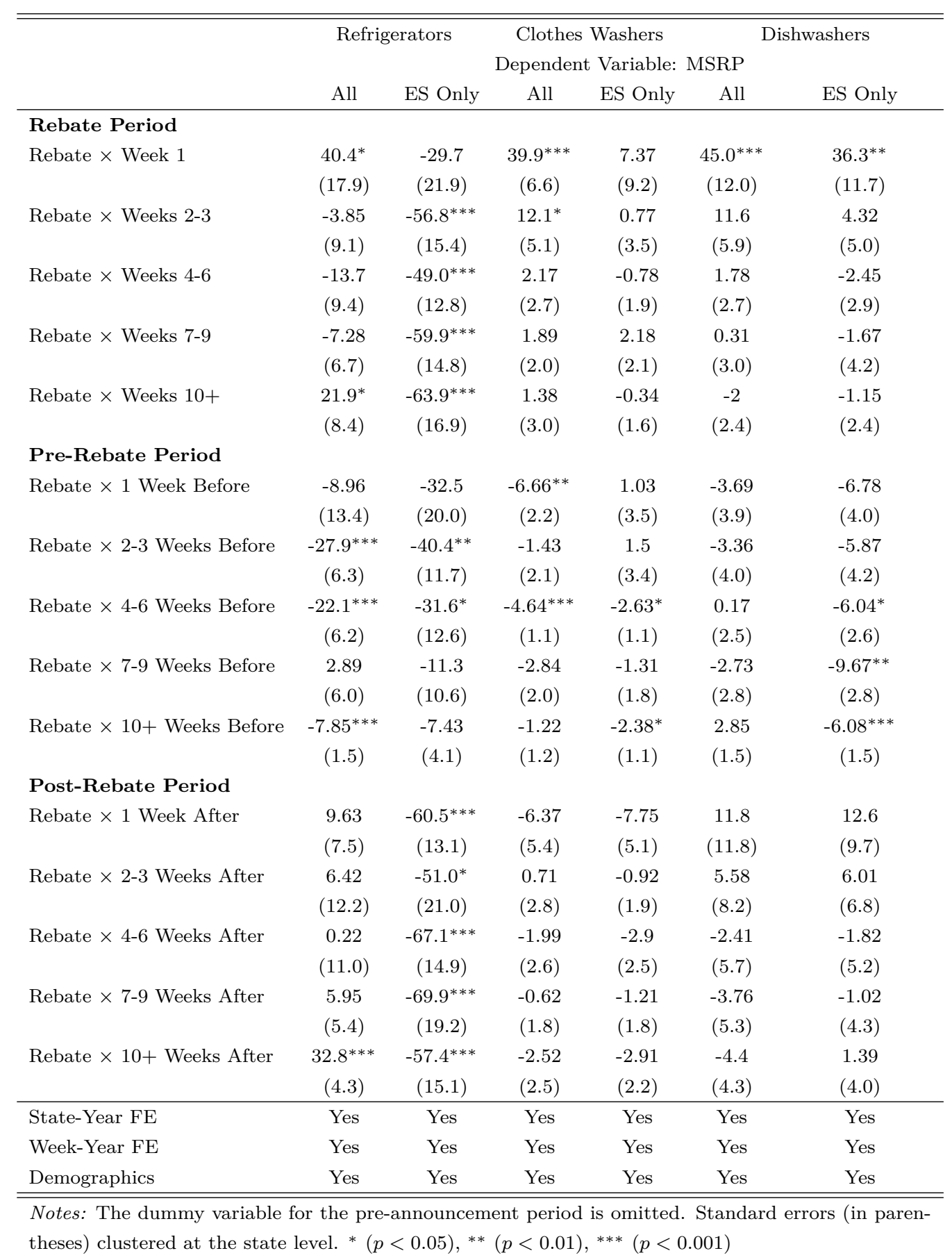


TABle 10. Cost-Effectiveness Analysis

\begin{tabular}{|c|c|c|c|c|c|c|c|c|c|c|}
\hline & \multirow[t]{2}{*}{$\mathrm{kWh} / \mathrm{y}$} & \multirow[t]{2}{*}{$\begin{array}{l}\text { Price } \\
(\$)\end{array}$} & \multirow[t]{2}{*}{ Size } & \multirow[t]{2}{*}{$\begin{array}{l}\text { Rebate } \\
\qquad(\$)\end{array}$} & \multicolumn{6}{|c|}{$\begin{array}{c}\text { Cost-Effectiveness }(\$ / \mathrm{kWh} \text { saved) } \\
\text { Proportion of Freeriders }\end{array}$} \\
\hline & & & & & $\begin{array}{l}\text { Preferred } \\
\text { Estimate }\end{array}$ & $0 \%$ & $25 \%$ & $50 \%$ & $75 \%$ & $90 \%$ \\
\hline \multicolumn{11}{|c|}{ Refrigerators } \\
\hline & & & & & $91 \%$ & & & & & \\
\hline $\mathrm{ES}$ & 478 & 1243 & 27.1 & 128 & 1.46 & 0.13 & 0.18 & 0.26 & 0.53 & 1.31 \\
\hline Non-ES & 543 & 1665 & 27.3 & & & & & & & \\
\hline Top 5\% & 342 & 818 & 19.7 & 128 & 0.52 & 0.05 & 0.06 & 0.09 & 0.19 & 0.47 \\
\hline Bottom $95 \%$ & 525 & 1544 & 27.1 & & & & & & & \\
\hline Top $10 \%$ & 367 & 725 & 20.4 & 128 & 0.57 & 0.05 & 0.07 & 0.10 & 0.21 & 0.52 \\
\hline Bottom $90 \%$ & 532 & 1577 & 27.3 & & & & & & & \\
\hline Top $20 \%$ & 403 & 1055 & 21.8 & 128 & 0.67 & 0.06 & 0.08 & 0.12 & 0.24 & 0.60 \\
\hline Bottom $80 \%$ & 545 & 1594 & 27.6 & & & & & & & \\
\hline \multicolumn{11}{|c|}{ Clothes Washers } \\
\hline & & & & & $92 \%$ & & & & & \\
\hline $\mathrm{ES}$ & 163 & 757 & 4.2 & 107 & 0.44 & 0.04 & 0.05 & 0.07 & 0.14 & 0.35 \\
\hline Non-ES & 364 & 428 & 3.1 & & & & & & & \\
\hline Top 5\% & 99 & 714 & 4.1 & 107 & 0.78 & 0.06 & 0.08 & 0.12 & 0.25 & 0.62 \\
\hline Bottom 95\% & 214 & 685 & 3.9 & & & & & & & \\
\hline Top $10 \%$ & 103 & 804 & 4.1 & 107 & 0.77 & 0.06 & 0.08 & 0.12 & 0.25 & 0.61 \\
\hline Bottom $90 \%$ & 219 & 675 & 3.9 & & & & & & & \\
\hline Top $20 \%$ & 115 & 780 & 4.2 & 107 & 0.74 & 0.06 & 0.08 & 0.12 & 0.24 & 0.59 \\
\hline Bottom $80 \%$ & 236 & 662 & 3.8 & & & & & & & \\
\hline \multicolumn{11}{|l|}{ Dishwashers } \\
\hline & & & & & $73 \%$ & & & & & \\
\hline $\mathrm{ES}$ & 279 & 699 & - & 84 & 0.61 & 0.16 & 0.22 & 0.33 & 0.66 & 1.65 \\
\hline Non-ES & 313 & 480 & - & & & & & & & \\
\hline Top 5\% & 186 & 996 & - & 84 & 0.19 & 0.05 & 0.07 & 0.10 & 0.21 & 0.52 \\
\hline Bottom 95\% & 294 & 618 & - & & & & & & & \\
\hline Top $10 \%$ & 214 & 868 & - & 84 & 0.25 & 0.07 & 0.09 & 0.13 & 0.27 & 0.67 \\
\hline Bottom $90 \%$ & 297 & 613 & - & & & & & & & \\
\hline Top $20 \%$ & 247 & 786 & - & 84 & 0.36 & 0.10 & 0.13 & 0.20 & 0.39 & 0.98 \\
\hline Bottom $80 \%$ & 304 & 593 & - & & & & & & & \\
\hline
\end{tabular}

Notes: The rebate amount for each appliance category is the non-weighted average of the rebate amount offered by each state. The preferred proportion of freeriders is obtained from Table 7, columns 10 and 11. For refrigerators and clothes washers, size is measured in cubic feet. For dishwashers, we report the proportion of models that are classified as tall. For all appliances, we assume a lifetime of 15 years. 
Online Appendix

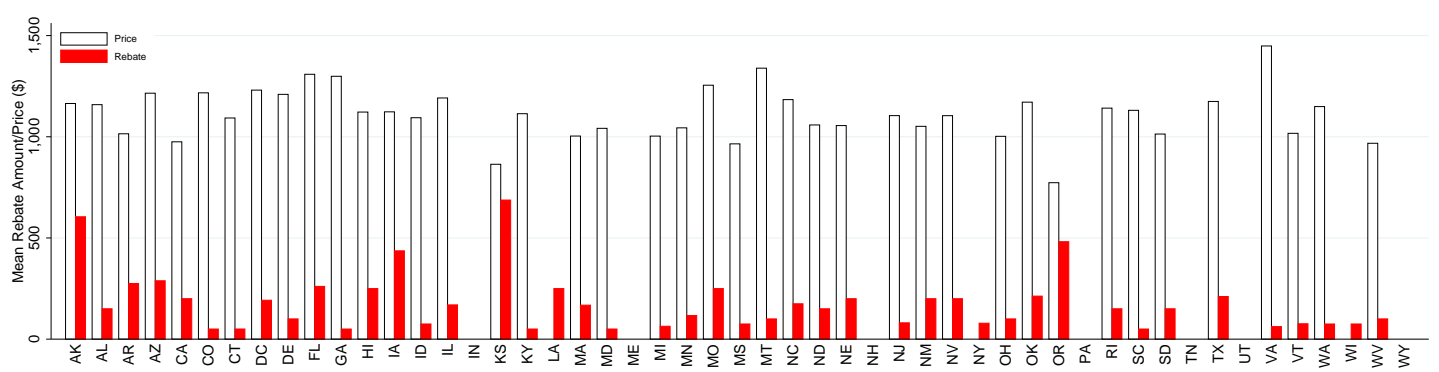

(a) Refrigerators

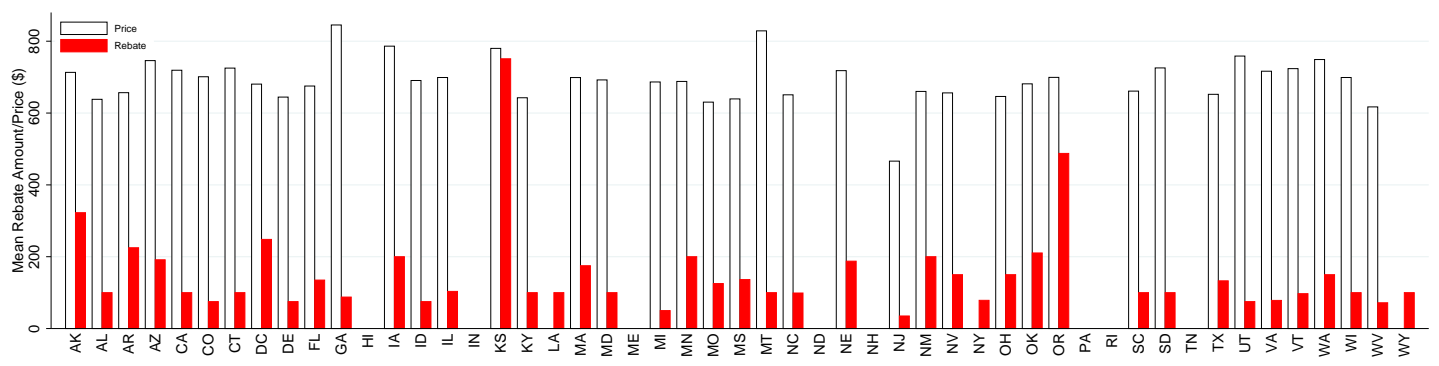

(b) Clothes Washers

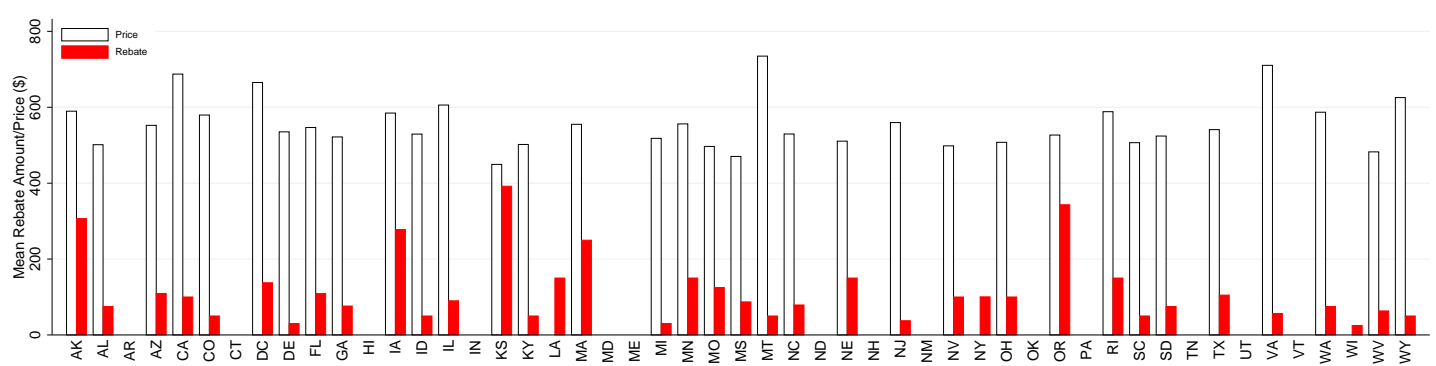

(c) Dishwashers

Figure A.1. Average Price vs. Rebate Amount

Each panel shows the average price of the appliance purchased (in white) and the average rebate amount claimed (in red). States with no average price but a positive rebate amount are states where program managers did not collect price information. States where both price and rebate information are missing did not offer rebates for this particular appliance. 


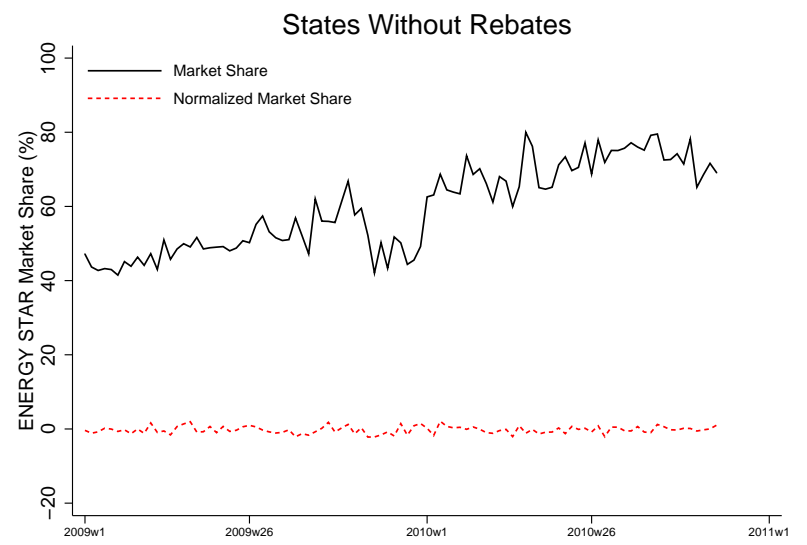

(a) Refrigerators

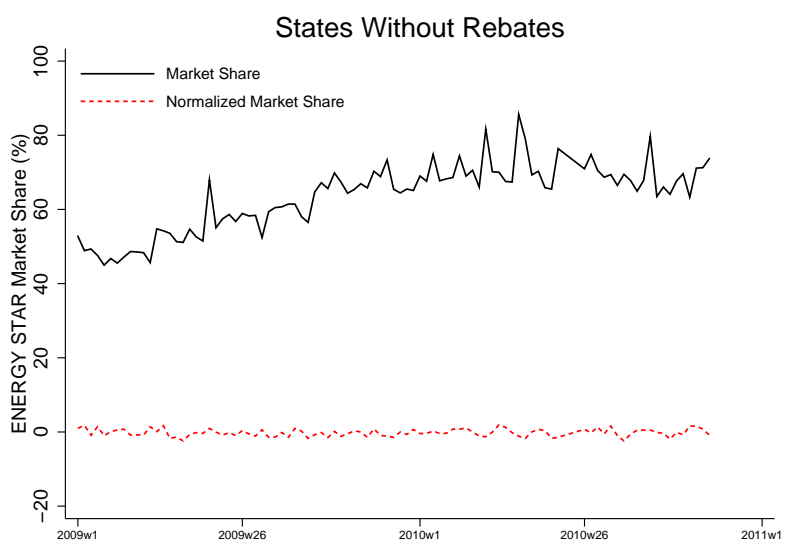

(b) Clothes Washers

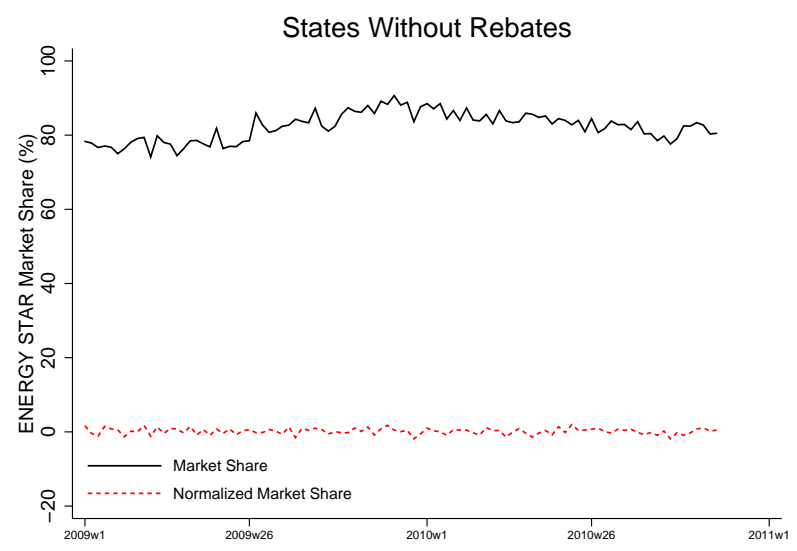

(c) Dishwashers

Figure A.2. ES Market Shares vs. Normalized Market Shares, States Without Rebates

Each panel shows the weekly ES market share for all states that did not offer rebates and the corresponding normalized market shares. Normalized market shares are the residuals of a regression of market shares on state and week-year fixed effects. The figure shows that, for states without rebates, the fixed effects capture most of the variations in market shares. 


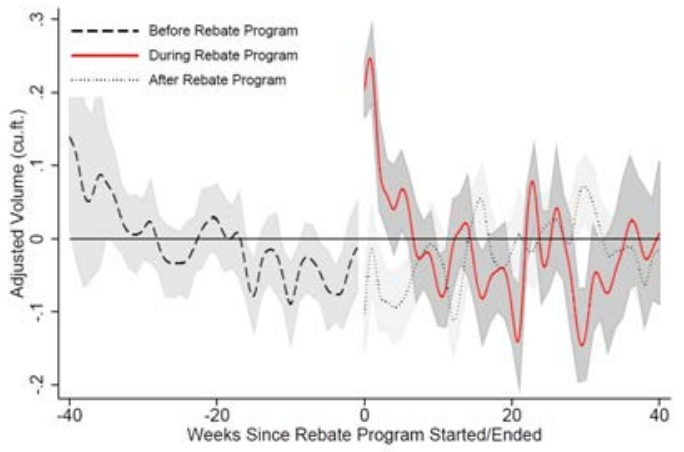

(a) Refrigerators

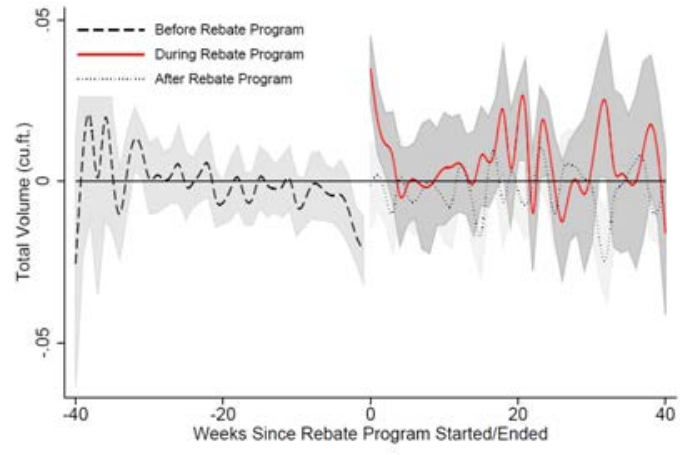

(b) Clothes Washers

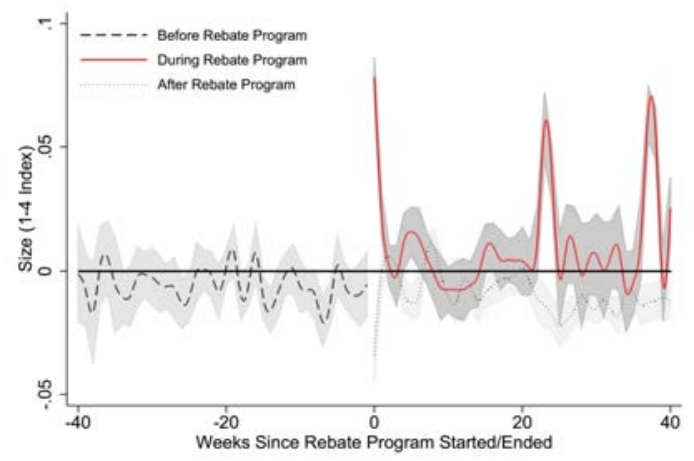

(c) Dishwashers

\section{Figure A.3. Size Purchased Since Program Start/End Date}

The figure shows the normalized size purchased fitted with a flexible regression spline on a variable that counts the number of weeks since the rebate program started/ended in each state. The figure presents the fitted spline and the $95 \%$ confidence interval. For refrigerators, size is the adjusted volume, which is the total volume of the refrigerator in cubic feet plus the volume of freezer multiplied by an adjustment factor. For clothes washers, size is measured in cubic feet. For dishwashers, size is a categorical variable that takes four values, where 1 = small, $2=$ medium, $3=$ tall, and $4=$ very tall. 
TABle A.1. External Validity

\begin{tabular}{|c|c|c|c|}
\hline & Retailer & Other Retailers & t-statistics \\
\hline \multicolumn{4}{|c|}{ Refrigerators } \\
\hline Price & 1154 & 1083 & 25.17 \\
\hline Rebate & 180 & 135 & 98.84 \\
\hline $\mathrm{kWh}$ & 480 & 456 & 60.92 \\
\hline Size & 22 & 20 & 14.46 \\
\hline \multicolumn{4}{|c|}{ Clothes Washers } \\
\hline Price & 699 & 674 & 24.41 \\
\hline Rebate & 114 & 113 & 4.66 \\
\hline $\mathrm{kWh}$ & 160 & 175 & -48.92 \\
\hline Size & 4 & 4 & 0.63 \\
\hline \multicolumn{4}{|c|}{ Dishwashers } \\
\hline Price & 554 & 543 & 7.64 \\
\hline Rebate & 116 & 85 & 86.97 \\
\hline $\mathrm{kWh}$ & 160 & 174 & -1.54 \\
\hline Size & 4 & 4 & 0.05 \\
\hline \multicolumn{4}{|c|}{$\begin{array}{l}\text { Notes: Using the DOE data alone, this table com- } \\
\text { pares the average price, rebate amount, kWh pur- } \\
\text { chased, and size of the appliances purchased at our } \\
\text { retailer (retailer from which we collected transac- } \\
\text { tion level data) versus all other retailers. Note that } \\
\text { some states did not record the retailer where the } \\
\text { purchase was made. }\end{array}$} \\
\hline
\end{tabular}


TABle A.2. Robustness Tests: State Fixed Effects

\begin{tabular}{|c|c|c|c|c|c|c|}
\hline \multirow[b]{2}{*}{ Dep. Var. } & \multicolumn{2}{|c|}{ Refrigerators } & \multicolumn{2}{|c|}{ Clothes Washers } & \multicolumn{2}{|c|}{ Dishwashers } \\
\hline & $\log$ (sales) & $\log (\mathrm{kWh})$ & $\log$ (sales) & $\log (\mathrm{kWh})$ & $\log ($ sales $)$ & $\log (\mathrm{kWh})$ \\
\hline \multicolumn{7}{|l|}{ Rebate Period } \\
\hline \multirow[t]{2}{*}{ Rebate $\times$ Week 1} & $0.15^{*}$ & $-0.0032^{*}$ & $0.14^{*}$ & $-0.056^{* * *}$ & $0.27^{*}$ & -0.0039 \\
\hline & $(0.061)$ & $(0.0014)$ & $(0.065)$ & $(0.0077)$ & $(0.100)$ & $(0.0031)$ \\
\hline \multirow{2}{*}{ Rebate $\times$ Weeks 2-3 } & $0.078^{*}$ & -0.00058 & $0.072^{*}$ & $-0.018^{*}$ & $0.081^{*}$ & -0.0012 \\
\hline & $(0.029)$ & $(0.0024)$ & $(0.035)$ & $(0.0076)$ & $(0.039)$ & $(0.0007)$ \\
\hline \multirow[t]{2}{*}{ Rebate $\times$ Weeks 4- 6} & -0.0035 & -0.001 & 0.011 & -0.0025 & 0.0081 & -0.00014 \\
\hline & $(0.010)$ & $(0.0007)$ & $(0.006)$ & $(0.0028)$ & $(0.009)$ & $(0.0006)$ \\
\hline \multirow[t]{2}{*}{ Rebate $\times$ Weeks 7-9 } & -0.011 & $-0.0018^{*}$ & 0.0078 & 0.0018 & 0.0064 & -0.00064 \\
\hline & $(0.014)$ & $(0.0008)$ & $(0.007)$ & $(0.0040)$ & $(0.014)$ & $(0.0007)$ \\
\hline \multirow{2}{*}{ Rebate $\times$ Weeks $10+$} & 0.0026 & $-0.0025^{* *}$ & 0.0085 & -0.00036 & 0.0082 & 0.000019 \\
\hline & $(0.010)$ & $(0.0009)$ & $(0.006)$ & $(0.0020)$ & $(0.007)$ & $(0.0005)$ \\
\hline \multicolumn{7}{|l|}{ Pre-Rebate Period } \\
\hline \multirow[t]{2}{*}{ Rebate $\times 1$ Week Before } & $-0.039^{*}$ & 0.00088 & $-0.057^{* * *}$ & 0.0057 & -0.043 & 0.00014 \\
\hline & $(0.017)$ & $(0.0009)$ & $(0.015)$ & $(0.0032)$ & $(0.028)$ & $(0.0012)$ \\
\hline \multirow[t]{2}{*}{ Rebate $\times 2-3$ Weeks Before } & $-0.024^{*}$ & 0.00061 & -0.024 & 0.0048 & -0.033 & 0.00042 \\
\hline & $(0.011)$ & $(0.0010)$ & $(0.012)$ & $(0.0040)$ & $(0.017)$ & $(0.0007)$ \\
\hline \multirow{2}{*}{ Rebate $\times 4-6$ Weeks Before } & $-0.030^{*}$ & 0.00038 & -0.0098 & $0.0048^{*}$ & -0.018 & -0.00012 \\
\hline & $(0.012)$ & $(0.0006)$ & $(0.008)$ & $(0.0020)$ & $(0.015)$ & $(0.0006)$ \\
\hline \multirow[t]{2}{*}{ Rebate $\times 7-9$ Weeks Before } & $-0.029^{*}$ & 0.0014 & -0.011 & 0.0041 & -0.017 & -0.000042 \\
\hline & $(0.011)$ & $(0.0009)$ & $(0.008)$ & $(0.0032)$ & $(0.009)$ & $(0.0006)$ \\
\hline \multirow[t]{2}{*}{ Rebate $\times 10+$ Weeks Before } & 0.0054 & -0.00036 & 0.0068 & 0.0011 & 0.00081 & 0.00044 \\
\hline & $(0.010)$ & $(0.0004)$ & $(0.006)$ & $(0.0018)$ & $(0.007)$ & $(0.0007)$ \\
\hline \multicolumn{7}{|l|}{ Post-Rebate Period } \\
\hline \multirow[t]{2}{*}{ Rebate $\times 1$ Week After } & 0.013 & -0.0011 & -0.0084 & -0.00014 & 0.035 & -0.0064 \\
\hline & $(0.018)$ & $(0.0009)$ & $(0.014)$ & $(0.0036)$ & $(0.033)$ & $(0.0038)$ \\
\hline \multirow[t]{2}{*}{ Rebate $\times 2-3$ Weeks After } & 0.023 & $-0.0026^{* *}$ & 0.01 & -0.0024 & 0.031 & -0.00093 \\
\hline & $(0.014)$ & $(0.0010)$ & $(0.009)$ & $(0.0037)$ & $(0.026)$ & $(0.0010)$ \\
\hline \multirow[t]{2}{*}{ Rebate $\times 4-6$ Weeks After } & -0.012 & -0.0013 & -0.0019 & 0.00052 & -0.0066 & 0.00031 \\
\hline & $(0.012)$ & $(0.0008)$ & $(0.010)$ & $(0.0026)$ & $(0.011)$ & $(0.0007)$ \\
\hline \multirow[t]{2}{*}{ Rebate $\times 7-9$ Weeks After } & -0.0008 & -0.0006 & 0.011 & -0.00059 & 0.0094 & 0.00047 \\
\hline & $(0.014)$ & $(0.0007)$ & $(0.009)$ & $(0.0034)$ & $(0.019)$ & $(0.0006)$ \\
\hline \multirow[t]{2}{*}{ Rebate $\times 10+$ Weeks After } & -0.015 & $-0.0018^{*}$ & 0.0059 & 0.0029 & 0.0015 & 0.00075 \\
\hline & $(0.011)$ & $(0.0007)$ & $(0.008)$ & $(0.0032)$ & $(0.011)$ & $(0.0006)$ \\
\hline \multirow[t]{2}{*}{ Constant } & - & $6.27^{* * *}$ & - & $5.36^{* * *}$ & - & $5.84^{* * *}$ \\
\hline & & $(0.0042)$ & & $(0.0120)$ & & $(0.0016)$ \\
\hline State FE & Yes & Yes & Yes & Yes & Yes & Yes \\
\hline Week-Year FE & Yes & Yes & Yes & Yes & Yes & Yes \\
\hline Demographics & Yes & Yes & Yes & Yes & Yes & Yes \\
\hline$R^{2}$ & 0.984 & 0.068 & 0.989 & 0.131 & 0.982 & 0.402 \\
\hline
\end{tabular}


TABle A.3. Robustness Tests: Refrigerators

\begin{tabular}{|c|c|c|c|c|c|}
\hline Dep. Var. & $\begin{array}{c}\mathbf{I} \\
\log (\mathrm{kWh})\end{array}$ & $\begin{array}{c}\text { II } \\
\log (\mathrm{kWh})\end{array}$ & $\begin{array}{c}\text { III } \\
\log (\mathrm{kWh})\end{array}$ & $\begin{array}{c}\text { IV } \\
\log (\mathrm{kWh})\end{array}$ & $\begin{array}{c}\mathbf{V} \\
\mathrm{kWh}\end{array}$ \\
\hline \multicolumn{6}{|l|}{ Rebate Period } \\
\hline Rebate $\times$ Week 1 & $\begin{array}{c}-0.0032^{*} \\
(0.0014)\end{array}$ & $\begin{array}{c}-0.0031^{*} \\
(0.0015)\end{array}$ & $\begin{array}{c}-0.0035^{*} \\
(0.0013)\end{array}$ & $\begin{array}{c}-0.0058^{* *} \\
(0.0020)\end{array}$ & $\begin{array}{c}-1.56^{*} \\
(0.72)\end{array}$ \\
\hline Rebate $\times$ Weeks 2-3 & $\begin{array}{c}-0.00058 \\
(0.0024)\end{array}$ & $\begin{array}{c}-0.00074 \\
(0.0024)\end{array}$ & $\begin{array}{r}-0.00061 \\
(0.0016)\end{array}$ & $\begin{array}{c}-0.00093 \\
(0.0030)\end{array}$ & $\begin{array}{l}-0.47 \\
(1.24)\end{array}$ \\
\hline Rebate $\times$ Weeks $4-6$ & $\begin{array}{c}-0.0010 \\
(0.00074)\end{array}$ & $\begin{array}{c}-0.0011 \\
(0.00074)\end{array}$ & $\begin{array}{l}-0.00063 \\
(0.00060)\end{array}$ & $\begin{array}{l}-0.0020^{*} \\
(0.00094)\end{array}$ & $\begin{array}{l}-0.63 \\
(0.42)\end{array}$ \\
\hline Rebate $\times$ Weeks 7-9 & $\begin{array}{l}-0.0018^{*} \\
(0.00077)\end{array}$ & $\begin{array}{l}-0.0018^{*} \\
(0.00079)\end{array}$ & $\begin{array}{l}-0.00090 \\
(0.00067)\end{array}$ & $\begin{array}{l}-0.0019 \\
(0.0011)\end{array}$ & $\begin{array}{c}-1.01^{* *} \\
(0.37)\end{array}$ \\
\hline Rebate $\times$ Weeks $10+$ & $\begin{array}{c}-0.0025^{* *} \\
(0.00089)\end{array}$ & $\begin{array}{c}-0.0026^{* *} \\
(0.00086)\end{array}$ & $\begin{array}{c}-0.0019^{* *} \\
(0.00069)\end{array}$ & $\begin{array}{c}-0.0042^{* * *} \\
(0.0011)\end{array}$ & $\begin{array}{l}-1.29^{*} \\
(0.52)\end{array}$ \\
\hline \multicolumn{6}{|l|}{ Pre-Rebate Period } \\
\hline Rebate $\times 1$ Week Before & $\begin{array}{c}0.00088 \\
(0.00091)\end{array}$ & $\begin{array}{c}0.00079 \\
(0.00094)\end{array}$ & $\begin{array}{l}-0.00024 \\
(0.00054)\end{array}$ & $\begin{array}{l}0.00060 \\
(0.0012)\end{array}$ & $\begin{array}{c}0.17 \\
(0.51)\end{array}$ \\
\hline Rebate $\times 2-3$ Weeks Before & $\begin{array}{l}0.00061 \\
(0.0010)\end{array}$ & $\begin{array}{l}0.00038 \\
(0.0010)\end{array}$ & $\begin{array}{l}-0.00066 \\
(0.00094)\end{array}$ & $\begin{array}{l}0.00059 \\
(0.0013)\end{array}$ & $\begin{array}{c}0.14 \\
(0.54)\end{array}$ \\
\hline Rebate $\times 4$ - 6 Weeks Before & $\begin{array}{c}0.00038 \\
(0.00062)\end{array}$ & $\begin{array}{c}0.00033 \\
(0.00061)\end{array}$ & $\begin{array}{l}-0.00040 \\
(0.00043)\end{array}$ & $\begin{array}{c}0.00022 \\
(0.00094)\end{array}$ & $\begin{array}{c}0.0036 \\
(0.31)\end{array}$ \\
\hline Rebate $\times 7-9$ Weeks Before & $\begin{array}{c}0.0014 \\
(0.00092)\end{array}$ & $\begin{array}{c}0.0013 \\
(0.00092)\end{array}$ & $\begin{array}{l}-0.00035 \\
(0.00075)\end{array}$ & $\begin{array}{c}0.0021^{*} \\
(0.00098)\end{array}$ & $\begin{array}{c}0.52 \\
(0.44)\end{array}$ \\
\hline Rebate $\times 10+$ Weeks Before & $\begin{array}{l}-0.00036 \\
(0.00043)\end{array}$ & $\begin{array}{l}-0.00047 \\
(0.00044)\end{array}$ & $\begin{array}{l}-0.00076 \\
(0.00039)\end{array}$ & $\begin{array}{l}-0.00014 \\
(0.00065)\end{array}$ & $\begin{array}{l}-0.27 \\
(0.20)\end{array}$ \\
\hline \multicolumn{6}{|l|}{ Post-Rebate Period } \\
\hline Rebate $\times 1$ Week After & $\begin{array}{c}-0.0011 \\
(0.00092)\end{array}$ & $\begin{array}{c}-0.0011 \\
(0.00093)\end{array}$ & $\begin{array}{c}-0.0022^{*} \\
(0.0010)\end{array}$ & $\begin{array}{l}-0.0014 \\
(0.0010)\end{array}$ & $\begin{array}{l}-0.60 \\
(0.47)\end{array}$ \\
\hline Rebate $\times 2-3$ Weeks After & $\begin{array}{c}-0.0026^{* *} \\
(0.00095)\end{array}$ & $\begin{array}{c}-0.0025^{* *} \\
(0.00091)\end{array}$ & $\begin{array}{l}-0.0015^{*} \\
(0.00067)\end{array}$ & $\begin{array}{l}-0.0032^{*} \\
(0.0012)\end{array}$ & $\begin{array}{l}-1.44^{*} \\
(0.56)\end{array}$ \\
\hline Rebate $\times 4-6$ Weeks After & $\begin{array}{c}-0.0013 \\
(0.00078)\end{array}$ & $\begin{array}{c}-0.0015 \\
(0.00081)\end{array}$ & $\begin{array}{c}-0.0016 \\
(0.00097)\end{array}$ & $\begin{array}{l}-0.0023^{* *} \\
(0.00085)\end{array}$ & $\begin{array}{l}-0.81 \\
(0.43)\end{array}$ \\
\hline Rebate $\times 7-9$ Weeks After & $\begin{array}{l}-0.00060 \\
(0.00069)\end{array}$ & $\begin{array}{l}-0.00060 \\
(0.00070)\end{array}$ & $\begin{array}{l}-0.0021^{*} \\
(0.00096)\end{array}$ & $\begin{array}{l}-0.0012 \\
(0.0011)\end{array}$ & $\begin{array}{l}-0.46 \\
(0.41)\end{array}$ \\
\hline Rebate $\times 10+$ Weeks After & $\begin{array}{l}-0.0018^{*} \\
(0.00070)\end{array}$ & $\begin{array}{l}-0.0019^{*} \\
(0.00071)\end{array}$ & $\begin{array}{c}-0.0012 \\
(0.00064)\end{array}$ & $\begin{array}{l}-0.0024^{*} \\
(0.00095)\end{array}$ & $\begin{array}{l}-1.09^{*} \\
(0.44)\end{array}$ \\
\hline Constant & $\begin{array}{l}6.27^{* * *} \\
(0.0042)\end{array}$ & $\begin{array}{l}6.26^{* * *} \\
(0.0021)\end{array}$ & $\begin{array}{l}6.26^{* * *} \\
(0.0019)\end{array}$ & $\begin{array}{l}6.27^{* * *} \\
(0.0037)\end{array}$ & $\begin{array}{c}534.7^{* * *} \\
(2.19)\end{array}$ \\
\hline State FE & Yes & Yes & Yes & Yes & Yes \\
\hline Week FE & Yes & Yes & Yes & Yes & Yes \\
\hline Demographics & No & No & Yes & Yes & Yes \\
\hline Sample & All & $\begin{array}{l}\text { Only with } \\
\text { Demo. }\end{array}$ & $\begin{array}{l}\text { Only with } \\
\text { Demo. }\end{array}$ & $\begin{array}{l}\text { Only with } \\
\text { Demo., } \\
\text { no IA, } \\
\text { FL, IL, } \\
\text { NC and } \\
\text { OR }\end{array}$ & $\begin{array}{l}\text { Only with } \\
\text { Demo. }\end{array}$ \\
\hline Nb Obs. & $>7 \mathrm{M}$ & $>4 \mathrm{M}$ & $>4 \mathrm{M}$ & $>4 \mathrm{M}$ & $>4 \mathrm{M}$ \\
\hline$R^{2}$ & 0.068 & 0.054 & 0.049 & 0.071 & 0.070 \\
\hline
\end{tabular}

Notes: The dummy variable for the pre-announcement period is omitted. Standards errors (in parentheses $)$ clustered at the state level. ${ }^{*}(p<0.05),{ }^{* *}(p<0.01),{ }^{* * *}(p<0.001)$ 
TABLE A.4. Robustness Tests: Clothes Washers

\begin{tabular}{|c|c|c|c|c|c|}
\hline Dep. Var. & $\begin{array}{c}\mathbf{I} \\
\log (\mathrm{kWh})\end{array}$ & $\begin{array}{c}\text { II } \\
\log (\mathrm{kWh})\end{array}$ & $\begin{array}{c}\text { III } \\
\log (\mathrm{kWh})\end{array}$ & $\begin{array}{c}\text { IV } \\
\log (\mathrm{kWh})\end{array}$ & $\begin{array}{c}\mathbf{V} \\
\mathrm{kWh}\end{array}$ \\
\hline \multicolumn{6}{|l|}{ Rebate Period } \\
\hline Rebate $\times$ Week 1 & $\begin{array}{c}-0.056^{* * *} \\
(0.0077)\end{array}$ & $\begin{array}{c}-0.058^{* * *} \\
(0.0085)\end{array}$ & $\begin{array}{c}-0.057^{* * *} \\
(0.0085)\end{array}$ & $\begin{array}{c}-0.058^{* * *} \\
(0.0098)\end{array}$ & $\begin{array}{c}-11.7^{* * *} \\
(1.67)\end{array}$ \\
\hline Rebate $\times$ Weeks 2-3 & $\begin{array}{l}-0.018^{*} \\
(0.0076)\end{array}$ & $\begin{array}{l}-0.018^{*} \\
(0.0078)\end{array}$ & $\begin{array}{c}-0.015 \\
(0.0075)\end{array}$ & $\begin{array}{l}-0.022^{*} \\
(0.0090)\end{array}$ & $\begin{array}{l}-3.58^{*} \\
(1.66)\end{array}$ \\
\hline Rebate $\times$ Weeks 4-6 & $\begin{array}{l}-0.0025 \\
(0.0028)\end{array}$ & $\begin{array}{l}-0.0028 \\
(0.0028)\end{array}$ & $\begin{array}{l}-0.0023 \\
(0.0020)\end{array}$ & $\begin{array}{l}-0.0053 \\
(0.0030)\end{array}$ & $\begin{array}{l}-0.34 \\
(0.71)\end{array}$ \\
\hline Rebate $\times$ Weeks 7-9 & $\begin{array}{c}0.0018 \\
(0.0040)\end{array}$ & $\begin{array}{c}0.0014 \\
(0.0043)\end{array}$ & $\begin{array}{l}-0.0012 \\
(0.0028)\end{array}$ & $\begin{array}{l}-0.0022 \\
(0.0048)\end{array}$ & $\begin{array}{c}0.92 \\
(0.98)\end{array}$ \\
\hline Rebate $\times$ Weeks $10+$ & $\begin{array}{c}-0.00036 \\
(0.0020)\end{array}$ & $\begin{array}{l}-0.00014 \\
(0.0020)\end{array}$ & $\begin{array}{l}-0.0017 \\
(0.0016)\end{array}$ & $\begin{array}{l}-0.0030 \\
(0.0042)\end{array}$ & $\begin{array}{c}0.10 \\
(0.52)\end{array}$ \\
\hline \multicolumn{6}{|l|}{ Pre-Rebate Period } \\
\hline Rebate $\times 1$ Week Before & $\begin{array}{c}0.0057 \\
(0.0032)\end{array}$ & $\begin{array}{l}0.0070^{*} \\
(0.0033)\end{array}$ & $\begin{array}{c}0.0037 \\
(0.0027)\end{array}$ & $\begin{array}{c}0.0034 \\
(0.0029)\end{array}$ & $\begin{array}{c}1.31 \\
(0.74)\end{array}$ \\
\hline Rebate $\times 2$-3 Weeks Before & $\begin{array}{c}0.0048 \\
(0.0040)\end{array}$ & $\begin{array}{c}0.0054 \\
(0.0041)\end{array}$ & $\begin{array}{c}0.0028 \\
(0.0026)\end{array}$ & $\begin{array}{c}0.0029 \\
(0.0032)\end{array}$ & $\begin{array}{c}1.10 \\
(0.95)\end{array}$ \\
\hline Rebate $\times$ 4- 6 Weeks Before & $\begin{array}{l}0.0048^{*} \\
(0.0020)\end{array}$ & $\begin{array}{l}0.0053^{*} \\
(0.0020)\end{array}$ & $\begin{array}{c}0.0026 \\
(0.0017)\end{array}$ & $\begin{array}{c}0.0041 \\
(0.0026)\end{array}$ & $\begin{array}{l}1.20^{*} \\
(0.53)\end{array}$ \\
\hline Rebate $\times 7-9$ Weeks Before & $\begin{array}{c}0.0041 \\
(0.0032)\end{array}$ & $\begin{array}{c}0.0042 \\
(0.0032)\end{array}$ & $\begin{array}{c}0.0031 \\
(0.0023)\end{array}$ & $\begin{array}{c}0.0017 \\
(0.0036)\end{array}$ & $\begin{array}{c}1.09 \\
(0.80)\end{array}$ \\
\hline Rebate $\times 10+$ Weeks Before & $\begin{array}{c}0.0011 \\
(0.0018)\end{array}$ & $\begin{array}{c}0.0014 \\
(0.0018)\end{array}$ & $\begin{array}{l}0.00054 \\
(0.0018)\end{array}$ & $\begin{array}{c}0.000050 \\
(0.0024)\end{array}$ & $\begin{array}{c}0.52 \\
(0.53)\end{array}$ \\
\hline \multicolumn{6}{|l|}{ Post-Rebate Period } \\
\hline Rebate $\times 1$ Week After & $\begin{array}{c}-0.00014 \\
(0.0036)\end{array}$ & $\begin{array}{l}0.00027 \\
(0.0039)\end{array}$ & $\begin{array}{c}0.0020 \\
(0.0031)\end{array}$ & $\begin{array}{l}-0.00021 \\
(0.0037)\end{array}$ & $\begin{array}{c}0.16 \\
(0.80)\end{array}$ \\
\hline Rebate $\times 2-3$ Weeks After & $\begin{array}{l}-0.0024 \\
(0.0037)\end{array}$ & $\begin{array}{l}-0.0022 \\
(0.0042)\end{array}$ & $\begin{array}{l}-0.0039 \\
(0.0041)\end{array}$ & $\begin{array}{l}-0.0049 \\
(0.0045)\end{array}$ & $\begin{array}{l}-0.35 \\
(0.74)\end{array}$ \\
\hline Rebate $\times 4-6$ Weeks After & $\begin{array}{l}0.00052 \\
(0.0026)\end{array}$ & $\begin{array}{c}0.0012 \\
(0.0027)\end{array}$ & $\begin{array}{l}-0.00023 \\
(0.0020)\end{array}$ & $\begin{array}{c}0.0013 \\
(0.0033)\end{array}$ & $\begin{array}{c}0.20 \\
(0.61)\end{array}$ \\
\hline Rebate $\times 7-9$ Weeks After & $\begin{array}{c}-0.00059 \\
(0.0034)\end{array}$ & $\begin{array}{c}-0.00084 \\
(0.0034)\end{array}$ & $\begin{array}{l}-0.0032 \\
(0.0028)\end{array}$ & $\begin{array}{l}-0.00043 \\
(0.0041)\end{array}$ & $\begin{array}{l}-0.22 \\
(0.76)\end{array}$ \\
\hline Rebate $\times 10+$ Weeks After & $\begin{array}{c}0.0029 \\
(0.0032)\end{array}$ & $\begin{array}{c}0.0029 \\
(0.0031)\end{array}$ & $\begin{array}{c}0.0014 \\
(0.0026)\end{array}$ & $\begin{array}{c}0.0037 \\
(0.0042)\end{array}$ & $\begin{array}{c}0.79 \\
(0.78)\end{array}$ \\
\hline Constant & $\begin{array}{l}5.36^{* * *} \\
(0.012)\end{array}$ & $\begin{array}{l}5.43^{* * *} \\
(0.0073)\end{array}$ & $\begin{array}{l}5.44^{* * *} \\
(0.0067)\end{array}$ & $\begin{array}{l}5.36^{* * *} \\
(0.0095)\end{array}$ & $\begin{array}{c}233.2^{* * *} \\
(2.98)\end{array}$ \\
\hline State FE & Yes & Yes & Yes & Yes & Yes \\
\hline Week FE & Yes & Yes & Yes & Yes & Yes \\
\hline Demographics & No & No & Yes & Yes & Yes \\
\hline Sample & All & $\begin{array}{l}\text { Only with } \\
\text { Demo. }\end{array}$ & $\begin{array}{l}\text { Only with } \\
\text { Demo. }\end{array}$ & $\begin{array}{l}\text { Only with } \\
\text { Demo., } \\
\text { no IA, } \\
\text { FL, IL, } \\
\text { NC and } \\
\text { OR }\end{array}$ & $\begin{array}{l}\text { Only with } \\
\text { Demo. }\end{array}$ \\
\hline \# Obs. & $>7 \mathrm{M}$ & $>3 \mathrm{M}$ & $>3 \mathrm{M}$ & $>3 \mathrm{M}$ & $>3 \mathrm{M}$ \\
\hline$R^{2}$ & 0.131 & 0.102 & 0.098 & 0.131 & 0.123 \\
\hline
\end{tabular}

Notes: The dummy variable for the pre-announcement period is omitted. Standard errors (in parentheses $)$ clustered at the state level. ${ }^{*}(p<0.05),{ }^{* *}(p<0.01),{ }^{* * *}(p<0.001)$ 
TABle A.5. Robustness Tests: Dishwashers

\begin{tabular}{|c|c|c|c|c|c|}
\hline Dep. Var. & $\begin{array}{c}\mathbf{I} \\
\log (\mathrm{kWh}) \\
\end{array}$ & $\begin{array}{c}\text { II } \\
\log (\mathrm{kWh})\end{array}$ & $\begin{array}{c}\text { III } \\
\log (\mathrm{kWh}) \\
\end{array}$ & $\begin{array}{c}\text { IV } \\
\log (\mathrm{kWh})\end{array}$ & $\begin{array}{c}\mathbf{V} \\
\mathrm{kWh}\end{array}$ \\
\hline \multicolumn{6}{|l|}{ Rebate Period } \\
\hline Rebate $\times$ Week 1 & $\begin{array}{l}-0.0039 \\
(0.0031)\end{array}$ & $\begin{array}{l}-0.0041 \\
(0.0032)\end{array}$ & $\begin{array}{l}-0.0039 \\
(0.0031)\end{array}$ & $\begin{array}{l}-0.0056 \\
(0.0041)\end{array}$ & $\begin{array}{l}-1.17 \\
(0.94)\end{array}$ \\
\hline Rebate $\times$ Weeks 2-3 & $\begin{array}{c}-0.0012 \\
(0.00073)\end{array}$ & $\begin{array}{c}-0.0013 \\
(0.00075)\end{array}$ & $\begin{array}{c}-0.0013 \\
(0.00077)\end{array}$ & $\begin{array}{l}-0.0014 \\
(0.0011)\end{array}$ & $\begin{array}{l}-0.36 \\
(0.22)\end{array}$ \\
\hline Rebate $\times$ Weeks $4-6$ & $\begin{array}{l}-0.00014 \\
(0.00062)\end{array}$ & $\begin{array}{l}-0.00017 \\
(0.00060)\end{array}$ & $\begin{array}{l}-0.00012 \\
(0.00059)\end{array}$ & $\begin{array}{c}0.00014 \\
(0.00088)\end{array}$ & $\begin{array}{l}-0.035 \\
(0.19)\end{array}$ \\
\hline Rebate $\times$ Weeks 7-9 & $\begin{array}{l}-0.00064 \\
(0.00069)\end{array}$ & $\begin{array}{l}-0.00068 \\
(0.00072)\end{array}$ & $\begin{array}{l}-0.00087 \\
(0.00060)\end{array}$ & $\begin{array}{c}-0.0015 \\
(0.00096)\end{array}$ & $\begin{array}{l}-0.21 \\
(0.21)\end{array}$ \\
\hline Rebate $\times$ Weeks $10+$ & $\begin{array}{l}0.000019 \\
(0.00045)\end{array}$ & $\begin{array}{c}-0.00000045 \\
(0.00045)\end{array}$ & $\begin{array}{l}-0.00029 \\
(0.00051)\end{array}$ & $\begin{array}{l}-0.00025 \\
(0.00086)\end{array}$ & $\begin{array}{c}0.0019 \\
(0.14)\end{array}$ \\
\hline \multicolumn{6}{|l|}{ Pre-Rebate Period } \\
\hline Rebate $\times 1$ Week Before & $\begin{array}{l}0.00014 \\
(0.0012)\end{array}$ & $\begin{array}{l}0.00010 \\
(0.0012)\end{array}$ & $\begin{array}{l}0.000046 \\
(0.00090)\end{array}$ & $\begin{array}{c}0.0016 \\
(0.0012)\end{array}$ & $\begin{array}{l}0.076 \\
(0.36)\end{array}$ \\
\hline Rebate $\times 2$ 2-3 Weeks Before & $\begin{array}{c}0.00042 \\
(0.00070)\end{array}$ & $\begin{array}{c}0.00044 \\
(0.00069)\end{array}$ & $\begin{array}{c}0.00063 \\
(0.00071)\end{array}$ & $\begin{array}{c}0.0011 \\
(0.00096)\end{array}$ & $\begin{array}{c}0.13 \\
(0.22)\end{array}$ \\
\hline Rebate $\times 4-6$ Weeks Before & $\begin{array}{l}-0.00012 \\
(0.00058)\end{array}$ & $\begin{array}{l}-0.00019 \\
(0.00059)\end{array}$ & $\begin{array}{c}0.00043 \\
(0.00070)\end{array}$ & $\begin{array}{c}0.00021 \\
(0.00090)\end{array}$ & $\begin{array}{l}-0.014 \\
(0.18)\end{array}$ \\
\hline Rebate $\times$ 7-9 Weeks Before & $\begin{array}{l}-0.000042 \\
(0.00058)\end{array}$ & $\begin{array}{r}-0.000073 \\
(0.00059)\end{array}$ & $\begin{array}{c}0.00021 \\
(0.00054)\end{array}$ & $\begin{array}{c}-0.000084 \\
(0.00091)\end{array}$ & $\begin{array}{c}-0.0039 \\
(0.18)\end{array}$ \\
\hline Rebate $\times 10+$ Weeks Before & $\begin{array}{c}0.00044 \\
(0.00065)\end{array}$ & $\begin{array}{c}0.00041 \\
(0.00064)\end{array}$ & $\begin{array}{c}0.00053 \\
(0.00062)\end{array}$ & $\begin{array}{c}0.0012 \\
(0.00079)\end{array}$ & $\begin{array}{c}0.15 \\
(0.21)\end{array}$ \\
\hline \multicolumn{6}{|l|}{ Post-Rebate Period } \\
\hline Rebate $\times 1$ Week After & $\begin{array}{l}-0.0064 \\
(0.0038)\end{array}$ & $\begin{array}{l}-0.0064 \\
(0.0039)\end{array}$ & $\begin{array}{l}-0.0055 \\
(0.0036)\end{array}$ & $\begin{array}{l}-0.0086^{*} \\
(0.0038)\end{array}$ & $\begin{array}{l}-1.91 \\
(1.13)\end{array}$ \\
\hline Rebate $\times 2$-3 Weeks After & $\begin{array}{l}-0.00093 \\
(0.0010)\end{array}$ & $\begin{array}{l}-0.0010 \\
(0.0010)\end{array}$ & $\begin{array}{l}-0.00096 \\
(0.00077)\end{array}$ & $\begin{array}{l}-0.0014 \\
(0.0014)\end{array}$ & $\begin{array}{l}-0.27 \\
(0.31)\end{array}$ \\
\hline Rebate $\times$ 4-6 Weeks After & $\begin{array}{c}0.00031 \\
(0.00066)\end{array}$ & $\begin{array}{c}0.00028 \\
(0.00065)\end{array}$ & $\begin{array}{r}-0.000048 \\
(0.00067)\end{array}$ & $\begin{array}{c}0.00014 \\
(0.00092)\end{array}$ & $\begin{array}{l}0.089 \\
(0.20)\end{array}$ \\
\hline Rebate $\times 7-9$ Weeks After & $\begin{array}{c}0.00047 \\
(0.00055)\end{array}$ & $\begin{array}{c}0.00044 \\
(0.00055)\end{array}$ & $\begin{array}{r}-0.000050 \\
(0.00059)\end{array}$ & $\begin{array}{c}0.00058 \\
(0.00081)\end{array}$ & $\begin{array}{c}0.15 \\
(0.17)\end{array}$ \\
\hline Rebate $\times 10+$ Weeks After & $\begin{array}{c}0.00075 \\
(0.00063)\end{array}$ & $\begin{array}{c}0.00074 \\
(0.00063)\end{array}$ & $\begin{array}{c}0.00050 \\
(0.00086)\end{array}$ & $\begin{array}{c}0.00090 \\
(0.00083)\end{array}$ & $\begin{array}{c}0.22 \\
(0.19)\end{array}$ \\
\hline Constant & $\begin{array}{l}5.84^{* * *} \\
(0.0016)\end{array}$ & $\begin{array}{l}5.83^{* * *} \\
(0.0014)\end{array}$ & $\begin{array}{l}5.83^{* * *} \\
(0.0014)\end{array}$ & $\begin{array}{l}5.84^{* * *} \\
(0.0023)\end{array}$ & $\begin{array}{c}343.8^{* * *} \\
(0.50)\end{array}$ \\
\hline State FE & Yes & Yes & Yes & Yes & Yes \\
\hline Week FE & Yes & Yes & Yes & Yes & Yes \\
\hline Demographics & No & No & Yes & Yes & Yes \\
\hline Sample & All & $\begin{array}{l}\text { Only with } \\
\text { Demo. }\end{array}$ & $\begin{array}{l}\text { Only with } \\
\text { Demo. }\end{array}$ & $\begin{array}{l}\text { Only with } \\
\text { Demo., } \\
\text { no IA, } \\
\text { FL, IL, } \\
\text { NC and } \\
\text { OR }\end{array}$ & $\begin{array}{l}\text { Only with } \\
\text { Demo. }\end{array}$ \\
\hline \# Obs. & $>5 \mathrm{M}$ & $>2 \mathrm{M}$ & $>2 \mathrm{M}$ & $>2 \mathrm{M}$ & $>2 \mathrm{M}$ \\
\hline$R^{2}$ & 0.402 & 0.398 & 0.374 & 0.408 & 0.420 \\
\hline
\end{tabular}

Notes: The dummy variable for the pre-announcement period is omitted. Standard errors (in parentheses $)$ clustered at the state level. ${ }^{*}(p<0.05),{ }^{* *}(p<0.01),{ }^{* * *}(p<0.001)$ 
TABLE A.6. The Effect of Rebates on Sales and kWh: Electric Water Heaters

\begin{tabular}{|c|c|c|c|c|c|c|c|c|}
\hline \multirow[t]{2}{*}{ Dep. Var. } & \multicolumn{4}{|c|}{$\log$ (sales) } & \multicolumn{4}{|c|}{$\overline{l o g}(\mathrm{kWh})$} \\
\hline & $\mathbf{I}$ & II & III & IV & I & II & III & IV \\
\hline \multicolumn{9}{|l|}{ All Periods } \\
\hline Rebate $\times$ Dall: 2 Months Before, & 0.0079 & & & & $-0.0080^{* *}$ & & & \\
\hline During, and 2 Weeks After & $(0.0079)$ & & & & $(0.0026)$ & & & \\
\hline Rebate $\times$ Dall: 4 Months Before, & & 0.012 & & & & $-0.0077^{* * *}$ & & \\
\hline During, and 2 Months After & & $(0.0068)$ & & & & $(0.0021)$ & & \\
\hline Rebate $\times$ Dall: Since Announce- & & & 0.015 & & & & $-0.0052^{* *}$ & \\
\hline ment to 3 Months After & & & $(0.0087)$ & & & & $(0.0016)$ & \\
\hline \multicolumn{9}{|l|}{ Rebate Period } \\
\hline \multirow[t]{2}{*}{ Rebate $\times$ Week 1} & & & & $0.067^{*}$ & & & & $-0.085^{* *}$ \\
\hline & & & & $(0.032)$ & & & & $(0.026)$ \\
\hline \multirow[t]{2}{*}{ Rebate $\times$ Weeks 2-3 } & & & & 0.037 & & & & $-0.030^{* *}$ \\
\hline & & & & $(0.020)$ & & & & $(0.0094)$ \\
\hline \multirow[t]{2}{*}{ Rebate $\times$ Weeks $4-6$} & & & & 0.015 & & & & -0.011 \\
\hline & & & & $(0.015)$ & & & & $(0.0059)$ \\
\hline \multirow[t]{2}{*}{ Rebate $\times$ Weeks 7-9 } & & & & 0.0028 & & & & 0.0015 \\
\hline & & & & $(0.011)$ & & & & $(0.0062)$ \\
\hline \multirow[t]{2}{*}{ Rebate $\times$ Weeks $10+$} & & & & 0.0026 & & & & -0.0024 \\
\hline & & & & $(0.014)$ & & & & $(0.0040)$ \\
\hline \multicolumn{9}{|l|}{ Pre-Rebate Period } \\
\hline \multirow[t]{2}{*}{ Rebate $\times 1$ Week Before } & & & & 0.022 & & & & 0.0025 \\
\hline & & & & $(0.015)$ & & & & $(0.0064)$ \\
\hline \multirow[t]{2}{*}{ Rebate $\times 2-3$ Weeks Before } & & & & 0.0027 & & & & -0.00024 \\
\hline & & & & $(0.016)$ & & & & $(0.0040)$ \\
\hline \multirow[t]{2}{*}{ Rebate $\times 4-6$ Weeks Before } & & & & 0.022 & & & & 0.0023 \\
\hline & & & & $(0.013)$ & & & & $(0.0035)$ \\
\hline \multirow[t]{2}{*}{ Rebate $\times 7-9$ Weeks Before } & & & & 0.015 & & & & 0.0030 \\
\hline & & & & $(0.018)$ & & & & $(0.0030)$ \\
\hline \multirow[t]{2}{*}{ Rebate $\times 10+$ Weeks Before } & & & & $0.026^{*}$ & & & & -0.00038 \\
\hline & & & & $(0.011)$ & & & & $(0.00064)$ \\
\hline \multicolumn{9}{|l|}{ Post-Rebate Period } \\
\hline \multirow[t]{2}{*}{ Rebate $\times 1$ Week After } & & & & -0.027 & & & & 0.0026 \\
\hline & & & & $(0.020)$ & & & & $(0.0052)$ \\
\hline \multirow[t]{2}{*}{ Rebate $\times 2-3$ Weeks After } & & & & -0.027 & & & & -0.0033 \\
\hline & & & & $(0.023)$ & & & & $(0.0065)$ \\
\hline \multirow[t]{2}{*}{ Rebate $\times 4-6$ Weeks After } & & & & -0.00014 & & & & 0.000095 \\
\hline & & & & $(0.016)$ & & & & $(0.0036)$ \\
\hline \multirow[t]{2}{*}{ Rebate $\times 7-9$ Weeks After } & & & & -0.011 & & & & 0.0035 \\
\hline & & & & $(0.015)$ & & & & $(0.0038)$ \\
\hline Rebate $\times 10+$ Weeks After & & & & -0.0070 & & & & 0.0054 \\
\hline & & & & $(0.012)$ & & & & $(0.0030)$ \\
\hline Constant & - & - & - & - & $8.45^{* * *}$ & $8.45^{* * *}$ & $8.45^{* * *}$ & $8.46^{* * *}$ \\
\hline & & & & & $(0.0042)$ & $(0.0043)$ & $(0.0044)$ & $(0.0043)$ \\
\hline State FE & Yes & Yes & Yes & Yes & Yes & Yes & Yes & Yes \\
\hline Week-Year FE & Yes & Yes & Yes & Yes & Yes & Yes & Yes & Yes \\
\hline Demographics & No & No & No & No & Yes & Yes & Yes & Yes \\
\hline$R^{2}$ & 0.935 & 0.935 & 0.935 & 0.935 & 0.063 & 0.063 & 0.063 & 0.067 \\
\hline
\end{tabular}

Notes: The dummy variable for the pre-announcement period is omitted. Standard errors (in parentheses $)$ clustered at the state level. ${ }^{*}(p<0.05),{ }^{* *}(p<0.01),{ }^{* * *}(p<0.001)$ 
TABLE A.7. Robustness Tests: Electric Water Heaters

\begin{tabular}{|c|c|c|c|c|c|}
\hline Dep. Var. & $\begin{array}{c}\mathbf{I} \\
\log (\mathrm{kWh})\end{array}$ & $\begin{array}{c}\text { II } \\
\log (\mathrm{kWh})\end{array}$ & $\begin{array}{c}\text { III } \\
\log (\mathrm{kWh}) \\
\end{array}$ & $\begin{array}{c}\text { IV } \\
\log (\mathrm{kWh})\end{array}$ & $\begin{array}{c}\mathbf{V} \\
\mathrm{kWh}\end{array}$ \\
\hline \multicolumn{6}{|l|}{ Rebate Period } \\
\hline Rebate $\times$ Week 1 & $\begin{array}{c}-0.085^{* *} \\
(0.026)\end{array}$ & $\begin{array}{c}-0.085^{* *} \\
(0.026)\end{array}$ & $\begin{array}{c}-0.064^{* *} \\
(0.018)\end{array}$ & $\begin{array}{c}-0.090^{* * *} \\
(0.025)\end{array}$ & $\begin{array}{c}-261.5^{* *} \\
(78.5)\end{array}$ \\
\hline Rebate $\times$ Weeks 2-3 & $\begin{array}{c}-0.030^{* *} \\
(0.0094)\end{array}$ & $\begin{array}{l}-0.031^{* *} \\
(0.0095)\end{array}$ & $\begin{array}{c}-0.027^{* *} \\
(0.0086)\end{array}$ & $\begin{array}{c}-0.034^{* * *} \\
(0.0093)\end{array}$ & $\begin{array}{c}-93.3^{* *} \\
(29.1)\end{array}$ \\
\hline Rebate $\times$ Weeks $4-6$ & $\begin{array}{c}-0.011 \\
(0.0059)\end{array}$ & $\begin{array}{c}-0.011 \\
(0.0060)\end{array}$ & $\begin{array}{l}-0.0085 \\
(0.0052)\end{array}$ & $\begin{array}{l}-0.014^{*} \\
(0.0056)\end{array}$ & $\begin{array}{l}-34.2 \\
(18.3)\end{array}$ \\
\hline Rebate $\times$ Weeks 7-9 & $\begin{array}{c}0.0015 \\
(0.0062)\end{array}$ & $\begin{array}{c}0.0017 \\
(0.0064)\end{array}$ & $\begin{array}{l}-0.0024 \\
(0.0045)\end{array}$ & $\begin{array}{l}-0.0015 \\
(0.0064)\end{array}$ & $\begin{array}{c}4.74 \\
(19.0)\end{array}$ \\
\hline Rebate $\times$ Weeks $10+$ & $\begin{array}{l}-0.0024 \\
(0.0040)\end{array}$ & $\begin{array}{l}-0.0021 \\
(0.0040)\end{array}$ & $\begin{array}{c}0.000017 \\
(0.0032)\end{array}$ & $\begin{array}{l}-0.0035 \\
(0.0043)\end{array}$ & $\begin{array}{l}-6.98 \\
(12.1)\end{array}$ \\
\hline \multicolumn{6}{|l|}{ Pre-Rebate Period } \\
\hline Rebate $\times 1$ Week Before & $\begin{array}{c}0.0025 \\
(0.0064)\end{array}$ & $\begin{array}{c}0.0027 \\
(0.0064)\end{array}$ & $\begin{array}{c}0.0041 \\
(0.0042)\end{array}$ & $\begin{array}{l}0.00078 \\
(0.0081)\end{array}$ & $\begin{array}{c}7.18 \\
(19.6)\end{array}$ \\
\hline Rebate $\times 2$-3 Weeks Before & $\begin{array}{l}-0.00024 \\
(0.0040)\end{array}$ & $\begin{array}{l}-0.00043 \\
(0.0040)\end{array}$ & $\begin{array}{c}0.0018 \\
(0.0028)\end{array}$ & $\begin{array}{l}-0.0022 \\
(0.0049)\end{array}$ & $\begin{array}{l}-1.49 \\
(12.2)\end{array}$ \\
\hline Rebate $\times$ 4- 6 Weeks Before & $\begin{array}{c}0.0023 \\
(0.0035)\end{array}$ & $\begin{array}{c}0.0022 \\
(0.0036)\end{array}$ & $\begin{array}{c}0.0018 \\
(0.0027)\end{array}$ & $\begin{array}{c}0.0013 \\
(0.0039)\end{array}$ & $\begin{array}{c}6.73 \\
(10.2)\end{array}$ \\
\hline Rebate $\times$ 7-9 Weeks Before & $\begin{array}{c}0.0030 \\
(0.0030)\end{array}$ & $\begin{array}{c}0.0029 \\
(0.0031)\end{array}$ & $\begin{array}{c}0.0017 \\
(0.0018)\end{array}$ & $\begin{array}{c}0.0040 \\
(0.0034)\end{array}$ & $\begin{array}{c}9.10 \\
(9.80)\end{array}$ \\
\hline Rebate $\times 10+$ Weeks Before & $\begin{array}{l}-0.00038 \\
(0.00064)\end{array}$ & $\begin{array}{l}-0.00032 \\
(0.00065)\end{array}$ & $\begin{array}{l}-0.00070 \\
(0.00051)\end{array}$ & $\begin{array}{l}-0.00073 \\
(0.00073)\end{array}$ & $\begin{array}{l}-1.76 \\
(2.34)\end{array}$ \\
\hline \multicolumn{6}{|l|}{ Post-Rebate Period } \\
\hline Rebate $\times 1$ Week After & $\begin{array}{c}0.0026 \\
(0.0052)\end{array}$ & $\begin{array}{c}0.0026 \\
(0.0052)\end{array}$ & $\begin{array}{l}0.00028 \\
(0.0042)\end{array}$ & $\begin{array}{l}-0.0012 \\
(0.0055)\end{array}$ & $\begin{array}{c}7.67 \\
(16.3)\end{array}$ \\
\hline Rebate $\times 2-3$ Weeks After & $\begin{array}{l}-0.0033 \\
(0.0065)\end{array}$ & $\begin{array}{l}-0.0032 \\
(0.0066)\end{array}$ & $\begin{array}{l}-0.00043 \\
(0.0032)\end{array}$ & $\begin{array}{l}-0.0053 \\
(0.0071)\end{array}$ & $\begin{array}{l}-10.1 \\
(20.3)\end{array}$ \\
\hline Rebate $\times 4-6$ Weeks After & $\begin{array}{c}0.000095 \\
(0.0036)\end{array}$ & $\begin{array}{l}0.00042 \\
(0.0036)\end{array}$ & $\begin{array}{c}0.0033 \\
(0.0032)\end{array}$ & $\begin{array}{l}-0.0034 \\
(0.0040)\end{array}$ & $\begin{array}{c}0.77 \\
(11.0)\end{array}$ \\
\hline Rebate $\times 7-9$ Weeks After & $\begin{array}{c}0.0035 \\
(0.0038)\end{array}$ & $\begin{array}{c}0.0039 \\
(0.0038)\end{array}$ & $\begin{array}{c}0.0053 \\
(0.0029)\end{array}$ & $\begin{array}{c}-0.000031 \\
(0.0031)\end{array}$ & $\begin{array}{c}11.6 \\
(11.4)\end{array}$ \\
\hline Rebate $\times 10+$ Weeks After & $\begin{array}{c}0.0054 \\
(0.0030)\end{array}$ & $\begin{array}{c}0.0056 \\
(0.0030)\end{array}$ & $\begin{array}{l}0.0067^{*} \\
(0.0030)\end{array}$ & $\begin{array}{c}0.0051 \\
(0.0034)\end{array}$ & $\begin{array}{c}16.7 \\
(9.04)\end{array}$ \\
\hline Constant & $\begin{array}{l}8.46^{* * *} \\
(0.0043)\end{array}$ & $\begin{array}{l}8.45^{* * *} \\
(0.0028)\end{array}$ & $\begin{array}{l}8.45^{* * *} \\
(0.0026)\end{array}$ & $\begin{array}{l}8.46^{* * *} \\
(0.0048)\end{array}$ & $\begin{array}{c}4716.0^{* * *} \\
(12.9)\end{array}$ \\
\hline State FE & Yes & Yes & Yes & Yes & Yes \\
\hline Week FE & Yes & Yes & Yes & Yes & Yes \\
\hline Demographics & No & No & Yes & Yes & Yes \\
\hline Sample & All & $\begin{array}{l}\text { Only with } \\
\text { Demo. }\end{array}$ & $\begin{array}{l}\text { Only with } \\
\text { Demo. }\end{array}$ & $\begin{array}{l}\text { Only with } \\
\text { Demo., } \\
\text { no IA, } \\
\text { FL, IL, } \\
\text { NC and } \\
\text { OR }\end{array}$ & $\begin{array}{l}\text { Only with } \\
\text { Demo. }\end{array}$ \\
\hline$R^{2}$ & 0.067 & 0.061 & 0.051 & 0.066 & 0.065 \\
\hline
\end{tabular}

Notes: The dummy variable for the pre-announcement period is omitted. Standard errors (in parentheses $)$ clustered at the state level. ${ }^{*}(p<0.05),{ }^{* *}(p<0.01),{ }^{* * *}(p<0.001)$ 


\section{TABLE A.8. Impact of Program Characteristics on Energy Savings}

\begin{tabular}{|c|c|c|c|}
\hline \multicolumn{4}{|c|}{ Dependent Variable: Percentage Energy Savings in Each State } \\
\hline & Refrigerators & Clothes Washers & Dishwashers \\
\hline \multirow[t]{2}{*}{ Rebate Amount (\$) } & -0.0037 & $0.024^{* * *}$ & $0.0010^{*}$ \\
\hline & $(0.0019)$ & $(0.0041)$ & $(0.00038)$ \\
\hline \multirow[t]{2}{*}{ Duration (weeks) } & 0.0020 & -0.0039 & 0.00025 \\
\hline & $(0.0015)$ & $(0.0042)$ & $(0.00028)$ \\
\hline \multirow[t]{2}{*}{ Advalorem $=1$} & 1.60 & -2.74 & $-0.36^{*}$ \\
\hline & $(0.84)$ & $(2.03)$ & $(0.13)$ \\
\hline \multirow[t]{2}{*}{ Online $=1$} & -0.036 & 1.16 & -0.021 \\
\hline & $(0.55)$ & $(1.20)$ & $(0.083)$ \\
\hline \multirow[t]{2}{*}{ Reservation System $=1$} & -0.21 & -1.18 & 0.050 \\
\hline & $(0.52)$ & $(1.19)$ & $(0.081)$ \\
\hline \multirow[t]{2}{*}{ Recycling Requirement=1 } & -0.30 & 0.053 & $0.24^{*}$ \\
\hline & $(0.57)$ & $(1.36)$ & $(0.091)$ \\
\hline \multirow[t]{2}{*}{ Recycling Incentive $=1$} & 0.56 & -0.082 & 0.010 \\
\hline & $(0.76)$ & $(1.76)$ & $(0.11)$ \\
\hline \multirow[t]{2}{*}{ Eligibility Criteria $=2$} & 1.34 & -1.81 & 0.41 \\
\hline & $(0.95)$ & $(3.73)$ & $(0.22)$ \\
\hline \multirow[t]{2}{*}{ Eligibility Criteria $=3$} & 1.32 & -1.37 & 0.41 \\
\hline & $(1.20)$ & $(3.94)$ & $(0.23)$ \\
\hline \multirow[t]{2}{*}{ Eligibility Criteria $=4$} & 0.64 & -1.69 & $0.55^{*}$ \\
\hline & $(1.45)$ & $(3.98)$ & $(0.24)$ \\
\hline \# Obs. & 42 & 42 & 36 \\
\hline$R^{2}$ & 0.332 & 0.611 & 0.621 \\
\hline
\end{tabular}

Notes: The dependent variable is the average energy savings in each state measured in percentage. A positive sign means that a "feature" increases savings. For instance, increasing the rebate amount for clothes washers from $\$ 0$ to $\$ 100$ increases savings by $2.4 \%$. The savings were estimated over the rebate period, two months before the start of the rebate period, and two weeks after the end of the rebate period. The dummy "advalorem" takes the value one when ad valorem rebates are offered. The dummy "online" takes the value one if rebates could be claimed online. The dummy "reservation system" is zero if consumers had to buy then apply, and takes the value one if reservations were allowed. The eligibility criteria are coded as follows: (1) ES (omitted), (2) ES baseline with marginal rebate increases for higher efficiency, (3) more efficient than ES, and (4) more efficient than ES baseline with marginal rebate increases for higher efficiency. Standard errors in parentheses. ${ }^{*}(p<0.05),{ }^{* *}(p<0.01),{ }^{* * *}(p<0.001)$ 


\section{TABle A.9. DOE's C4A Energy Savings Estimates}

\begin{tabular}{lccccc}
\hline \hline & $\begin{array}{c}\mathrm{kWh} / \mathrm{y} \text { saved } \\
(\mathrm{D} \& \mathrm{R})\end{array}$ & $\begin{array}{c}\overline{k W h} / y^{E S}-\overline{k W h} / y^{\text {Non-ES }} \\
(\mathrm{NPD}, \text { non-sales weighted })\end{array}$ & $\begin{array}{c}\overline{k W h} / y^{E S}-\overline{k W h} / y^{\text {Non-ES }} \\
\text { adjustment: 5-year } \\
\text { Accelerated Replacement }\end{array}$ & $\begin{array}{c}\text { \% Freeriders } \\
\text { No Accelerated } \\
\text { Replacement }\end{array}$ & $\begin{array}{c}\text { \% Freeriders } \\
\text { 5-year Accelerated } \\
\text { Replacement }\end{array}$ \\
\hline Refrigerator & 116 & 65 & 97 & $<0 \%$ & $<0 \%$ \\
Washer & 257 & 201 & 344 & $<0 \%$ & $25 \%$ \\
Dishwasher & 57 & 34 & 82 & $<0 \%$ & $30 \%$ \\
\hline \hline
\end{tabular}

Notes: Sources: Department of Energy (DOE), D\&R International (2013), and NPD Marketing Group. The difference in average electricity consumption between ES and non-ES models $\left(\overline{k W h} / y^{E S}-\overline{k W h} / y^{N o n-E S}\right)$ is the difference observed in the choice set of the NPD data for the years 2010-2011 (Table 10). The adjustment for the accelerated replacement uses the sales-weighted average electricity consumption purchased in the year 2001 observed in the NPD data. For refrigerators, the 2001 average is obtained directly from the DOE data that provide information on the appliances replaced. 
Table A.10. Cost-Effectiveness Analysis with Adjustment for Accelerated Replacement

\begin{tabular}{|c|c|c|c|c|c|c|c|c|c|c|}
\hline & \multirow[t]{2}{*}{$\mathrm{kWh} / \mathrm{y}$} & \multirow[t]{2}{*}{$\begin{array}{c}\text { Price } \\
(\$)\end{array}$} & \multirow[t]{2}{*}{ Size } & \multirow[t]{2}{*}{$\begin{array}{l}\text { Rebate } \\
(\$)\end{array}$} & \multicolumn{6}{|c|}{$\begin{array}{c}\text { Cost-Effectiveness ( } \$ / \mathrm{kWh} \text { saved) } \\
\text { Proportion of Freeriders }\end{array}$} \\
\hline & & & & & $\begin{array}{l}\text { Preferred } \\
\text { Estimate }\end{array}$ & $0 \%$ & $25 \%$ & $50 \%$ & $75 \%$ & $90 \%$ \\
\hline \multicolumn{11}{|c|}{ Refrigerators } \\
\hline & & & & & $91 \%$ & & & & & \\
\hline $\mathrm{ES}$ & 478 & 1243 & 27.1 & 128 & 0.98 & 0.09 & 0.12 & 0.18 & 0.35 & 0.88 \\
\hline Non-ES & 543 & 1665 & 27.3 & & & & & & & \\
\hline Top 5\% & 342 & 818 & 19.7 & 128 & 0.43 & 0.04 & 0.05 & 0.08 & 0.15 & 0.39 \\
\hline Bottom $95 \%$ & 525 & 1544 & 27.1 & & & & & & & \\
\hline Top $10 \%$ & 367 & 725 & 20.4 & 128 & 0.47 & 0.04 & 0.06 & 0.09 & 0.17 & 0.43 \\
\hline Bottom $90 \%$ & 532 & 1577 & 27.3 & & & & & & & \\
\hline Top $20 \%$ & 403 & 1055 & 21.8 & 128 & 0.55 & 0.05 & 0.07 & 0.10 & 0.20 & 0.49 \\
\hline Bottom $80 \%$ & 545 & 1594 & 27.6 & & & & & & & \\
\hline \multicolumn{11}{|c|}{ Clothes Washers } \\
\hline & & & & & $92 \%$ & & & & & \\
\hline ES & 163 & 757 & 4.2 & 107 & 0.26 & 0.02 & 0.03 & 0.04 & 0.08 & 0.21 \\
\hline Non-ES & 364 & 428 & 3.1 & & & & & & & \\
\hline Top 5\% & 99 & 714 & 4.1 & 107 & 0.29 & 0.02 & 0.03 & 0.05 & 0.09 & 0.23 \\
\hline Bottom $95 \%$ & 214 & 685 & 3.9 & & & & & & & \\
\hline Top $10 \%$ & 103 & 804 & 4.1 & 107 & 0.29 & 0.02 & 0.03 & 0.05 & 0.09 & 0.23 \\
\hline Bottom $90 \%$ & 219 & 675 & 3.9 & & & & & & & \\
\hline Top $20 \%$ & 115 & 780 & 4.2 & 107 & 0.29 & 0.02 & 0.03 & 0.05 & 0.09 & 0.23 \\
\hline Bottom $80 \%$ & 236 & 662 & 3.8 & & & & & & & \\
\hline \multicolumn{11}{|l|}{ Dishwashers } \\
\hline & & & & & $73 \%$ & & & & & \\
\hline $\mathrm{ES}$ & 279 & 699 & - & 84 & 0.25 & 0.07 & 0.09 & 0.14 & 0.27 & 0.68 \\
\hline Non-ES & 313 & 480 & - & & & & & & & \\
\hline Top $5 \%$ & 186 & 996 & - & 84 & 0.13 & 0.03 & 0.05 & 0.07 & 0.14 & 0.34 \\
\hline Bottom 95\% & 294 & 618 & - & & & & & & & \\
\hline Top $10 \%$ & 214 & 868 & - & 84 & 0.15 & 0.00 & 0.05 & 0.08 & 0.16 & 0.41 \\
\hline Bottom $90 \%$ & 297 & 613 & - & & & & & & & \\
\hline Top $20 \%$ & 247 & 786 & - & 84 & 0.19 & 0.00 & 0.07 & 0.10 & 0.21 & 0.52 \\
\hline Bottom $80 \%$ & 304 & 593 & - & & & & & & & \\
\hline
\end{tabular}

Notes: The rebate amount for each appliance category is the non-weighted average of the rebate amount offered by each state. The preferred proportion of freeriders is obtained from Table 7, columns 10 and 11. For refrigerators and clothes washers, size is measured in cubic feet. For dishwashers, we report the proportion of models that are classifies as tall. For all appliances, we assume a lifetime of 15 years. 